\title{
STUDY OF A DIRECT MEASURING SKIN FRICTION GAGE WITH RUBBER COMPOUNDS FOR DAMPING
}

by

Samantha A. Magill

Thesis Submitted to the Faculty of Virginia Polytechnic Institute and State University in Partial Fulfillment of the Requirements for the Degree of Master of Science in Aerospace Engineering

\section{Dr. Joseph A. Schetz, Chairman}

Dr. Rakesh K. Kapania

Dr. Bernard Grossman

July, 1999

Blacksburg, Virginia

Keywords: Skin Friction, Rubber, Damping

Copyright 1999, Samantha A. Magill 


\title{
STUDY OF A DIRECT MEASURING SKIN FRICTION GAGE WITH RUBBER COMPOUNDS FOR DAMPING
}

\author{
Samantha A. Magill
}

\section{(ABSTRACT)}

A study was conducted on the measurement of skin friction, the least understood component of drag. Skin friction is considered the "last frontier" in drag redu ction for supersonic flight, but to understand skin friction, it must be accurately mea sured. This study utilized the direct measuring technique for skin friction. A small device, termed a skin friction gage, measures the stress on a cantilever beam topped with a movable surface piece as a shear flow passes over the flush surface. The improvement of these devices for various flow fields is ongoing. A problem that arose with many designs was leakage of a gap-filling liquid. The typical direct measuring skin friction gage uses oil in a gap between the cantilever beam and the encasement to dampen vibrations, to create an even flow over the surface, and for temperature co mpensation. In high speed testing the oil leaks out; therefore, a gage with rubber to fill the gap instead of oil was introduced.

This study employed a finite element method model to fully understand the strains involved with the rubber and the skin friction gage. The development of a calibration device, called the Calibration Rig, for the rubber skin friction gages was constructed. The Calibration Rig was successful, but deemed to be more cumbersome than initially expected. This led to the development of a thin rubber sheet to cover the face of the gage instead of rubber filling the entire gap. More finite element method modeling was done to finalize the design of a gage with a rubber sheet. The design consisted of a plastic skin friction gage with an approximately 0.015 in. thick rubber sheet, a 0.0625 in. wide gap between the floating head on the cantilever beam and the encasement to be filled with oil, and semi-conductor strain gages to measure the beam deflection.

Vibration tests were performed to determine if the rubber sheet produced the required damping. These tests were successful, and so much so, that the oil for damping was not necessary. However, supersonic wind tunnel tests at Mach 2.4 
which were done at Virginia Polytechnic Institute and State University, initially yielded unfavorable results. The rubber sheet failed during the violent process o starting and unstarting of the tunnel. More study on the adhesive mounting of the rubber sheet to the skin friction gage face is needed. 


\section{ACKNOWLEDGEMENTS}

My sincerest gratitude to my advisor Dr. J.A. Schetz for giving me the oppatunity to make myself a better engineer. Without his guidance and support, this endeavor could never have been fulfilled. I also thank my other committee members for their support, Dr. R.K. Kapania, and Dr. B. Grossman. The help of Dr. A. Wicks o the Mechanical Engineering Department was appreciated.

The technical expertise and advice of the gentlemen of the Aerospace and Ocean Engineering Shop including the departmental electrician was well used and greatly appreciated. These gentlemen are Bruce Stanger, Greg Dudding, Kent Morris, and Gary Stafford.

I would also like to extend my thanks to the skin friction research team for the manual help, support, and advice. These young people are Alexander Remington, Theodore Smith, Randy Hutchinson, Dan Lofstrom, Jurie Bezuidenhout, Alex Sang, and Michelle Wilson. And I can not forget the friends I have made in the department, they are the best just for being there.

Lastly, I must recognize my family, for who without their love I would have never have gotten this far. Thank you, Mom, Dad, and Eva. 


\section{TABLE OF CONTENTS}

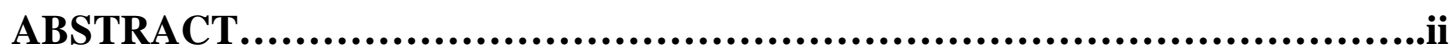

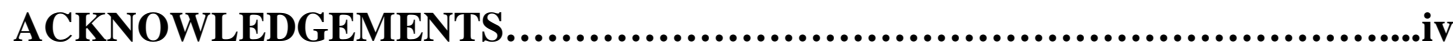

TABLE OF CONTENTS..........................................................v

NOMENCLATURE..........................................................viii

LIST OF FIGURES............................................................

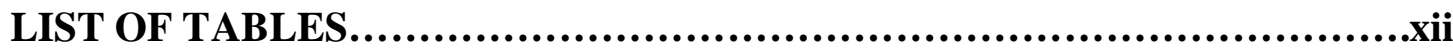

1 INTRODUCTION........................................................................................ 1

1.1 What is Skin Friction and Why Measure It? ............................................ 1

1.2 Skin Friction Measuring Techniques .............................................................. 3

1.2.1 Indirect versus Direct Methods ........................................................... 3

1.2.2 Chronological Development of Direct Skin Friction Measuring Tech ..... 6

1.2.3 Direct Skin Friction Measurement Problems with the Floating Head ... 12

1.2.3.1 Gap Filler Material: Why and Types ............................................... 13

1.3 Scope of Investigati ………………............................................... 14

2 General Skin Friction Gage ................................................................................... 15

2.1 Calibration Technique for Skin Friction Gages ................................15

2.2 Semi-Conductor Strain Gages ………………….................................. 20

3 FINITE ELEMENT METHOD ANALYSIS OF A SKIN FRICTION ....... 23

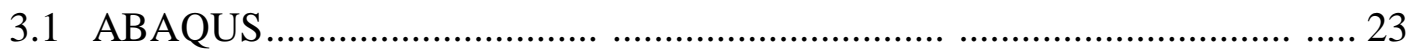

3.2 FEM Model Completion....................................................................... 25

3.3 FEM Model Cases................................................................................. 26

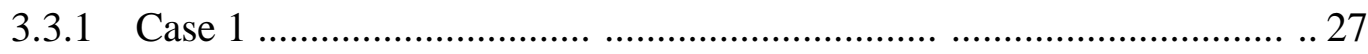

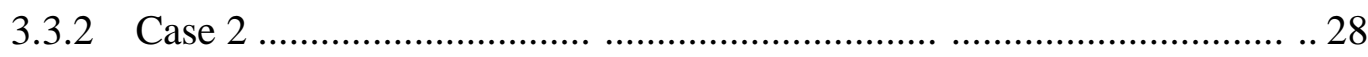

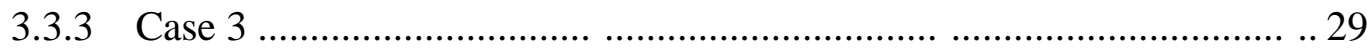

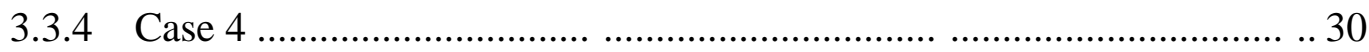

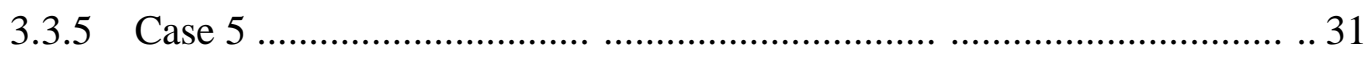

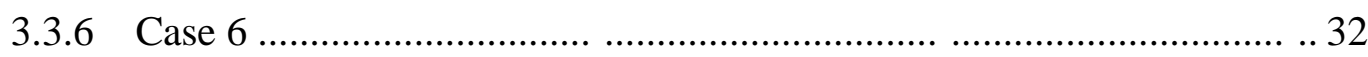




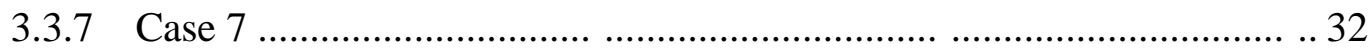

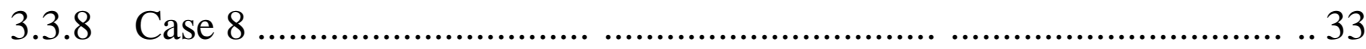

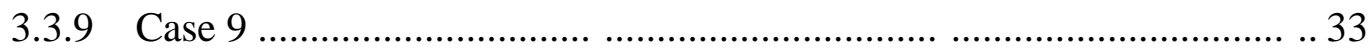

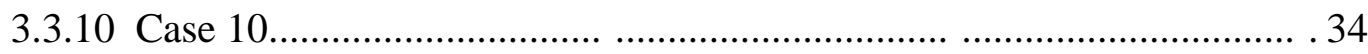

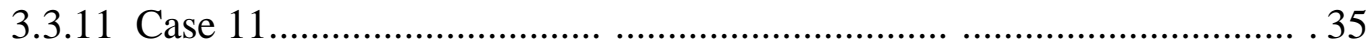

4 CALIBRATION RIG.................................................................................. 36

4.1 Derivation of Equation 7 ................................................................... 37

4.2 Achieving Fully Developed Flow ……………….................................. . 39

4.3 Calibration Rig Computerization ............................................................. 45

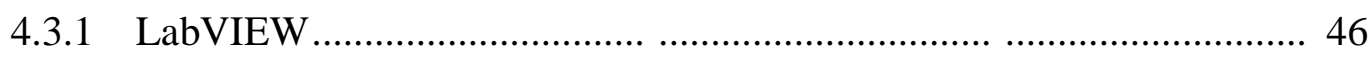

4.3.2 AT-MIO-16XE-50 NI DAQ board .................................................. 46

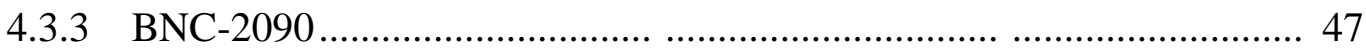

4.4 Uncertain y Analysis on the Calibration Rig............................................... 47

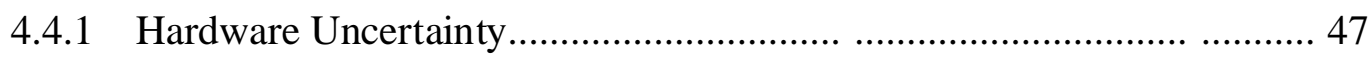

4.4.2 Measured Variable Uncertainty Analysis .............................................. 49

5 DESIGN OF RUBBER SHEET SKIN FRICTION GAGE ............................ 51

5.1 Fabrication of a Thin Silicone Rubber Shee ………………….................. 51

5.2 Preliminary Design of the Silicone Rubber Sheet Skin Friction Gage …....... 52

5.3 Optimization of Silicone Rubber Sheet Thickness and Gap Size of the Skin Friction Gage ..................................................................................... 54

\section{VIBRATION TESTING OF SILICONE RUBBER SHEET SKIN FRI C-}

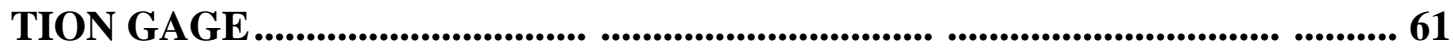

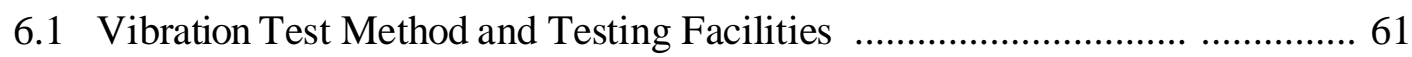

6.2 Theoretical Calculations for Natural Frequency ............................................ 63

6.3 Vibration Testing Results ......................................................................... 65

6.3.1 Center of Mass Calculations ........................................................... . 69

6.4 RTV-566 Silicone Rubber Layup ......................................................... . . 71

7 CALIBRATION RIG RESULTS …................................................................ 75

7.1 Calibration Ratio Theory ....................................................................... 75

7.2 Calibration Rig Runs .......................................................................... 76 
8 VIRGINIA TECH SUPERSONIC TUNNEL TESTING RESULTS........... 78

8.1 Virginia Tech Supersonic Wind Tunnel Tests ........................................ 78

8.2 Supersonic Tunnel Runs ................................................................... 79

9 CONCLUSIONS AND RECOMMENDATIONS ..................................... 82

APPENDIX A-Specifications for Materials Used ................................. ............... A-1

APPENDIX B-Specifications for Semi-Conductor Strain Gages........................ B-1

APPENDIX C-Calculations for Measured Vairiable Uncertainty Analysis......C-1

APPENDIX D-Facilities Employed.............................................D-1

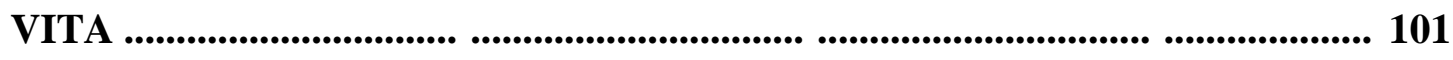




\section{NOMENCLATURE}

A

C

$\mathrm{C}_{\mathrm{f}}$

d

E

F

f

g

GF

$\mathrm{h}$

I

$\mathrm{k}$

L

M

$\mathrm{m}$

$\mathrm{p}$

$\mathrm{R}$

S

$\mathrm{t}$

u

V

V

V

W

$\mathrm{X}$

$\bar{X}$

$\bar{x}$

$\mathrm{y}$

$\bar{Y}$

$\bar{y}$

Area

Calibration constant

Skin friction coefficient

diameter

Modulus of Elasticity, Voltage, Error

Force

Force vector

Gravity

Gage Factor

Height of channel from center line

Moment of inertia

Stiffness

Length

Moment, Mass of floating head

Mass of cantilever bea

Pressure

Resistance

Position

time

Velocity in x-direction

Velocity, Volume, Voltage

Velocity vector

Velocity in y-direction

Velocity in z-direction

Axial direction

$\mathrm{x}$-location of centroid for gage

$\mathrm{x}$-location of centroid for section

Direction normal to $\mathrm{x}$ in the same plane

$y$-location of centroid for gage

$y$-location of centroid for section 


$\begin{array}{ll}Z & \text { Direction normal to } \mathrm{x} \text { and } \mathrm{y} \\ \Delta & \text { Change } \\ \mu & \text { Viscosity } \\ v & \text { Poisson's Rati } \\ \rho & \text { Density } \\ \tau & \text { Shear Stress } \\ \omega & \text { Frequency }\end{array}$

\section{Subscripts}

$\begin{array}{ll}\text { a } & \text { Absolute } \\ \text { arss } & \text { Overall } \\ \text { eff } & \text { Effective } \\ \text { HEAD } & \text { Excitation } \\ \text { i } & \text { Floating head } \\ \text { M } & \text { Section, } \mathrm{i}=1,2,3, \ldots \\ \mathrm{m} & \text { Mass of floating head } \\ \mathrm{n} & \text { Mass of cantilever bea } \\ \text { o } & \text { Natural } \\ \text { output } & \text { Original } \\ \text { PES } & \text { Output } \\ \text { T } & \text { Polyethersulfone plastic } \\ \text { true } & \text { Total } \\ \text { w } & \text { True } \\ & \text { Wall }\end{array}$




\section{LIST OF FIGURES}

Figure 1-Forces Acting on an Airplane (GRC NASA, 1999) ................................. 1

Figure 2-Boundary Layer Over Airfoil Section (MIT, 1999) ................................. 2

Figure 3-Basic Schematic of Floating Head, Flexure, and Flow Direction ................. 5

Figure 4 -Classification of Techniques for Measuring Skin Friction from Winter ...... 5

Figure 5-Typical Non-Nulling Skin Friction Gage Design Concept (Novean, 1996B) 7

Figure 6-General Calibration Technique ….................................................... 16

Figure 7-Calibration of Skin Friction Gages 40 and 43 ................................... 17

Figure 8-calibration of Skin Friction Gage 40R.............................................. 18

Figure 9-Calibration of Skin Friction Gage 40RO ........................................... 18

Figure 10-Calibration of Gage 40Red ........................................................ 19

Figure 11-Calibration of Skin Friction Gage 43Red ........................................... 19

Figure 12-Wheatstone Bridge Circuit .............................................................. 20

Figure 13 -Basic Cantilever Beam Strain Set $\quad$............................................... 21

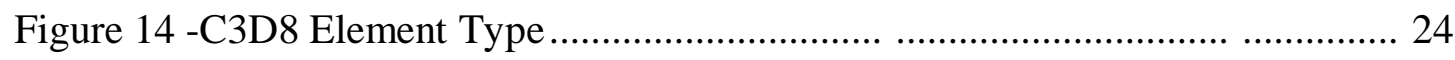

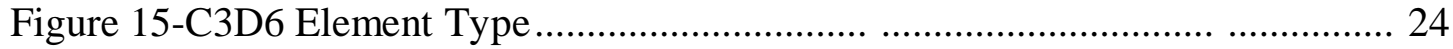

Figure 16-Example of CLOAD Distribution (node C and elements 1-4) ................. 26

Figure 17-Location of Improper (Red) and Proper (Blue) Maximum/Minimum Strain

Figure 18-Strain Contour Plot of the Beam is Case 2 ........................................ 29

Figure 19-Strain Contour Plot of the Entire Gage for Case 4 ............................... 31

Figure 20-Strain Contour Plot of the Beam for Case 7 .................................... 33

Figure 21-Strain Contour Plot of the Beam for Case 9 ...................................... 34

Figure 22-Strain Contour Plot of the Rubber for Case 10 .................................. 35

Figure 23-Basic Original Calibration Rig Design ............................................ 36

Figure 24 -Forces Acting on a Two-Dimensional Fluid Elemen ........................... 38

Figure 25-Fully Developed 2-D Channel Flow .................................................. 39

Figure 26-Calibration Rig Utilizing Glycerine................................................ 41

Figure 27-NPC-1220 Pressure Sensor .............................................................. 42

Figure 28-Schematic for NPC-1220 Pressure Sensor Circuit ............................... 43

Figure 29-Air Dead-Weight Tester (Mansfield \& Green Manual) ........................... 44 
Figure 30-Pressure Distribution in Calibration Rig.....

Figure 31-Center Piece Design for the Silicone Rubber Sheet Skin Friction Gage: (a)

Rendered Picture and (b) Dimensional Schematic ....................................... 54

Figure 32-Optimization of Gap Size with a Silicone Rubber Sheet of 0.007 in........ 55

Figure 33-Strain Contour Plot of Silicone Rubber Sheet Skin Friction Gage with a

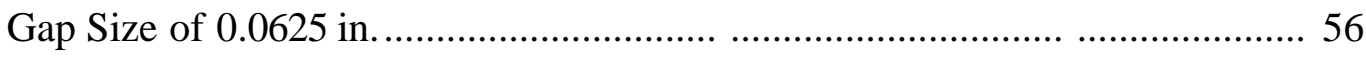

Figure 34-Optimization of Silicone Rubber Sheet Thickness................................ 57

Figure 35-Strain in Silicone Rubber for Sheet Thickness Optimization ................... 57

Figure 36-Strain in Silicone Rubber for Gap Size Optimization ............................ 58

Figure 37-Housing for the Silicone Rubber Sheet Skin Friction Gage: (a)Rendered

View and (b)Dimensional Schematic ........................................................ 59

Figure 38-Schematic of Silicone Rubber Sheet Skin Friction Gage Assembly .......... 60

Figure 39-Vibration Testing Setup (Inman, 1996) ............................................. 62

Figure 40-Theoretical Model of Silicone Rubber Sheet Skin Friction Gage ............. 63

Figure 41-Frequency Response Plot ......................................................... 65

Figure 42-Vibration Results without a Gap Filler at 1-g ................................... 66

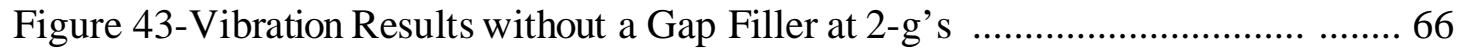

Figure 44-Vibrational Results of the "Off" Axis for Gage 43 ................................ 67

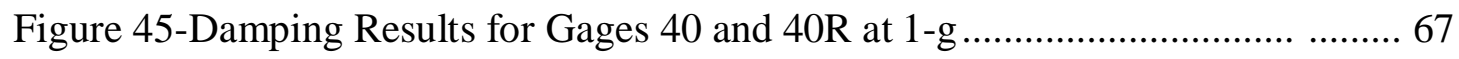

Figure 46-Damping Results for Gages 40 and 40R at 2-g's............................... 68

Figure 47-Damping Results of Gage 40RO at 1-g .......................................... 68

Figure 48-Damping Results for Gage 40RO at 2-g's.......................................... 69

Figure 49-Center of Mass Geometric Sections .............................................. 70

Figure 50-Center of Mass Frequency Response Comparison ............................... 71

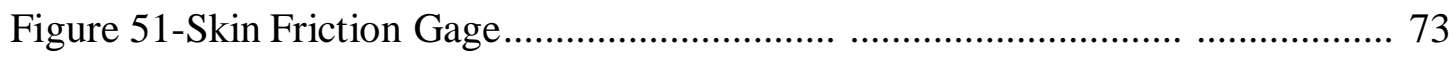

Figure 52-Skin Friction Gage with Unshaped Silicone Rubber Sheet .................... 73

Figure 53-Skin Friction Gage with Silicone Rubber, RTV-566, Sheet Affixed to Top

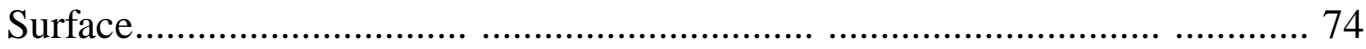

Figure 54 -Pressure Distribution in Calibration Rig for Gage 43Red ..................... 77

Figure 55-Schematic of Virginia tech Supersonic Wind Tunnel, a) side view, b) top view

Figure 56-Example of Supersonic Tunnel Run ............................................. 80 


\section{LIST OF TABLES}

Table 1-Advantages and Disadvantages of Experimental Skin Friction Measurement

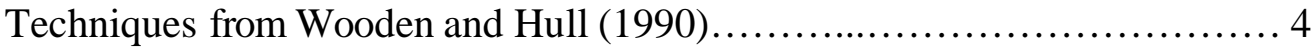

Table 2-Chronological Development of Direc Skin Friction Measurement

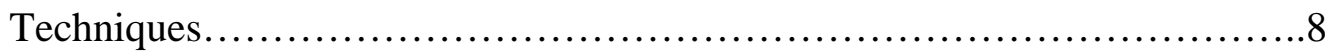

Table 3 -Results of ABAQUS Study on Silicone Rubber Filled Skin Friction Gage . 27

Table 4-Hardware Uncertainty Analysis on Calibration Rig................................ 48

Table 5 -Optimization of Floating Head Diameter and Length of Cantilever Bea .. 53

Table 6 -Center of Mass Calculations for Gage 43 ............................................... 70

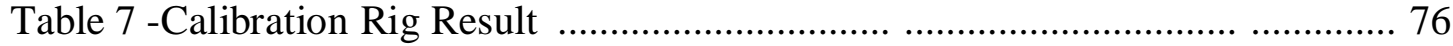

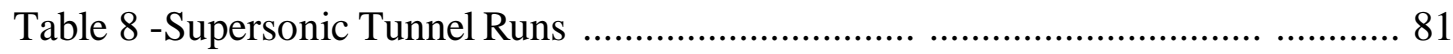




\section{INTRODUCTION}

\subsection{What is Skin Friction and Why Measure It?}

Four aerodynamic forces act on a body in flight: lift, weight, thrust, and drag, and Figure 1 shows the direction and placement of these forces.

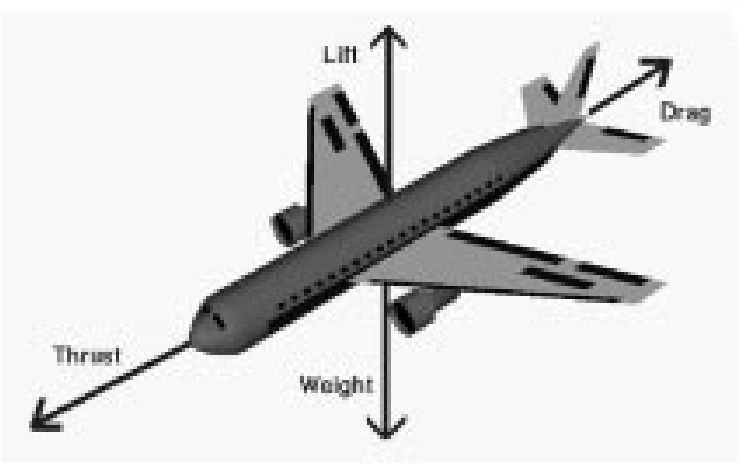

Figure 1-Forces Acting on an Airplane (GRC NASA, 1999)

Drag is the retarding force acting on a body moving through a fluid parallel and opp osite to the direction of motion (Webster, 1991). Drag is separated into three main categories: induced, parasite, and wave drag. Induced drag is created in the process o developing lift, parasite drag is due to skin friction and form, and wave drag is the pressure drag on supersonic shapes due to the shock wave (Anderson, 1990). Parasite drag is present any time the airplane is moving through the atmosphere, even in a zero-lift condition. Components of the airplane, such as, wings, fuselage, landing gear etc. contribute to parasite drag (Manual of Flight, 1993). Skin friction drag is a type of parasite drag, and it is located in the thin layer adjacent to a body within which the major effects of viscosity are concentrated (Kuethe and Chow, 1986). This layer is the boundary layer (B.L.). Figure 2 is typical representation of the boundary layer over an airfoil section. 

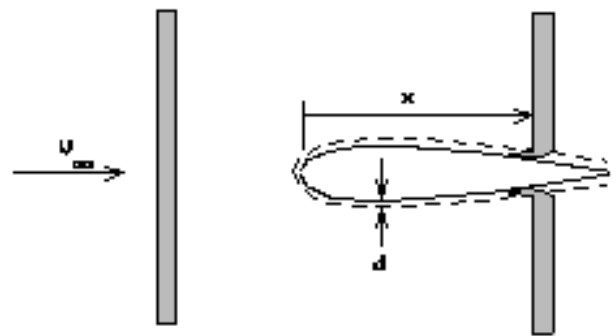

\section{Figure 2-Boundary Layer Over Airfoil Section (MIT, 1999)}

The knowledge of skin friction drag or any other drag is vital in the understanding of the performance of a system "whether it be a ship or an aircraft or the flow through a pipe" (Winter, 1977). Skin friction accounts for about half the total drag on an aircraft, and when airflow separates from the wing, becoming turbulent, the drag ncreases. Maintaining laminar flow over a wing reduces skin friction, thereby, increasing performance. Laminar flow over a subsonic wing has long been achieved, but laminar flow over a supersonic wing has been termed the "holy grail" of aerodynamics by J. Lavell. Lavell is the project manager for the F-16XL Supersonic La inar Flow Control Experiment at NASA's Langley Research Center. A reduction of skin friction to the point of laminar supersonic flow could be the deciding factor in making supersonic commercial transport economically feasible for all travelers.

Skin friction is most commonly expressed as a coefficient of shear stress,

$$
C_{f}=\frac{\tau_{w}}{\frac{1}{2} \rho V^{2}},
$$

where $\tau_{w}$ is the shear stress at the wall, $\rho$ is the density, and $V$ is the boundary layer edge velocity. The wall shear is expressed in Equation 2,

$$
\tau_{w}=\left(\mu \frac{\partial u}{\partial y}\right)_{y=w a l l},
$$

where $\mu$ is the viscosity of the fluid, and $\frac{\partial u}{\partial y}$ is the change in velocity normal to the body surface. The determining factor in Equation 1 and 2 is the shear stress, and throughout this study the shear stress will be the measured variable. 


\subsection{Skin Friction Measuring Techniques}

Measurements of skin friction or surface friction date at least as far back as Bea ufoy in 1793 (Chapman and Kester, 1953). Some of the first systematic investigations of drag were made by Froude in 1872 for ship dynamics. He measured the shear forces on a series of planks towed at various speeds along a tank (Winter,1977). Over the years, various techniques have been tested. As previously implied, the need for information on skin friction increased sharply with the advent of supersonic flight. This called for the precise measurements of skin friction in compressible turbulen flows. Indirect methods for measuring skin friction were more feasible in the early studies. As technology advanced, direct measurements of skin friction became more useful and commonplace. Dhawan (1952) defined the difference between indirect and direct measurements of skin friction. Indirect measurements endeavor to determine the components of the right-hand side of Equation 2, and direct measurements rely on a bulk measurement of the skin friction itself, to determine the left-hand side of Equation 2. Reynolds analogy is sometimes grouped with indirect methods, but more often grouped alone.

\subsubsection{Indirect versus Direct Methods}

Wooden and Hull (1990) developed a small chart listing the advantages and disadvantages of direct and indirect methods; it is shown here in Table 1. 
Table 1-Advantages and Disadvantages of Experimental Skin Friction Mea surement Techniques from Wooden and Hull (1990)

\begin{tabular}{|c|c|c|}
\hline Method & Advantages & Disadvantages \\
\hline $\begin{array}{c}\text { Direct Measure- } \\
\text { ment (Force) }\end{array}$ & $\begin{array}{l}\text { - Most believable } \\
\text { - High precision meas- } \\
\text { urement } \\
\text { - High precision calibra- } \\
\text { tion } \\
\text { - Direction sensitive }\end{array}$ & $\begin{array}{c}\text { - Tare sensitive } \\
\text { - Small force } \\
\text { - High cost } \\
\text { - Large size (inside model) } \\
\text { - Direction sensitive }\end{array}$ \\
\hline $\begin{array}{l}\text { Indirect Meas- } \\
\text { urements (Lami- } \\
\text { nar Sublayer total } \\
\text { pressure) }\end{array}$ & $\begin{array}{c}\text { - Simple } \\
\text { - } \quad \text { Low cost (after calibra- } \\
\text { tion) } \\
\text { - High precision meas- } \\
\text { urement }\end{array}$ & $\begin{array}{l}\text { - } \text { Flow calibration required } \\
\text { - Medium precision curve fit } \\
\text { - Minimum B.L. thickness lim- } \\
\text { ited } \\
\text { - Direction sensitive }\end{array}$ \\
\hline $\begin{array}{l}\text { Reynolds Anal- } \\
\text { ogy (Thermal } \\
\text { measurement) }\end{array}$ & $\begin{array}{cc}- & \text { Dual purpose sensor } \\
\bullet \quad \text { Low cost } \\
\text { - Not direction sensitive }\end{array}$ & $\begin{array}{l}\text { - } \quad \text { Calibration not available } \\
\text { - Low precision measurement } \\
\text { - B.L. edge conditions required } \\
\text { - Not direction sensitive }\end{array}$ \\
\hline
\end{tabular}

Table 1 includes Reynolds analogy, which will not be discussed here, but for more information refer to Winter (1977) or Novean (1996A).

Indirect measurements of skin friction require some additional information about the flow so that the skin friction can be inferred from the measured quantity. Three commonly used instruments for indirect measurement are the Pitot tube, the hot-wire anemometer, and the interferometer. These instruments measure the velocity profile by knowing the local static pressure and density for the Pitot tube, the local densit for the hot-wire anemometer, and the local temperature for the interferometer. The indirect methods are subject to numerous errors, and limitations. These are due to the difficulty of the instrument, (the most difficult to use being the interferometer) and also due to the assumptions, additional calculations, and/or inferences of the information used to determine the skin friction (Winter, 1977).

Direct measurements are usually performed with a direct shear stress determination. Directly measuring shear stress is considered superior, because it does not rely on any assumptions about the nature of the flow field. The method of direct shear stress measurement is simple in principle. A shear stress develops as fluid flows over the surface to move a small element of the surface in the direction of flow. This e e- 
ment is termed the floating head/element, because it is attached to a flexure and surrounded by a thin gap. Figure 3 is a simple schematic of the floating head and flow direction.

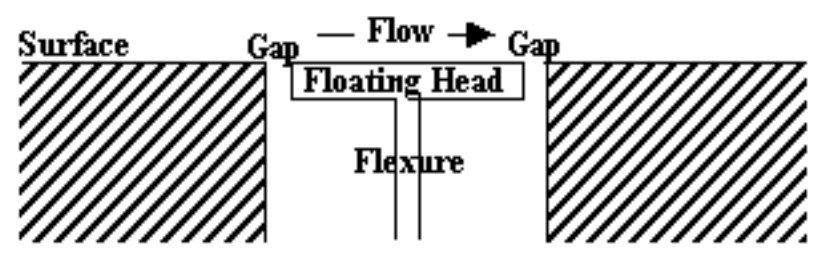

\section{Figure 3-Basic Schematic of Floating Head, Flexure, and Flow Direction}

The deflection of the element can be calibrated to indicate the magnitude of the shear stress. Direct measurements are considered better in accuracy and simple b elievability, but direct measurements are not without problems, especially in supe $r$ sonic flow. The source of error that this work is concerned with is the thin gap that must separate the moving element from the surface. It can change the distribution of velocity and pressure (Dhawan, 1952). It is also important to minimize the motion o the floating head due to vibrations and/or noise; filling the space of the thin gap with a pliable material can provide sufficient damping. Figure 4 is a flowchart of the classification of techniques for measuring skin friction from Winter (1977).

\section{Classification of Techniques for Meakuring Skin Friction}

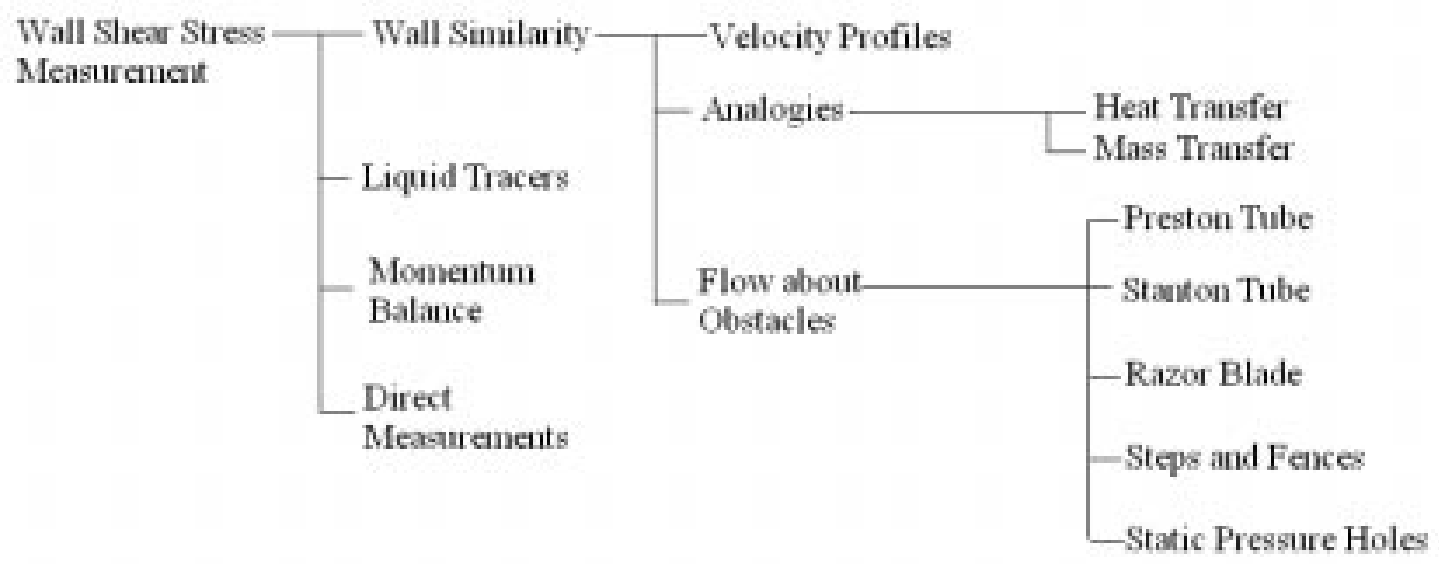

Figure 4 -Classification of Techniques for Measuring Skin Friction from Winte (1977)

A more in-depth review of indirect methods is given in Dhawan (1952). Since the work considered here is solely based on direct skin friction measurements, the co n- 
tinuing literature review will only deal with the development of direct skin friction measurements.

\subsubsection{Chronological Development of Direct Skin Friction Measuring Tec h- niques}

A useful overview of any technological development can be given in the form o a chart or a list. A large chart or list on the development of direct skin friction mea suring techniques is presented in this section. Table 2 is a composite from Winter (1977), Schetz (1997), and others. The chart begins in 1929, but as all ready noted in Section 1.2, skin friction measurements began as early as 1793 . Pioneers in skin fr ction include Froude in 1872, Kempf in 1929, and Schoenherr in 1932. Kempf used a pontoon with large panels mounted on balances to directly measure skin friction, and Schoenherr is considered the most notable in the early skin friction estimation for i ncompressible flow (Winter, 1977). Schoenherr (1932) gives a good review of skin friction experiments prior to 1932.

In the latter part of Table 2, the work of Novean is described. His high e nthalpy work led to development of new materials, like polyethersulfone plastic and silicone rubber, for the design of skin friction gages, and it is his favorable results obtained at Virginia Polytechnic Institute and State University that dictated this study. The others listed past Novean, include Pulliam and Remington, who are peers at Virginia Polytechnic Institute and State University, and their work is ongoing.

The terms nulling, non-nulling, and gap filler are used in Table 2. If the skin friction gage is of the nulling type, the floating head will not have a net deflection with a shear force. If the skin friction gage is non-nulling, it will deflect with a shear force (e.g. parallel linkage). In the nulling design, a restoring force equal to the shear force is applied through complex mechanical devices. Such configurations are very

delicate, have a slow response time, and cannot measure two components of the wall shear. In the non-nulling design, mechanical devices are not necessary, but the protrusion of a deflecting floating head into the flow can be a concern (Novean, 1996A). Careful design can overcome that concern, and the resulting configuration is simpler, more robust, capable of a high frequency response, and can also measure the two components of shear stress. 
The typical, modern, non-nulling design from Virginia Polytechnic Institut and State University consists of a small cantilever beam with circular cross-section, positioned normal to the fluid flow with a floating head, as shown in Figure 5. Strain gages mounted at the beam base measure the deflection as an output voltage. The floating head is separated by a gap from the wall or mounting device. The wall or mounting device is referred to as the housing. A gap filler could be inserted between the floating head and the housing for damping and to smooth air flow. For example, the most common gap filler to date is oil. This oil prevents flow in and out of the gap, thus minimizing the pressure gradient effects. The oil also adds thermal protection for high temperature tests. Oil as a gap filler is not infallible. In high speed flows, the capillary forces between the oil and gap are too weak and the oil can leak out, thus destroying the smooth air flow and creating a mess. This study investigates answers to the leakage. The particular skin friction gage design concept in Figure 5 is the common schematic for the gages discussed and designed in this project.

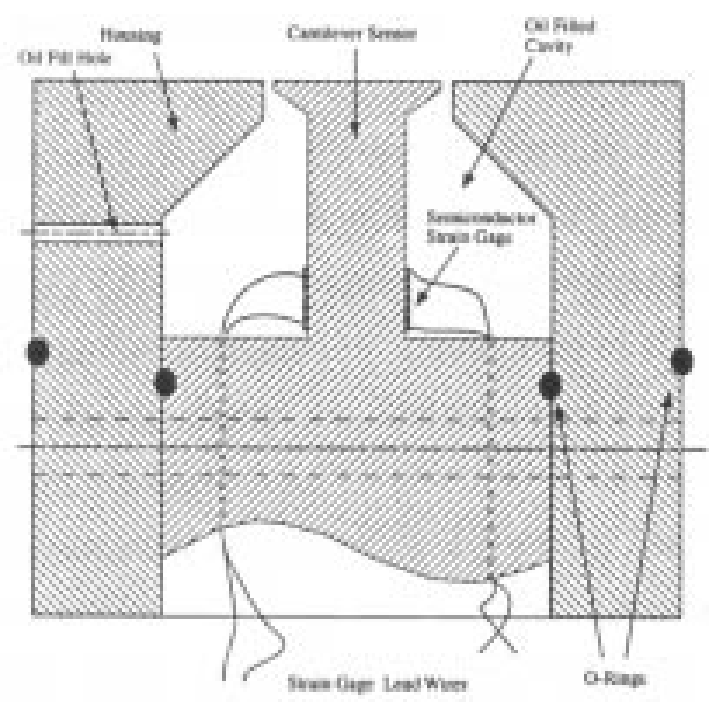

Figure 5-Typical Non-Nulling Skin Friction Gage Design Concept (Novean, 1996B) 
Table 2 - Chronological Development of Direct Skin Friction Measurement Techniques

\begin{tabular}{|c|c|c|c|c|c|c|c|c|}
\hline Reference & Year & Test Conditions & $\begin{array}{l}\text { Nulling or } \\
\text { Non-Nullin }\end{array}$ & $\begin{array}{l}\text { Size of Floating } \\
\text { Element }(\mathrm{mm})\end{array}$ & $\begin{array}{l}\text { Type of Suspension/Position /Force Trans- } \\
\text { duce }\end{array}$ & Gap Filler & $\begin{array}{c}2 \mathrm{D} / 3 \mathrm{D} \\
\text { Flow }\end{array}$ & Remarks \\
\hline Kempf & 1929 & Bottom of a pontoon, $77 \mathrm{~m}$ long, $\operatorname{Re} \leq 5 \times 10^{8}$ & Nullin & $309 \times 1010$ & Pulleys and springs & None & $2 \mathrm{D}$ & $\begin{array}{l}\text { Measurements made in water. Sche- } \\
\text { matic, Figure } 2 \text { (Winter, 1977) }\end{array}$ \\
\hline Schoenherr & 1932 & $\begin{array}{l}\text { "Catamaran Friction Planes", } 0.3 \text { to } 3.0 \mathrm{ft} / \mathrm{s} \\
\operatorname{Re} \approx 2 \times 10^{6}\end{array}$ & Nullin & $\begin{array}{l}914.4 \times 457.2 \text { to } \\
1828.8 \times 914.4\end{array}$ & Weights pulled by gravit & None & $2 \mathrm{D}$ & $\begin{array}{l}\text { Towing tank in water and glycerine } \\
\text { Schematic Figure } 3 \text { (Schoenherr, } \\
\text { 1932) }\end{array}$ \\
\hline Schultz-Grunow & 1940 & $\begin{array}{l}\mathrm{U}=20 \mathrm{~m} / \mathrm{s} \\
1.6 \times 10^{6}<\mathrm{Re}_{\mathrm{x}}<16 \times 10^{6}\end{array}$ & Nullin & $300 \times 500^{*}$ & Optical/manually-operated offset torsion bar & None & $2 \mathrm{D}$ & Very large \\
\hline Weiler \& Hartwi & 1952 & Supersonic wind tunnel & Nullin & $25 \mathrm{dia}$ & $\begin{array}{l}\text { Flexures } \\
\text { LVDT }^{* *}\end{array}$ & None & $2 \mathrm{D}$ & $\begin{array}{l}\text { Schematic, Figure } 3 \text { of Winter (1977) } \\
\text { DRL, University of Texas }\end{array}$ \\
\hline Chapman, and Keste & 1953 & $\begin{array}{l}\text { Subsonic and supersonic turbulent flow } \\
\text { Axial flow over cylinders } \\
4 \times 10^{6} \leq \operatorname{Re}_{\mathrm{x}} \leq 32 \times 10^{6}\end{array}$ & Nullin & $\begin{array}{l}\text { Cylinder, } \\
\mathrm{L} / \mathrm{D}=8,13 \text {, and } 23\end{array}$ & Transducer & None & $2 \mathrm{D}$ & $\begin{array}{l}\text { Ames Lab NACA } \\
\text { (Chapman and Kester, 1953) }\end{array}$ \\
\hline Coles & 1953 & $\begin{array}{l}M=1.97,0.4 \times 10^{6}<\operatorname{Re}_{x}<10 \times 10^{6} \\
M=2.57,0.4 \times 10^{6}<\operatorname{Re}_{x}<9 \times 10^{6} \\
M=3.70,0.5 \times 10^{6}<\operatorname{Re}_{x}<8 \times 10^{6}\end{array}$ & Nullin & $6.2 \times 37.9$ & $\begin{array}{l}\text { Flexure Assemble (Parallel linkage) } \\
\text { Schaevitz variab le reluctance transformer } \\
\text { (LVDT) }\end{array}$ & oil & $2 \mathrm{D}$ & $\begin{array}{l}\text { Schematic, Figures } 15-17 \text { of } \\
\text { Coles(1952) } \\
\text { Jet Propulsion Laboratory }\end{array}$ \\
\hline Dhawan & 1953 & $\begin{array}{l}\text { Low speed } 6 \times 10^{6}<\operatorname{Re}_{\mathrm{x}}<60 \times 10^{6} \\
\text { Subsonic } 0.2<\mathrm{M}<0.8,0.3 \times 10^{6}<\operatorname{Re}_{\mathrm{x}}<1.2 \times 10^{6} \\
\text { Supersonic } 1.24<\mathrm{M}<1.44\end{array}$ & Nullin & $\begin{array}{l}11.5 \times 63 \\
2 \times 20\end{array}$ & $\begin{array}{l}\text { Parallel interchangeable } \\
\text { LVDT }\end{array}$ & None & $2 \mathrm{D}$ & $\begin{array}{l}\text { GALCIT “Correlation" Tunnel } \\
\text { Schematic, Figure } 6 \text { of Dhawan } \\
\text { (1952) }\end{array}$ \\
\hline Eimer & 1953 & Hypersonic, M=5.8, Laminar Flat Plate with condesation & Nullin & $50.8 \times 25.4$ & $\begin{array}{l}\text { Schaevitz transformer (LVDT) } \\
\text { Chemical Balance and Flexures }\end{array}$ & None & $2 \mathrm{D}$ & $\begin{array}{l}\text { GALCIT-Hypersonic 5X5in tunnel } \\
\text { Schematic, Figures } 17 \& 18 \text { of } \\
\text { Eimer (1953) }\end{array}$ \\
\hline Hakkinen & 1953 & $\begin{array}{l}\text { Turbulent boundary layer of flat plate at high subsonic } \\
\text { Mach numbers to Mach }=1.75 \\
0.33 \times 10^{6}<\operatorname{Re}_{x}<1.2 \times 10^{6}\end{array}$ & Nullin & $20 \times 2$ & Schaevitz transformer (LVDT) & None & $2 \mathrm{D}$ & $\begin{array}{l}\text { Similar to Dhawan's gage } \\
\text { Schematic Figure } 1 \text { of Hakkinen } \\
\text { (1955) GALCIT }\end{array}$ \\
\hline $\begin{array}{l}\text { Blumer, (Bradfield, \& } \\
\text { DeCoursin) }\end{array}$ & 1954 & $\begin{array}{l}M=2.6,1 \times 10^{6}<\operatorname{Re}_{x}<8 \times 10^{6} \\
\text { Axially symmetric conical, turbulent boundary layer }\end{array}$ & Nullin & 254 long, $15^{\circ}$ cone & Schaevitz transformer (LVDT) & None & $2 \mathrm{D}$ & $\begin{array}{l}\text { University of Minnesota, Rosemount } \\
\text { Aeronautical Laborator } \\
\text { Schematic Figure 4 (Blumer. 1954) }\end{array}$ \\
\hline Wolff & 1956 & $\begin{array}{l}\text { Subsonic, } 64 \mathrm{ft} / \mathrm{s} \text { to } 286 \mathrm{ft} / \mathrm{s} \\
\text { Laminar flow over various Flat Plates }\end{array}$ & Nullin & $1006.475 \times 749.3$ & Baldwin cantilever spring strain gages & None & $2 \mathrm{D}$ & $\begin{array}{l}\text { University of Minnesota } \\
\text { Schematic Figure } 2 \text { (Wolff, 1956) } \\
\text { Flat Plates of glass, painted glass, \& }\end{array}$ \\
\hline
\end{tabular}


Table 2 cont'd - Chronological Development of Direct Skin Friction Measurement Techniques

\begin{tabular}{|c|c|c|c|c|c|c|c|c|}
\hline Reference & Year & Test Conditions & $\begin{array}{l}\text { Nulling or Non- } \\
\text { Nullin }\end{array}$ & $\begin{array}{l}\text { Size of Floating } \\
\text { Element }(\mathrm{mm})\end{array}$ & $\begin{array}{l}\text { Type of Suspension/Position /Force Trans- } \\
\text { duce }\end{array}$ & $\begin{array}{l}\text { Gap } \\
\text { Filler }\end{array}$ & $\begin{array}{r}2 \mathrm{D} / 3 \mathrm{D} \\
\text { Flow } \\
\end{array}$ & Remarks \\
\hline Lyons \& Fente & 1957 & Supersonic Flight & Nullin & 50 dia & $\begin{array}{l}\text { Double parallel inter-connected linkage } \\
\text { to eliminate sensitivity to linear and rota- }\end{array}$ & None & $2 \mathrm{D}$ & Tested on rockets \\
\hline Everett & 1958 & $\begin{array}{l}\text { Incompressible liquid flow with variable chan- } \\
\text { nel height }\end{array}$ & Nullin & $\begin{array}{l}25.4 \text { dia \& } \\
25.146 \text { dia }\end{array}$ & $\begin{array}{l}\text { Beryllium-copper flexure } \\
\text { Schaevitz transformer (LVDT) }\end{array}$ & $\begin{array}{l}\text { Silicone } \\
\text { Fluid }\end{array}$ & $2 \mathrm{D}$ & $\begin{array}{l}\text { Variable gap size and thickness } \\
\text { Schematic, Figure } 4 \text { of Everett }\end{array}$ \\
\hline Smith \& Walker & 1958 & $\begin{array}{l}0.11<\mathrm{M}<0.32 \\
10^{6}<\mathrm{Re}_{\mathrm{x}}<40<10^{6}\end{array}$ & Nullin & 50 dia & $\begin{array}{l}\text { Parallel linkage } \\
\text { LVDT } \\
\text { Kelvin current balance }\end{array}$ & None & $2 \mathrm{D}$ & \\
\hline MacArthur & 1963 & Shock Tunnel/Impulse Facilities & Nullin & 6.4 dia & $\begin{array}{l}\text { Parallel linkage } \\
\text { Lead zirconium titanate piezoeletric ceramic }\end{array}$ & None & $2 \mathrm{D}$ & $\begin{array}{l}\text { Overcame difficulty in measuring } \\
\text { small forces. It was complex with }\end{array}$ \\
\hline Moulic & 1963 & $\begin{array}{l}\mathrm{M}=6 \\
\text { Low Densit }\end{array}$ & Nullin & $0.25 \times 25$ & $\begin{array}{l}\text { Side flexure pivot } \\
\text { LVDT }\end{array}$ & None & $2 \mathrm{D}$ & $\begin{array}{l}\text { Studied strong interaction region near } \\
\text { leading edge of flat plate }\end{array}$ \\
\hline O’Donnell & 1964 & $\mathrm{M}=2.67, \mathrm{Re}_{\bullet}=10070$ & Nullin & 25 dia & Parallel Linkage & None & $2 \mathrm{D}$ & $\begin{array}{l}\text { Studied effects of misalignment of } \\
\text { floating head }\end{array}$ \\
\hline Young \& Westkaempe & 1965 & Supersonic flow with heat transfer and surface & Nullin & $25 \mathrm{dia}$ & Parallel linkage & None & $2 \mathrm{D}$ & \\
\hline Dershin et al. & 1966 & Supersonic flow with mass transfer & Nullin & "Pointed ellipse" & $\begin{array}{l}\text { Parallel linkage } \\
\text { LVDT }\end{array}$ & None & $2 \mathrm{D}$ & \\
\hline Moore \& McVe & 1966 & High temperature hypersonic flows & Nullin & NA & $\begin{array}{l}\text { Flexure pivot } \\
\text { Pneumatic position sensor }\end{array}$ & None & $2 \mathrm{D}$ & \\
\hline Brown \& Joubert & 1969 & Low-speed adverse pressure gradients & Nullin & 19 dia & $\begin{array}{l}\text { Parallel linkage } \\
\text { LVDT }\end{array}$ & None & $2 \mathrm{D}$ & $\begin{array}{l}\text { Studied pressure gradient forces with } \\
\text { in gap }\end{array}$ \\
\hline Fowke & 1969 & Supersonic speeds & Nullin & 127 dia & $\begin{array}{l}\text { Flexure pivot } \\
\text { LVDT }\end{array}$ & None & $2 \mathrm{D}$ & \\
\hline Bruno, Yanta \& Risher & 1969 & Supersonic speeds including flows with heat transfer & Nullin & 20.3 dia & $\begin{array}{l}\text { Flexure pivot } \\
\text { LVDT }\end{array}$ & None & $2 \mathrm{D}$ & $\begin{array}{l}\text { Force variable by changing loading } \\
\text { spring }\end{array}$ \\
\hline Winter \& Gaudet & 1970 & $\begin{array}{l}0.2<\mathrm{M}<2.8 \\
16 \times 10^{6}<\operatorname{Re}_{\mathrm{x}}<200 \times 10^{6}\end{array}$ & Nullin & 368 dia & $\begin{array}{l}\text { Parallel linkage } \\
\text { Resistance strain gauges }\end{array}$ & None & $2 \mathrm{D}$ & Surface roughness tests \\
\hline
\end{tabular}


Table 2 cont'd - Chronological Development of Direct Skin Friction Measurement Techniques

\begin{tabular}{|c|c|c|c|c|c|c|c|c|}
\hline References & Year & Test Conditions \& Location & $\begin{array}{l}\text { Nulling or } \\
\text { Non-Nullin }\end{array}$ & $\begin{array}{l}\text { Size of Floating } \\
\text { Element }(\mathrm{mm})\end{array}$ & $\begin{array}{l}\text { Type of Suspension/Position } \\
\text { Force Transduce }\end{array}$ & Gap Filler & $\begin{array}{l}2 \mathrm{D} / 3 \mathrm{D} \\
\text { Flow }\end{array}$ & Remarks \\
\hline Hastings \& Sawyer & 1970 & $\begin{array}{l}M=4 \\
10 \times 10^{6}<\operatorname{Re}_{x}<30 \times 10^{6}\end{array}$ & Nullin & 7.9 dia & $\begin{array}{l}\text { Parallel linkage } \\
\text { LVDT }\end{array}$ & None & $2 \mathrm{D}$ & \\
\hline Paros (Kistler) & 1970 & $\begin{array}{l}\text { Used in a wide range of conditions i } \mathrm{n}- \\
\text { cluding flight. Cooling system avail- } \\
\text { able }\end{array}$ & Nullin & 9 dia & $\begin{array}{l}\text { Pivoted about crossed-spring } \\
\text { flexure. } \\
\text { Differential capacity }\end{array}$ & None & $2 \mathrm{D}$ & $\begin{array}{l}\text { Schematic, Figure } 4 \text { of Winter } \\
\text { (1977) }\end{array}$ \\
\hline Miller & 1971 & $\begin{array}{l}\text { Low-speed flow. Favourable pressure } \\
\text { gradient }\end{array}$ & Nullin & 25 dia & $\begin{array}{l}\text { Parallel linkage } \\
\text { LVDT }\end{array}$ & & $2 \mathrm{D}$ & $\begin{array}{l}\text { Extension of Brown \& Joubert } \\
\text { in } 1961\end{array}$ \\
\hline Franklin & 1973 & Subsonic wind tunnel and water chan- & Nullin & 16 dia & Pivoted. Variable geometry & None & $2 \mathrm{D}$ & \\
\hline Morsy & 1974 & Low speed flow past circular cylinder & Nullin & $50.1 \times 3.2$ & $\begin{array}{l}\text { Jewelled pivots. } \\
\text { Clock springs } \\
\text { LVDT }\end{array}$ & None & $2 \mathrm{D}$ & \\
\hline Van Kuren & 1974 & High-temperature hypersonic flows with & Nullin & $12 \times 12$ & Parallel linkage & None & $2 \mathrm{D}$ & \\
\hline Ozarapoglu \& Vinh & 1975 & Low-speed. Adverse pressure gradients & Nullin & 127 dia & $\begin{array}{l}\text { Air bearings } \\
\text { LVDT }\end{array}$ & None & $2 \mathrm{D}$ & $\begin{array}{l}\text { Studied effects of changing gap } \\
\text { geometry. Errors in skin friction }\end{array}$ \\
\hline Waltrup \& Schetz & 1973 & \multirow{3}{*}{$\begin{array}{l}\text { Complex supersonic flow with a strong } \\
\text { adverse pressure gradient and with inje c- } \\
\text { tion through porous and tangential slots }\end{array}$} & \multirow[t]{3}{*}{ Nullin } & \multirow[t]{3}{*}{$25.4 \mathrm{dia}$} & \multirow[t]{3}{*}{ LVDT } & \multirow[t]{3}{*}{ Silicone oil } & \multirow[t]{3}{*}{$2 \mathrm{D}$} & \multirow[t]{3}{*}{ Supersonic Wind Tunnel } \\
\hline Kenworthy \& Schetz & 1973 & & & & & & & \\
\hline Van Overeem \& Schetz & 1975 & & & & & & & \\
\hline Nerney \& Schetz & 1977 & \multirow{2}{*}{ low speed, and turbulent flow on smooth, } & \multirow[t]{2}{*}{ Non-Nullin } & \multirow[t]{2}{*}{25.4 dia } & \multirow[t]{2}{*}{ Semi-conductor Strain Gages } & \multirow[t]{2}{*}{ Silicone oil } & \multirow[t]{2}{*}{$2 \mathrm{D}$} & \multirow[t]{2}{*}{ Virginia Tech Supersonic Tunne } \\
\hline \begin{tabular}{|l} 
Kong \& Schetz \\
Collier \& Schetz
\end{tabular} & $\frac{1981-2}{1984}$ & & & & & & & \\
\hline $\begin{array}{l}\text { Deturris, Hellbaum, \& } \\
\text { Schetz }\end{array}$ & 1990 & $\begin{array}{l}\text { Hot high-speed flow. } \\
\mathrm{M}=3, \mathrm{~T}=1667 \mathrm{~K} \&\end{array}$ & Nullin & $12.7 \mathrm{dia}$ & $\begin{array}{l}\text { Semi-conductor Strain Gages } \\
\text { (DSC sensor) }\end{array}$ & Silicone oil & $3 \mathrm{D}$ & $\begin{array}{l}\text { Cooling of strain gages with water } \\
\text { Schematic, Figure } 3 \text { of Schetz } \\
\text { (1997) }\end{array}$ \\
\hline Kelly, Simmons, \& Paull & 1992 & Impulse tests, hypersonic flow & Non-Nullin & $10 \mathrm{dia}$ & Piezoelectric transducers & Thermal cover & $2 \mathrm{D}$ & $\begin{array}{l}\text { Prototype, no successful tests, yet } \\
\text { University of Queensland, Australia } \\
\text { Schematic, Figure } 8 \text { of Novean }\end{array}$ \\
\hline
\end{tabular}


Table 2 cont'd - Chronological Development of Direct Skin Friction Measurement Techniques

\begin{tabular}{|c|c|c|c|c|c|c|c|c|}
\hline References & Year & Test Conditions \& Location & $\begin{array}{l}\text { Nulling or } \\
\text { Non-Nullin }\end{array}$ & $\begin{array}{l}\text { Size of Floating } \\
\text { Element }(\mathrm{mm})\end{array}$ & $\begin{array}{l}\text { Type of Suspension/Position /Force } \\
\text { Transducer }\end{array}$ & $\begin{array}{l}\text { Gap } \\
\text { Filler }\end{array}$ & $\begin{array}{l}2 \mathrm{D} / 3 \mathrm{D} \\
\text { Flow }\end{array}$ & Remarks \\
\hline $\begin{array}{l}\text { Chadwick, Deturris, \& } \\
\text { Schetz }\end{array}$ & 1993 & $\begin{array}{c}\text { Very high heat flux } \\
\mathrm{M}=10-12, \mathrm{~T}_{\mathrm{t}}=4500 \mathrm{~K} \\
\mathrm{a}=2000 \mathrm{KW} / \mathrm{m}^{2} \&\end{array}$ & Non-Nullin & $6.35 \mathrm{dia}$ & Crystal Strain Gages & $\begin{array}{l}\text { Silicone } \\
\text { oil }\end{array}$ & $3 \mathrm{D}$ & $\begin{array}{l}\text { Schematic, Figure } 6 \text { of } \\
\text { DeTurris(1992) } \\
\text { NASA Ames DCAF }\end{array}$ \\
\hline $\begin{array}{l}\text { Bowersox, Chadwick, } \\
\text { Diewert, \& Schetz }\end{array}$ & 1995 & $\begin{array}{l}\text { Impulse tests } \\
\mathrm{M}=14 \text { \& } \\
\text { 1. NASA Ames } 16 \text { “ } \\
\text { Shock Tunnel, } \mathrm{t}=2.0 \mathrm{~ms}\end{array}$ & Non-Nullin & $8.13 \mathrm{dia}$ & Semi-conductor Strain Gages & $\begin{array}{c}\text { Silicone } \\
\text { oil }\end{array}$ & $2 \mathrm{D}$ & $\begin{array}{l}\text { Low thermal conductivity plastic } \\
\text { Schematic, Figure } 8 \text { of Schetz } \\
\text { (1997) }\end{array}$ \\
\hline Paik \& Schetz & 1995 & $\begin{array}{l}\text { Supersonic flow heat flux flow } \\
\operatorname{Re}_{\mathrm{x}}=4.87 \times 10^{7} \mathrm{M}=2.4 \text { at } 300 \mathrm{~K}\end{array}$ & Non-Nullin & $12.7 \mathrm{dia}^{*}$ & Foil Strain Gages & $\begin{array}{l}\text { Silicone } \\
\text { oil }\end{array}$ & $2 \mathrm{D}$ & $\begin{array}{l}\text { Water cololed and heta flux } \\
\text { microsensor, Schematic Figure } 1 \text { of } \\
\text { Paik (1995) }\end{array}$ \\
\hline $\begin{array}{l}\text { Novean, Bowersox, \& } \\
\text { Schetz }\end{array}$ & 1996 & $\begin{array}{l}\text { Shock Tunnel, M=12-14, } \tau=200-3000 \mathrm{~Pa} \\
\text { HYPULSE, M=14HP(high pressure) }, \tau=800-3000 \mathrm{~Pa} \\
\text { Supersonic Tunnel, M=2..D4 }\end{array}$ & Non-Nullin & $4.55,4.6,5.4 \mathrm{dia}$ & Semi-conductor Strain Gages & $\begin{array}{l}\text { Silicone oil } \\
\text { \& Rubber } \\
\text { RTV615 }\end{array}$ & $2 \mathrm{D}$ & $\begin{array}{l}\text { Good, except when shocks impinge } \\
\text { on floating head } \\
\text { Schematics Figures } 92-96 \text { of } \\
\text { Novean (March, 1996) } \\
\text { NASA Ames } 16 \text { Inch Shock Tunnel }\end{array}$ \\
\hline Remington \& Schetz & 1999 & esigned for Transonic, $\mathrm{M}=0.7$ to $0.99, \tau=0.3$ to $1.45 \mathrm{psf}$ & Non-Nullin & $4.2,6.35,9.53 \mathrm{dia}$ & $\begin{array}{l}\text { Kistler-Morse Strain gages } \\
\text { Eddv current daminino }\end{array}$ & None & $2 \mathrm{D}$ & $\begin{array}{l}\text { Schematic in Figure } 57 \text { of } \\
\text { Reminoton (1000) }\end{array}$ \\
\hline Pulliam \& Schetz & 1999 & $\begin{array}{l}\text { Designed for supersonic and high temperature } \\
\text { environments }\end{array}$ & Non-Nullin & $1.6256 \mathrm{dia}$ & Fiber optics & Silicone oil & $2 \mathrm{D}$ & Under construction \\
\hline
\end{tabular}

*Estimated from Sketch

** Linear Variable Differential Transformer (LVDT) 


\subsubsection{Direct Skin Friction Measurement Problems with the Floating Head}

The prevalent problems are in the detailed design of the skin friction gage. Winter (1977) provides a list of problems to consider:

1. Provision of a transducer for measuring small forces or deflections, and the compromise between the requirement to measure local properties and the necessity of having an element of sufficient size that the force on it can be mea sured accurately.

2. The effect of the necessary gaps around the floating head.

3. The effects of misalignment of the floating head.

4. Forces arising from the pressure gradient.

5. The effects of gravity or of acceleration if the balance is to be used in a moving vehicle.

6. Effects of temperature changes.

7. Effects of heat transfer.

8. Use with boundary-layer injection or suction.

9. Effects of leaks.

10. Protection of the measuring systems against transient normal forces during starting and stopping if the balance is to be used in a supersonic tunnel.

These problems are often solved for only one or a set of condition(s); ther efore, they occur again or cause more problems with the onset of a new environment. For example, problem 1 has commonly been handled by using semi-conductor strain gages which amplify the output of a conventional strain gage by 100 times. For high temperatures, the semi-conductor strain gages must be cooled, or one must use another measuring device. Most of the problems listed have been treated to one degree or another in Table 2. Problems 2,4,7, and 9 initiated this study and the need for damping. 


\subsubsection{Gap Filler Material: Why and Types}

Several reasons exist for filling the gap surrounding the floating head. First strong pressure gradients cause pressure drag in and around the gap. The solution was to fill the gap with a liquid such as silicone oil. The liquid simply "shifts to relieve any pressure difference", and capillary forces retain the liquid within the small gap (Schetz, 1997). This also provides a smooth uninhibited surface flush to the flow, thus allowing the deflection of the floating head to be an accurate representation of the shear stress. Second, the liquid acts as a damper for vibrations in testing facilities and flight tests. Third, the liquid is a heat transfer medium for hot and high heat flux flows. If the skin friction gage is water cooled, then the gap filler allows the beam and floating head to be the same temperature as the housing.

Silicone oil has been the gap filler for many skin friction gages, but slow leakage during testing is a recurring problem. Schetz and Novean (1996A) replaced the silicone oil with silicone rubber in one effort to eliminate the need for checking and refilling the oil in the gap. The exposed rubber in the gap placed additional forces on the head when subjected to flow, and the simple calibration technique of hanging weights from the head was no longer accurate. This study introduces a new idea for filling the gap by adhering a thin silicone rubber sheet to the face of the skin friction gage - this is the floating head, the gap, and the housing. This would retain the oil and create a smooth surface for external flow, ideally without interfering significantly with the motion of the head. 


\subsection{Scope of Investigation}

The recent adaptations to use silicone rubber in lieu of silicone oil, attempted to solve one problem, leakage, but added others. The need for skin friction measurements in more and more complex flows led to high-enthalpy tests, requiring the known skin friction gage design to be rugged as well as accurate. The silicone rubber was also chosen, because accessibility of the gage to replace the leaked oil was often limited. The two-part RTV-615 from General Electric was chosen because of its low viscosity to easily pour into the gap, its use as an electronic encapsulant (so not harm the strain gages), and its durability and pliability. The specifications on RTV-615 are in Appendix A. The problems caused by the silicone rubber as a gap filler do not seem to out-weigh the advantages; therefore, more study of the material and its effects on the skin friction gage are necessary. First, Novean (1996B) began a finite element method (FEM) analysis with the program ABAQUS (described in Chapter 2) to study the effects of the rubber on the floating head. As expected, the rubber does exert an additional force on the beam, causing it to deflect further, but the analysis was inco m-

plete. There were problems implementing the entire skin friction gage: beam, rubber, and housing (Novean, 1996B).

The initial problem statement is to complete the FEM analysis in order to obtain a full understanding of the rubber and its effects on the skin friction gage and to develop an accurate and efficient method of calibration. A study often brings up more questions than the original problem statement set out to answer. This work develops into numerous questions and answers not specifically stated here, and a new gap filling method is introduced in the latter stages. 


\section{GENERAL SKIN FRICTION GAGE}

This section explains the calibration technique and the semi-conductor strain gages used to measure shear stress. Figure 5 depicts the baseline design from Novean (1996A) of the skin friction gage to be used in this study. These skin friction gages were co nstructed of a high-temperature plastic called Polyethersulfone, PES, manufactured b Victrex. The plastic was used to reduce the mass of the floating head and the beam, and to increase the strain for a given wall shear stress.

\subsection{Calibration Technique for Skin Friction Gages}

The semi-conductor strain gages located on opposite sides of the cantilever beam yield a voltage output in response to a deflection in the beam. The response is linear for strain gages; therefore, a simple static calibration can be performed. A known weight is attached parallel to the direction of flow and perpendicular to the floating head surface. The weights are anywhere from $200 \mathrm{mg}$ to $10 \mathrm{~g}$ in increments dependent on availability of the weights. The weight is commonly attached with cellophane tape, sewing thread, and a paper cone to hold the weight. A tare can be taken with the cellophane tape,

thread, and cone apparatus to zero the balance. Figure 6 is an example of the calibration method. 


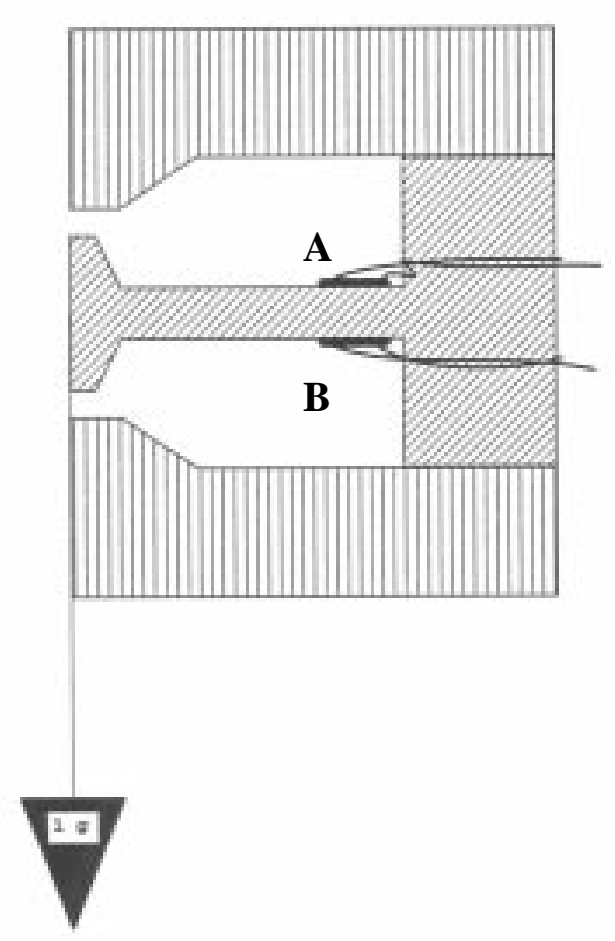

Figure 6-General Calibration Technique

This calibration method has worked extremely well with the skin friction gages filled with oil. It is simple and efficient. The effect of the shear stress on the oil is negligible; therefore, a weight located at the head center, parallel to the flow, and in the plane of the strain gages is an accurate model of the flow for calibration. The effect of the shear stress on a rubber fill is not negligible. The shear force acts on the floating head of the gage and the surface area of the silicone rubber. This increases the shear stress seen by the strain gages; therefore, the aforementioned calibration method is incorrect. For an accurate calibration the known weight would have to be distributed evenly over the surface of the floating head and silicone rubber.

The calibration of each particular skin friction gage used here is presented below in Figure 7 through Figure 11. The calibration of each skin friction gage is a straight line. For a known weight in grams, on the abscissa, the semi-conductor strain gage produces a voltage on the ordinate. The skin friction gage has to be calibrated in two directions. In Figure 6 the weight acts with gravity having the A side of the beam in tension and the $\mathrm{B}$ 
side of the beam in compression; that is one direction. Having the weight flipped with the A side of the beam in compression and the B side of the beam in tension, is the other $\mathrm{d}$ irection. These two directions are demonstrated in Figure 7 through Figure 11, as positive and negative slopes. Ideally, these slopes should be equal and opposite, that is why strain gages are purchased in pairs to ensure the gages are the same.

Figure 7 is an accurate calibration, bu Figure 8 through Figure 11 show a decrease in slope. The rubber sheet has been added to the last four calibration figures, $\mathrm{d}$ ecreasing the sensitivity. More discussion on this decrease in sensitivity is given in later Chapters.

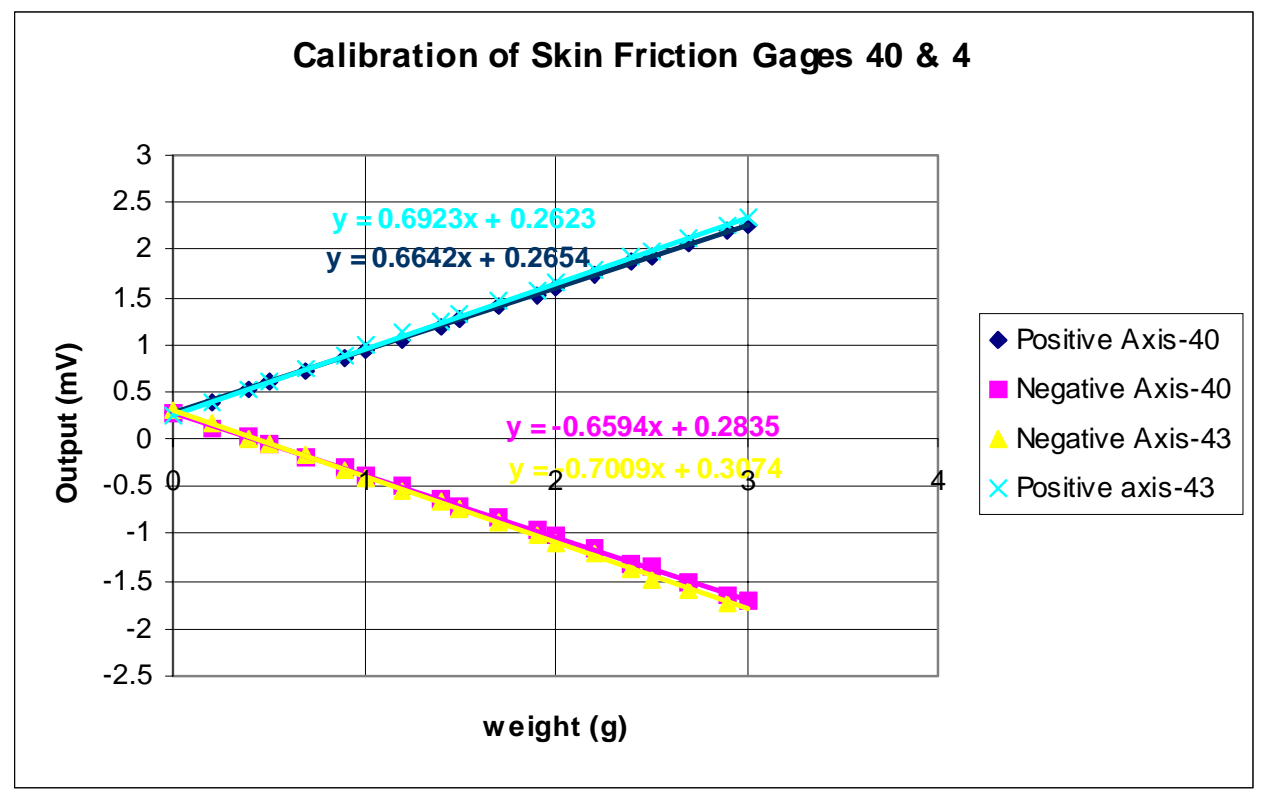

Figure 7-Calibration of Skin Friction Gages 40 and 43 


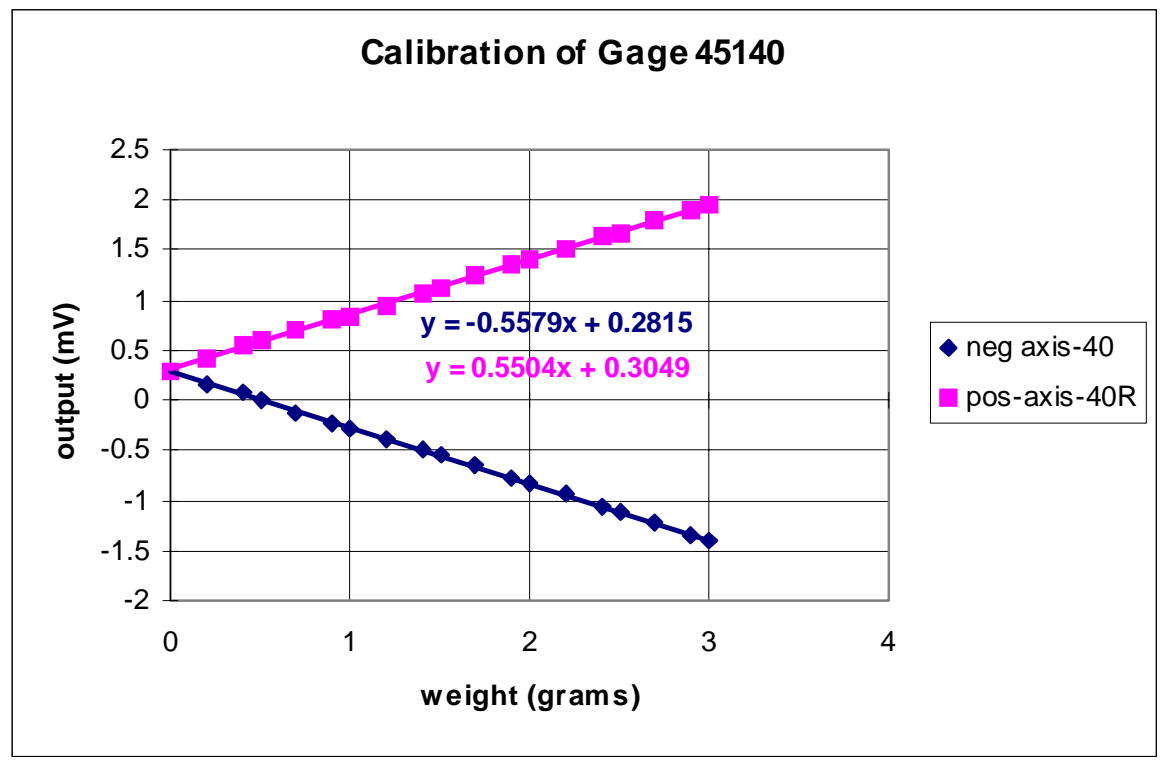

Figure 8-calibration of Skin Friction Gage 40R

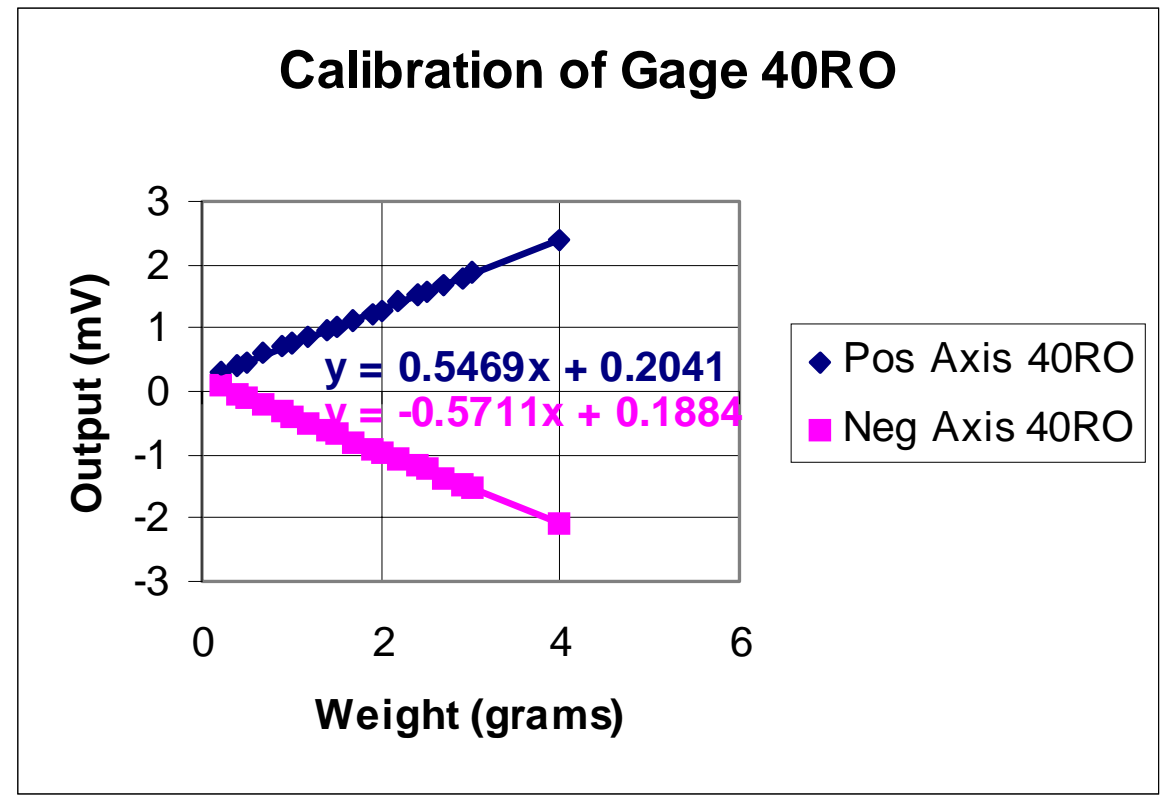

Figure 9-Calibration of Skin Friction Gage 40RO 


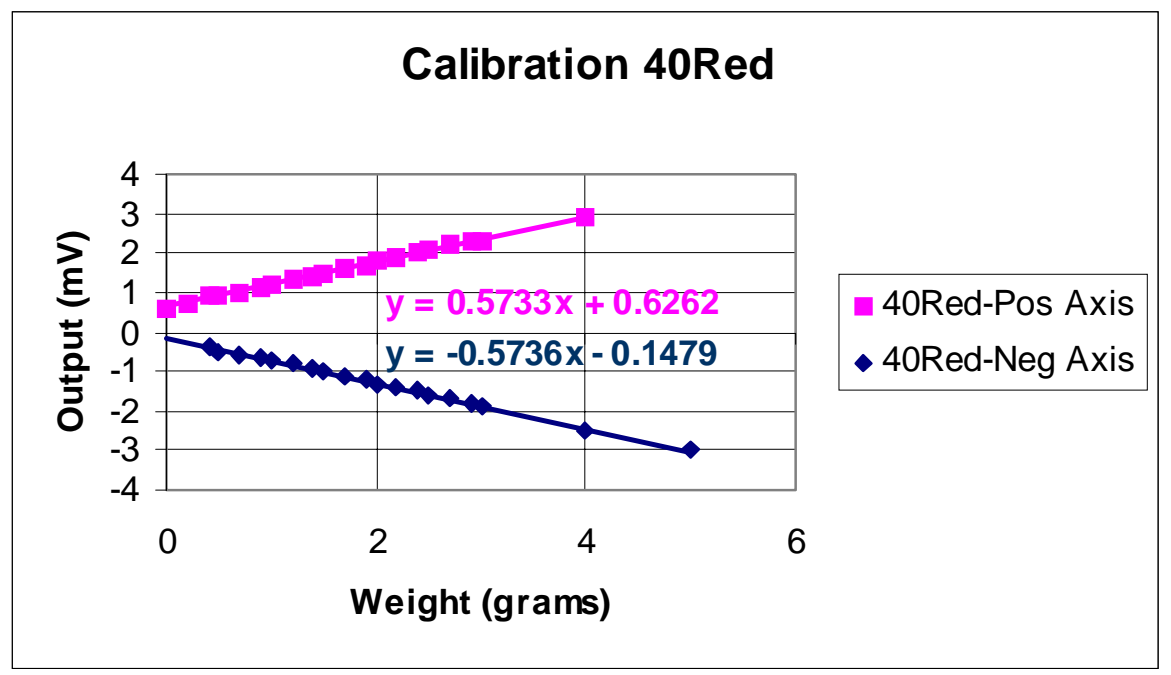

Figure 10-Calibration of Gage 40Red

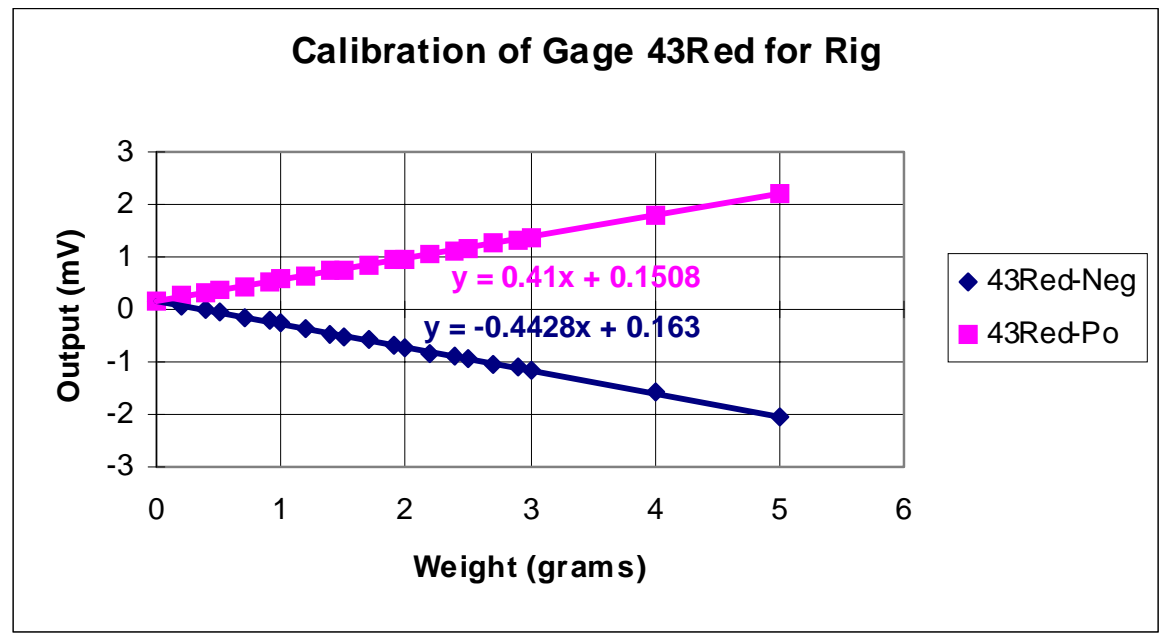

Figure 11-Calibration of Skin Friction Gage 43Red

The calibration curves presented do not have a zero y-intercept, because the excitation voltage is very low $(1 \mathrm{~V})$. Since, the excitation voltage is low, the tare did not yield a balance at zero. The excitation was not increased for these tests, in order to limit noise and electrical heating. More information on this is given in the following section. 


\subsection{Semi-Conductor Strain Gages}

A strain gage is an element that senses the change in strain and converts it to an electric output, where strain is the ratio of the change in length of a specimen to the orig inal length of the specimen. The strain gage, itself, stretches and compresses with movement, and this changes the resistance of the material in the strain gage, yielding a change in electric output. Strain gages are configured in a Wheatstone Bridge circuit shown in Figure 12.

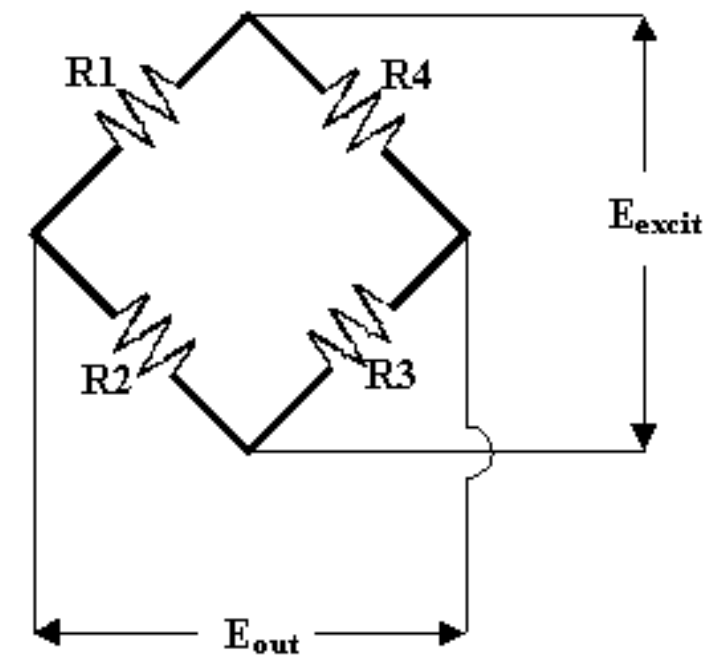

\section{Figure 12-Wheatstone Bridge Circuit}

Strain is related to resistance change by Equation 3,

$$
\varepsilon=\frac{\Delta R}{R_{o}(G F)},
$$

where, $\varepsilon$ is the strain, $\mathrm{R}$ is the resistance, and GF is the gage factor. Gage factor is the measurement of sensitivity of a strain gage. For a typical cantilever beam arrangemen with two active gages with equal and opposite strains, the output voltage for a bridge circuit is

$$
E_{\text {output }}=\frac{E_{\text {excit }} G F \varepsilon}{2}
$$


$E_{\text {output }}$ and $E_{\text {excit }}$ are the output voltage and the excitation voltage, respectively. The strain in a cantilever beam with a load at the end is

$$
\varepsilon=\frac{F L d}{2 E I},
$$

where E is the Young's Modulus Elasticity, I is the moment of inertia. Figure 13 shows the basic configuration.

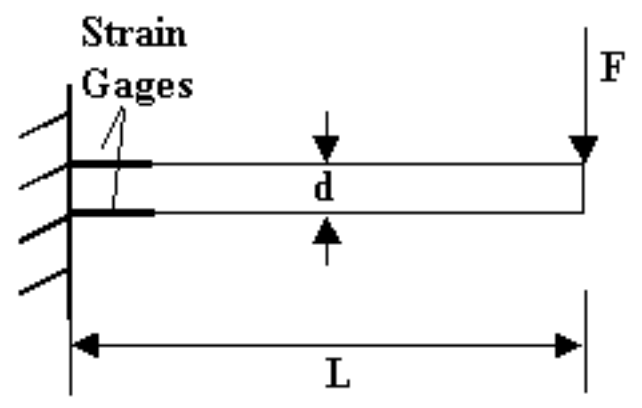

\section{Figure 13 -Basic Cantilever Beam Strain Setup}

Substituting Equation 5 into Equation 4, gives

$$
E_{\text {output }}=E_{\text {excit }} \frac{G F}{2} \frac{F L d}{2 E I} .
$$

Semi-conductor strain gages have a very high sensitivity that is necessary to sense the small deflections of the cantilever beam in the skin friction gages studied here. The gage factor is $135-150$, which is a hundred times greater than a metal foil conventional strain gage. These strain gages operate on the theory of piezoresistivitsy, which is the change of electrical resistance to applied stress. The semi-conductor strain gages used are silicone based and were supplied by Micron Instruments. The attachment and specifications of the semi-conductor strain gages are located in Appendix B.

A Measurements Group 2310 signal conditioning amplifier has multiple fun ctions. The semi-conductor strain gages used earlier were only a half a Wheatstone Bridge and had to be completed with the 2310 unit. The semi-conductor strain gages from Micron Instruments are a full bridge. The 2310 unit supplies the excitation voltage, balan c- 
ing effects (a tare), filtering, and gain. For this work an excitation of $1 \mathrm{~V}$, and a gain of 1 were set by Micron Instruments. These settings produced a small output voltage on the order of 0.1 to $1.0 \mathrm{mV}$, but for the skin friction gage it was necessary to minimize noise. Note, such a small voltage output requires a minimum of 16-bit data acquisition board. 16-bit board would have a residual of 0.00001526 , corresponding to a voltage of 0.01526 $\mathrm{mV}$.

The temperature sensitivity of semi-conductor strain gages is amplified over conventional strain gages. Temperature does two things to yield an apparent strain. One is the inherit change in resistance due to a change in temperature, and the second is the di fferential thermal expansion between the semi-conductor and the substrate to which the gage is bonded. The change in strain output is approximately $10 \%$ to $20 \%$ for $100^{\circ} \mathrm{F}$, and most manufacturers compensate for this (Chadwick, 1992). The semi-conductor strain gages purchased from Micron Instruments have a temperature compensation circuit built in-line with the strain gage. This circuit in theory cancels out the temperature effects. 


\section{FINITE ELEMENT METHOD ANALYSIS OF A SKIN FRIC- TION GAGE}

The finite element program ABAQUS was used in conjunction with the earlier results of Novean (1996B) to produce a finite element model of a skin friction gage with a gap filler of silicone rubber. The goals of this model are to simulate how the gap filler, the cantilever beam, and the housing will deform with shear stresses. This information is necessary in order to design a skin friction gage for a specific applic ation. Typical issues of importance are the choice of gap size and the resulting change in sensitivity of the gage for a given shear value.

\subsection{ABAQUS}

ABAQUS contains numerous engineering simulation programs based on the finite element method. It can provide the simplest linear analysis to complex non-linear analysis. ABAQUS has an extensive library of elements to suit virtually any geom etry, as well as a list of material models to simulate anything from metal to resilien foam. It can also be used to study more than structural problems, like heat transfer, mass diffusion, thermal management of electrical components, acoustics, soil mechanics, and piezoelectric analysis (ABAQUS/Standard, 1998).

The input data for ABAQUS, and most finite element programs, is broken into option blocks. The option block titles are descriptive and easy to understand. For instance *PLASTIC would label the option block that defines plastic behavior (ABAQUS/Standard, 1998). A typical input file would first define all the nodes of an object with $\mathrm{x}, \mathrm{y}$, and $\mathrm{z}$ locations. Next, the elements are defined by connecting the nodes, and then the material(s) properties would be defined, and lastly the parameters for the loads to be applied are given.

Some terms indigenous to ABAQUS to be discussed are defined here.

TYPE: the geometry of the element

C3D8: $\quad$ continuum, 3-dimensional, 8-node linear brick element type (Figure 14) 
C3D6: continuum, 3-dimensional, 6-node linear pie element type (Figure 15)

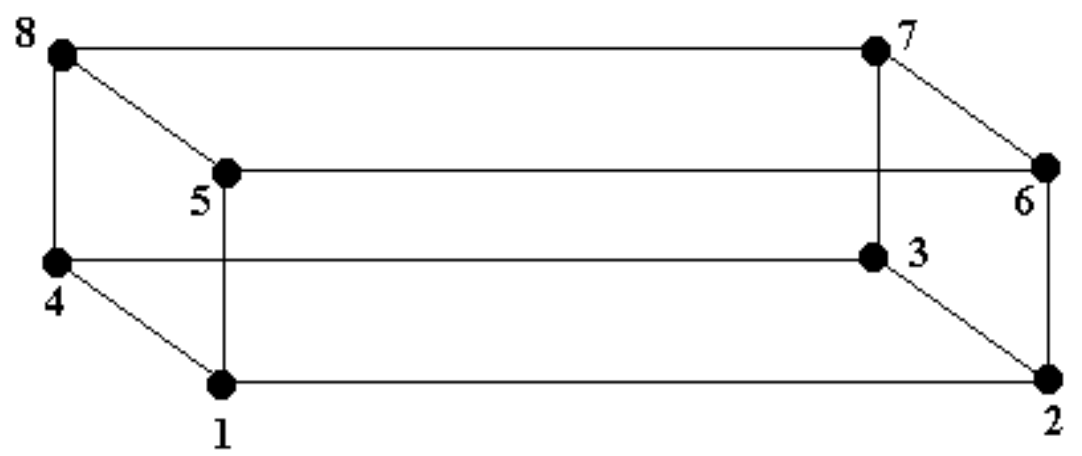

Figure 14 -C3D8 Element Type

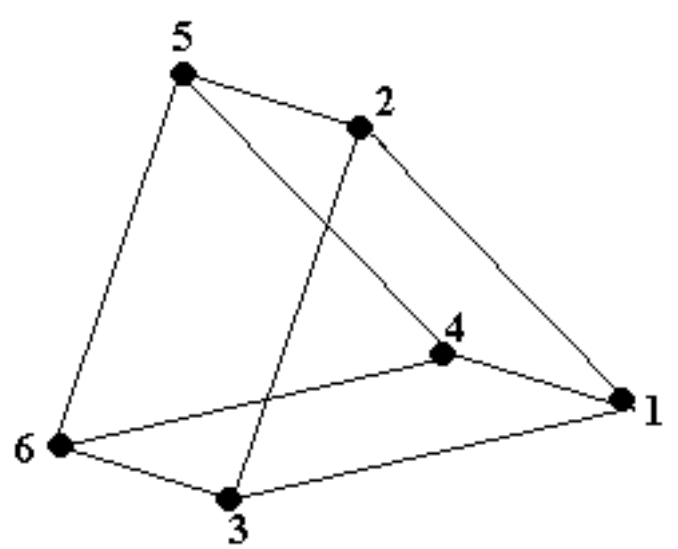

Figure 15-C3D6 Element Type

C3D8H: $\quad$ continuum, 3-dimensional, 8-node linear brick, hybrid, constant pres sure element type

DLOAD: distributed load

CLOAD: concentrated load, load concentrated on nodes

ENCASTRE: Boundary condition fixing a node(s) in all 6 degrees of freedom (DOF) (ABAQUS User's Manual, 1998) 


\subsection{FEM Model Completion}

The parameters of the active part of the skin friction gage modeled by Novean (1996B) and the author (see Figure 5) are as follows:

Floating head diameter

Silicon rubber diameter

Total gage diameter

Gage height

Shear loading
$4.6 \mathrm{~mm}$,

$9.52 \mathrm{~mm}$,

$25.4 \mathrm{~mm}$ ( 1 in),

$6.4 \mathrm{~mm}$,

$1000 \mathrm{~Pa}$.

Novean developed a preliminary FEM model of the skin friction gage without the housing. The attempts to add the housing failed because of the element TYPE choice. The silicone rubber element TYPE chosen by Novean was C3D8, which was the same as for the plastic material of the cantilever beam. The line would appear as, ELEMENT, TYPE=C3D8. The proper choice for the silicone rubber is a hybrid element TYPE, C3D8H. A hybrid element is chosen when the material is incompressible (Poisson's Ratio $=0.5)$ or almost incompressible $(0.48 \geq$ Poisson's Ratio $<0.5)$. Poisson's Ratio is the ratio of lateral strain to the axial strain of a specimen. Incompress ible material solutions cannot be obtained through displacement history, since a hydrostatic pressure can be added without changing displacement (ABAQUS User's Ma nual, 1998). The 2-part RTV-615 silicone rubber from General Electric had a Poisson's Ratio of 0.495 ; therefore, a hybrid element was necessary and implemented here. The housing was added with the use of hybrid elements for the silicone rubber, and the results of the strain analysis were satisfactory.

Novean used a distributed load, DLOAD. Novean had to construct a fictitious thin membrane to apply the load across the top of the gage. This method was not the most accurate, since the membrane was not actually part of the design; a CLOAD was determined to be more accurate. The CLOAD distribution was achieved by simple geometry without altering the shape and size of the gage. Given the $1000 \mathrm{~Pa}$ shear stress chosen for these studies, the exposed surface area of each element can be determined, and a force for each element can be calculated $\left(\mathrm{F}=\tau_{\mathrm{w}} \mathrm{A}\right)$. Subsequently, the force applied to each node could be determined. For example, a brick element would have four nodes exposed to the surface pressure; the force would be divided by four and added to the other applicable forces. Figure 16, perhaps, explains this better. 


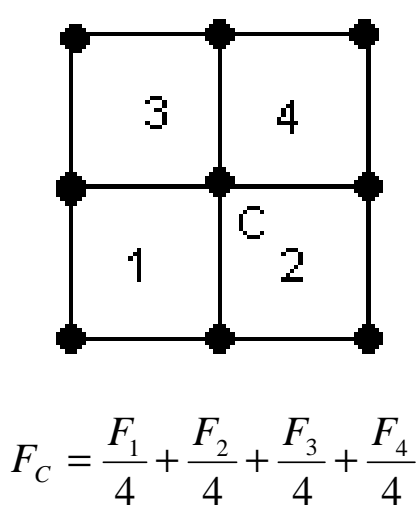

Figure 16-Example of CLOAD Distribution (node C and elements 1-4)

A Microsoft Excel spreadsheet program was written to quickly determine the magn itiude and location of the forces.

The original model by Novean had an improper maximum/minimum strain placement. The maximum/minimum strain in a cantilever beam should be equal and opposite on either side of the beam base. It appeared one element up from the base, see Figure 17.

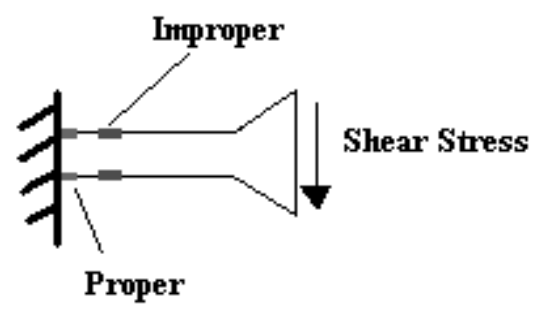

Figure 17-Location of Improper and Proper Maximum/Minimum Strain

This problem was traced to the FEM grid, and grid refinement corrected the max imum/minimum strain location to be at the beam base.

\subsection{FEM Model Cases}


Calculations for eleven cases were performed. The first three cases were similar to the models of Novean. Cases 4 - 6 were the FEM model including the housing with different loading areas applied. Cases 7-11 were grid refinements, to ensure the accuracy of the finite element size chosen. The results of all eleven cases are in Table 3. The "Theory" column in purple are values obtained from simple cantilever beam analysis performed by Novean (1996B), and the green column titled "Novean" are values caluculated by Novean (1996B). The most important column in blue is the columns titled "Beam". This column gives the strain values at the location of the strain gages. The other columns in blue are the strain in the rubber and the housing. No grid refinement was performed on the housing, because it is a rigid component. Note, for all cases the strain in the z-direction or 3-direction (denoted in ABAQUS as E33) is the reported strain. Several strain contour plots are depicted for cases where such information is considered significant.

\section{Table 3 -Results in ABAQUS on Rubber Filled Skin Friction Gage}

\begin{tabular}{|c|c|c|c|c|c|c|c|c|c|c|}
\hline \multirow[t]{2}{*}{ Strain } & \multicolumn{2}{|c|}{ Beam (C3D6 /C3D8*) } & \multicolumn{2}{|c|}{ Rubber(C3D8H) } & \multicolumn{2}{|c|}{ Housing(C3D8) } & \multicolumn{2}{|c|}{ Theory, Beam } & \multicolumn{2}{|c|}{ Novean, Bea } \\
\hline & Max & Min & Max & Min & Max & Min & Max & Min & Max & Min \\
\hline \multicolumn{11}{|l|}{ Case } \\
\hline ELEMENT & 101 & 117 & $\mathrm{NI}$ & $\mathrm{NI}$ & $\mathrm{NI}$ & $\mathrm{NI}$ & 2 & 18 & 101 & 117 \\
\hline 2 & $2.080 \mathrm{E}-05$ & $-2.080 \mathrm{E}-05$ & $8.520 \mathrm{E}-05$ & $-8.520 \mathrm{E}-05$ & $\mathrm{NI}$ & $\mathrm{NI}$ & NA & NA & NA & NA \\
\hline ELEMENT & 101 & 117 & 1532 & 1548 & $\mathrm{NI}$ & $\mathrm{NI}$ & 2 & 18 & 101 & 117 \\
\hline 4 & $2.490 \mathrm{E}-05$ & $-2.490 \mathrm{E}-05$ & $2.200 \mathrm{E}-03$ & $-2.200 \mathrm{E}-03$ & $2.500 \mathrm{E}-08$ & $-2.500 \mathrm{E}-08$ & NA & NA & NA & NA \\
\hline ELEMENT & 101 & 117 & 1588 & 1572 & 3318 & 3302 & 2 & 18 & & \\
\hline 5 & 2.490E-05 & $-2.490 \mathrm{E}-05$ & $2.200 \mathrm{E}-03$ & $-2.200 \mathrm{E}-03$ & $2.580 \mathrm{E}-05$ & $-2.580 \mathrm{E}-05$ & NA & NA & NA & NA \\
\hline ELEMENT & 2 & 18 & 1588 & 1572 & 3318 & 3302 & 2 & 18 & & \\
\hline 8 & $2.960 \mathrm{E}-05$ & $-2.960 \mathrm{E}-05$ & $2.170 \mathrm{E}-03$ & $-2.170 \mathrm{E}-03$ & $2.920 \mathrm{E}-08$ & $-2.920 \mathrm{E}-08$ & NA & NA & NA & NA \\
\hline ELEMENT & 2 & 18 & 1588 & 1572 & 3318 & 3302 & 2 & 18 & & \\
\hline 9 & 2.960E-05 & $-2.960 \mathrm{E}-05$ & $2.170 \mathrm{E}-03$ & $-2.170 \mathrm{E}-03$ & $2.920 \mathrm{E}-08$ & $-2.920 \mathrm{E}-08$ & NA & NA & NA & NA \\
\hline ELEMENT & 2 & 18 & 1588 & 1572 & 3318 & 3302 & 2 & 18 & & \\
\hline 10 & 2.916E-05 & $-2.916 \mathrm{E}-05$ & $2.009 \mathrm{E}-03$ & $-2.009 E-03$ & $3.362 \mathrm{E}-08$ & $-3.362 \mathrm{E}-08$ & NA & NA & NA & NA \\
\hline ELEMENT & 2 & 18 & 1558 & 1572 & 3318 & 3302 & 2 & 18 & & \\
\hline 11 & 2.910E-05 & $-2.910 \mathrm{E}-05$ & $2.166 \mathrm{E}-03$ & $-2.166 \mathrm{E}-03$ & $2.999 \mathrm{E}-08$ & $-2.999 \mathrm{E}-08$ & NA & NA & NA & NA \\
\hline ELEMENT & 2 & 18 & 1588 & 1572 & 3318 & 3302 & 2 & 18 & & \\
\hline
\end{tabular}

Note: NI, not implemented and NA, not available

${ }^{*}$ Cases 1-6 are beam element type C3D6, and Cases 7-11 are C3D8

\subsubsection{Case 1}


Case 1 was with the cantilever beam, only. The reason for Case 1 was to use the simplest case Novean modeled to assure understanding of the ABAQUS program As seen in Table 3, the results compare well. For cases 1-6, the maximum and min imum strain occur at nodes 101 and 117, which are the height of one finite element above the beam base, this inaccuracy will later solve itself with grid refin ement.

\subsubsection{Case 2}

Case 2 added the 2-part RTV-615 silicone rubber around the beam. The shear load was only applied to the floating head. Novean had modeled the rubber as a C3D8 element. The rubber has a Poisson Ratio(v) of 0.495 , which is almost incompressible (for incompressible materials, $\mathrm{v}=0.5$ ); therefore, an element type $\mathrm{C} 3 \mathrm{D} 8 \mathrm{H}$ instead o C3D8 was used here. All rubber elements for future cases will utilize the element type $\mathrm{C} 3 \mathrm{D} 8 \mathrm{H}$. This element designation will eliminate the problem Novean had in adding the housing. Figure 18 is a contour plot of the strain in the z-direction or 3-direction of the beam. The blue shades are compressive strains and the red shades are tensile strains. The maximum absolute strain is $20.8 \mu \varepsilon$, occurring at elements 101 and 117 , equal and opposite. The maximum absolute strain should occur at elements 2 and 18. The results of Case 2 are numerically listed in Table 3. Case 2 was an intermediat step and did not have the results of Novean (green column in Table 3) for compar ison. 


\section{ABAQUS}

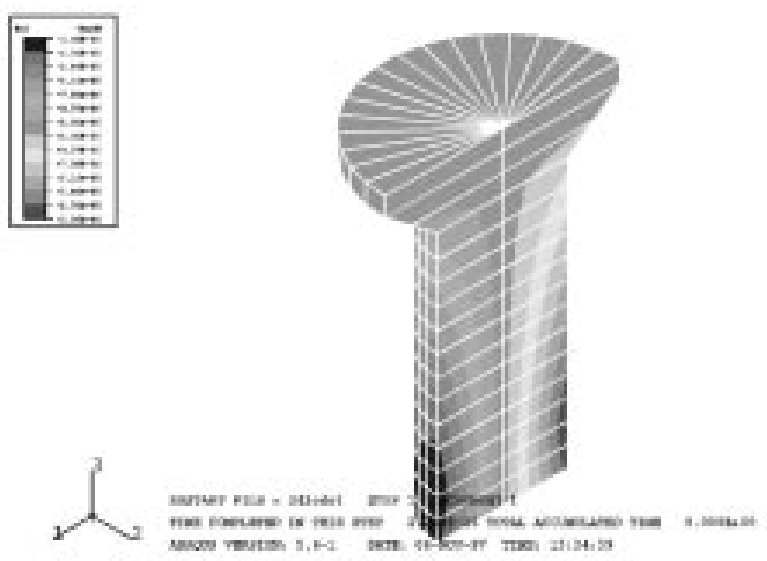

Figure 18-Strain Contour Plot of the Beam is Case 2

\subsubsection{Case 3}

Case 3 consisted of the beam and rubber with the shear loading applied to the head and top rubber face. Since the housing had not yet been added, the results should compare favorably with those of Novean, regardless of the element type. A geometric ratio between the head and the rubber face can be multiplied by the strain of Case 2 , in the blue "Beam" column of Table 3, to yield estimated results in the purple column. The geometric ratio is the area of the head and the top rubber face to the area of the head alone.

The measured geometric ratio is 3.22 , calculations by Novean yielded an e ffective ratio of 3.17, and the current results of Case 3 yielded a ratio of 3.23. This is acceptable, because the percent error is less than $1 \%$. The results for Case 3 are $\mathrm{n} \mathrm{u}$ - 
merically shown in Table 3. Note:E332 $=2.08 \mathrm{E}-5$ is the maximum strain in the beam for Case 2.

\subsubsection{Case 4}

Case 4 had the beam, rubber fill, and a rigid housing with the load applied to the beam head and rubber face. The housing was a thin ring with an outer diameter of 10mm. A boundary condition, ENCASTRE, was implemented in ABAQUS. This boundary condition restricts all 6 degrees of freedom (DOF) from movement. Case 4 assumed the housing was large and stiff compared to the rubber and beam, and $\mathrm{i}$ would not experience any deflection due to the rubber and beam.

For this case and future cases, there were no results from Novean (1996B) to compare, but given general engineering experience, the values of strain and displacement should decrease with the addition of the housing. The actual decrease is doc umented in the blue columns of Table 3. Figure 19 is the strain contour plot in the 3direction for the beam, rubber, and thin rigid housing. The sections are visually separated with black outlines. 


\section{ABAQUS}

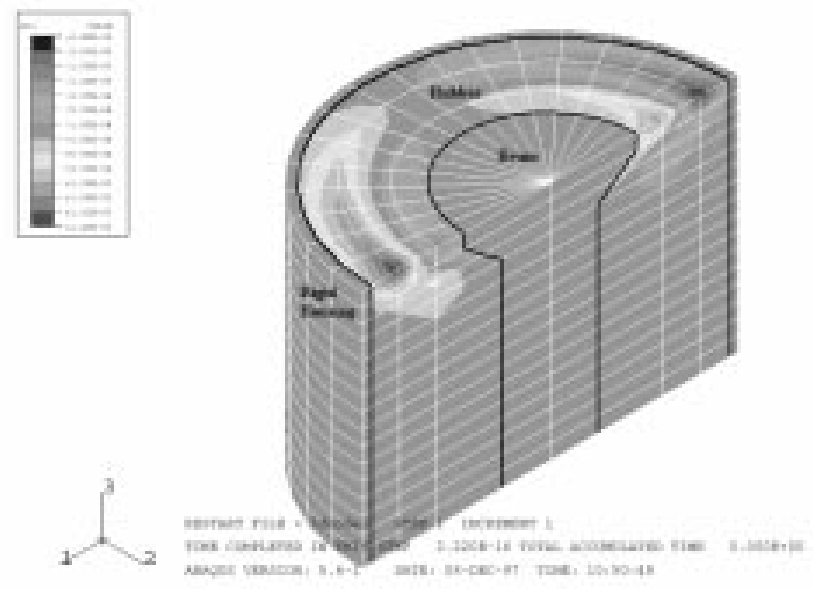

Figure 19-Strain Contour Plot of the Entire Gage for Case 4

\subsubsection{Case 5}

Case 5 added the entire housing with an outer diameter of $25.4 \mathrm{~mm}$ or $1 \mathrm{in}$. The load was applied to the beam head and rubber face. Results from Case 4 and 5 should be exact, if the assumption in Case 4 of a rigid housing is valid. The results do match to Case 4, as expected, and they are represented in Table 3. 


\subsubsection{Case 6}

Case 6 was Case 5 with the load applied to the beam head, rubber face, and housing face. Intuition says the strain in the beam and rubber should decrease and increase in the housing, consequently, decreasing the displacement slightly. Table 3 documents the beam and rubber decrease and the housing increase of strain compared to Case 5 in the blue co lumns.

\subsubsection{Case 7}

Case 7 began the grid refinement process. The grid refinement started with the beam. Case 7 added one ring of C3D8 elements of diameter $0.2 \mathrm{~mm}$ with the load a pplied to the beam head, rubber face, and housing face. The strain did change from Case 6 showing the need for grid refinement. The results are in Table 3.

The goal of a grid refinement is to ensure adequate element size, and refin ement will continue until no changes occur. Again, the strain in the 3-direction, E33, at the beam base is the most important here ; therefore, it is the component of strain tha must remain constant for the grid refinement to be complete. In this case, the results yielded a maximum and minimum strain at the true beam base (elements 2 and 18). For the easiest visualization of the maximum and minimum strain, the beam is turned upside-down in Figure 20. 


\section{ABAOUS}

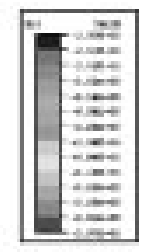

Figure 20-Strain Contour Plot of the Beam for Case 7

\subsubsection{Case 8}

Case 8 added another ring of C3D8 elements of diameter $1.0 \mathrm{~mm}$. The E33 strain at elements 2 and 18 again were the maximum and minimum. The strain a beam base did change slightly from Case 7, seen in the blue column titled "Beam" in Table 3; therefore, another grid refinement is to be done for the beam

\subsubsection{Case 9}

Case 9 was a continuation of the beam refinement. The intersection of multiple nodes at the center of the beam was considered an unfavorable grid; therefore, a small hole was constructed with a diameter of $0.02 \mathrm{~mm}$. The results are the same as Case 8, and are in Table 3 under the blue column titled "Beam". The grid refinement 
on the beam was deemed complete. Figure 21 is the strain contour plot of the beam, again depicted upside-down for better viewing. The figure also shows the hole at the center of the beam.

\section{ABAQUS}
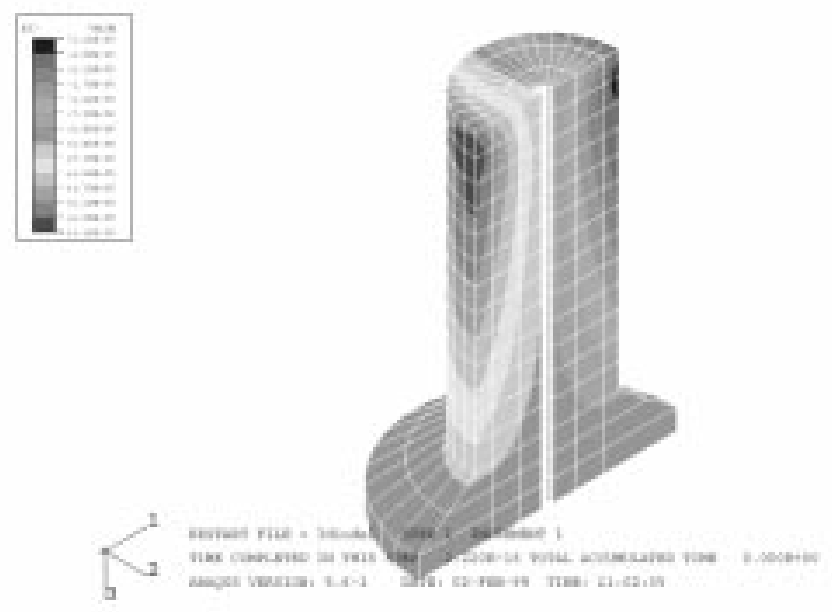

Figure 21-Strain Contour Plot of the Beam for Case 9

\subsubsection{Case 10}

Case 10 began the grid refinement on the rubber, adding one ring of $\mathrm{C} 3 \mathrm{D} 8 \mathrm{H}$ elements of diameter $7 \mathrm{~mm}$. The strain changed slightly in the rubber and in the beam compared to Case 9, as should be expected. The strain changed more significantly in the housing. The results are in the blue columns labeled "Beam", "Rubber", and "Housing" in Table 3. Figure 22 is a strain contour plot of rubber only, since the rubber in being refined. Notice the strain concentrations are at the edges were the beam and housing meet the rubber. It is also interesting to notice the tensile and compre ssive strains - one acting at the contact of the rubber and housing and the other acting at the contact of the rubber and beam. 


\section{ABAQUS}

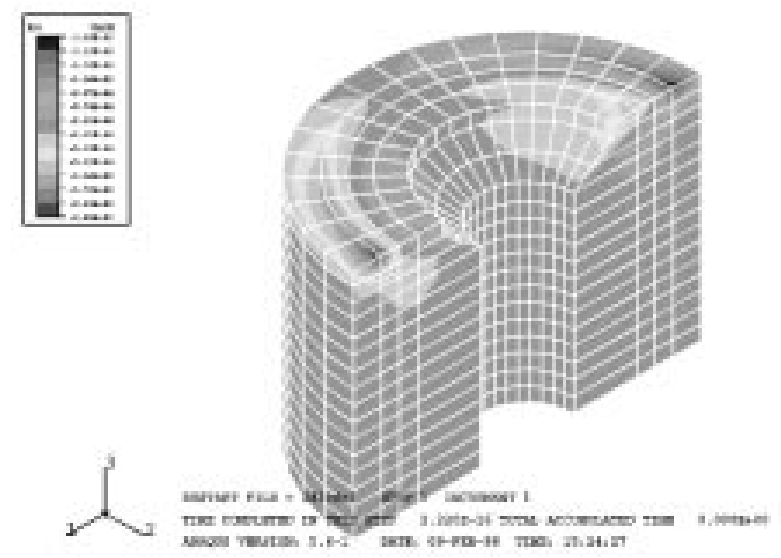

Figure 22-Strain Contour Plot of the Rubber for Case 10

\subsubsection{Case 11}

Case 11 added one final ring of $\mathrm{C} 3 \mathrm{D} 8 \mathrm{H}$ elements to the rubber with a diameter of $5.4 \mathrm{~mm}$. The results yielded no significant change in the strain at the beam base and location of the strain gages; therefore, the grid refinement on the skin friction gage was judged complete. The results from Case 11 are in Table 3. With the completion of the FEM analysis, any shear load can be applied to the beam head, rubber face, and housing face, and the resulting effects can be viewed with confidence of the accuracy. 


\section{CALIBRATION RIG}

The purpose of the Calibration Rig is to calibrate skin friction gages filled with silicone rubber. Chapter 2 detailed the reasons necessary for a new calibration device. The Calibration Rig utilizes a synthetic grade glycerine, USP 99.7\% (United States Pharmacopoeia, specifications in Appendix A), to create a shear stress that can be a pplied to the entire surface area of the silicone rubber filled skin friction gage. Glycerine flows under fully-developed conditions through a two dimensional channel of length $\mathrm{L}=16$ in. , lined with pressure ports an inch a part, and one or two rubber filled skin friction gages lie flush with the floor towards the end of the channel. See FIgurex

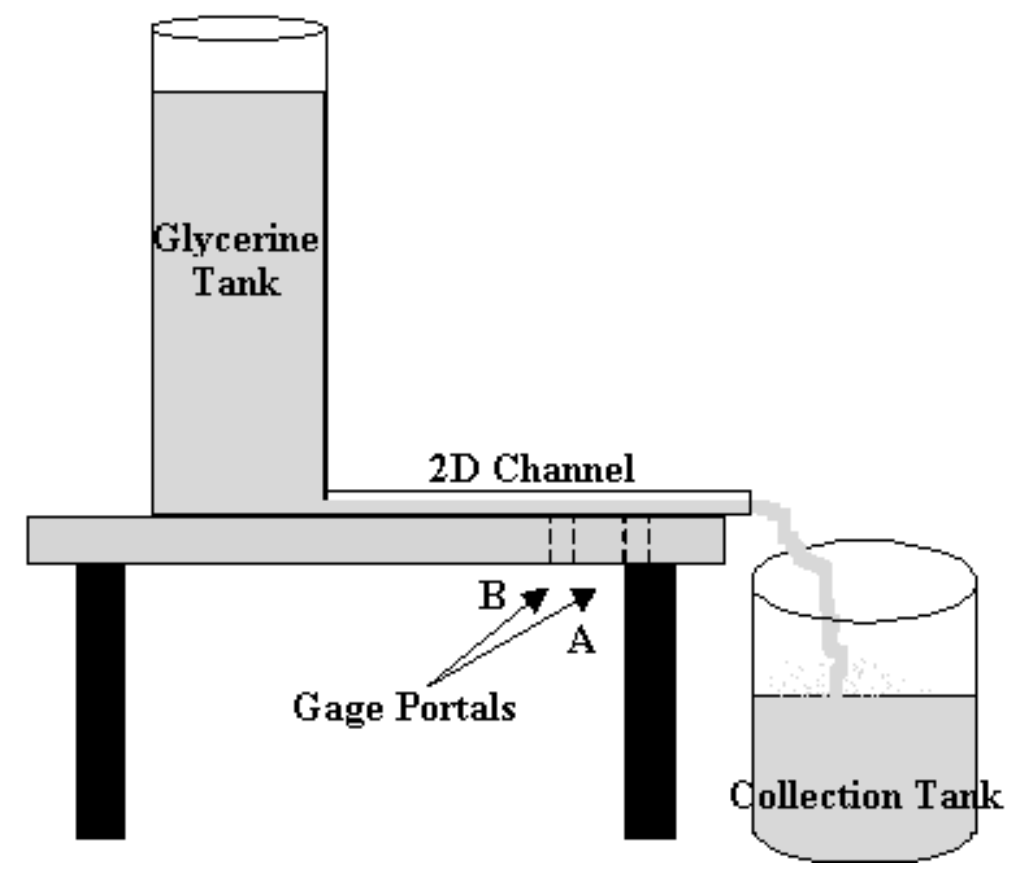

Figure 23-Basic Original Calibration Rig Design

The pressure distribution can then be measured, and the shear stress can be calculated using Equation 7,

$$
\tau_{w}=-\frac{d p}{d x} h,
$$

where $\mathrm{h}$ is the channel height measured from the centerline, $\tau_{\mathrm{w}}$ is the shear stress, and $\frac{d p}{d x}$ is the pressure gradient. For calibration, three methods were determined capable of changing the shear level; the height of the channel, h, the height of the glycerine 
tank, and the area exit opening/control valve can be varied. The height of the channe being varied is an obvious change in shear through Equation 7. The other two met hods change the pressure gradient. Varying the height of the glycerine tank, changes the initial pressure at the start of the channel, thus changing the overall pressure gr adient. At a closed position of the exit control valve, the pressure gradient is zero, and the pressure gradient increases with velocity as it opens to a full position. For any situation the subsequent voltage outputs from the strain gages can be recorded for each segmented change to create a linear calibration curve.

The initial Calibration Rig design was engineered by Michelle Wilson. The idea appeared simple to construct and employ. Glycerine was originally chosen, because of its high viscosity and dramatic changes in viscosity due to temperature. Glycerine at $20{ }^{\circ} \mathrm{C}$ has viscosity of $1410 \mathrm{cp}$, at $\quad{ }^{\circ} \mathrm{C}$ has viscosity of $612 \mathrm{cp}$, and at ${ }^{\circ} \mathrm{C}$ has viscosity of $3900 \mathrm{cp}$. The temperature of the glycerine can be changed with the use of tap water and copper tubing running through the interior of the rig. With the derivation of Equation 7, it was clear that the viscosity has no affect on the shear stress. The viscosity of the fluid does affect the rate at which the fluid flows through the twodimensional channel, thus affecting the run time.

\subsection{Derivation of Equation 7}

When Newton's second law of motion is applied to a fluid element acted upon by pressure and gravity, it results in (Kuethe and Chow, 1986),

$$
\rho \Delta x \Delta y \Delta z \frac{D \mathbf{V}}{D t}=\mathbf{f}
$$

$\rho \Delta x \Delta y \Delta z$ is the fluid element mass. $\frac{D \mathbf{V}}{D t}$ is the substantial or material derivative, which is defined as $\frac{D Q}{D t}=\frac{\partial Q}{\partial t}+\frac{\partial Q}{\partial s} V$. The derivatives $\frac{\partial Q}{\partial t}$ and $\frac{\partial Q}{\partial s}$ are the loca variation of time at a given position and the variation with change of position at a given time, respectively. $\frac{\partial Q}{\partial s} V$ is the time rate of change of $\mathrm{Q}$ due to the change o 
position. $Q$ is an arbitrary variable of a fluid property (Karamcheti, 1980). The flow under consideration is two dime nsional, so,

$$
\frac{D \mathbf{V}}{D t}=\frac{D u}{D t}=\left(\frac{\partial u}{\partial t}+u \frac{\partial u}{\partial x}+v \frac{\partial u}{\partial y}\right)=0 .
$$

The first term on the right hand side of Equation $8, \mathbf{f}$, is the force vector. The pressure and shear forces acting on a two dimensional fluid element are depicted in Figure 24.

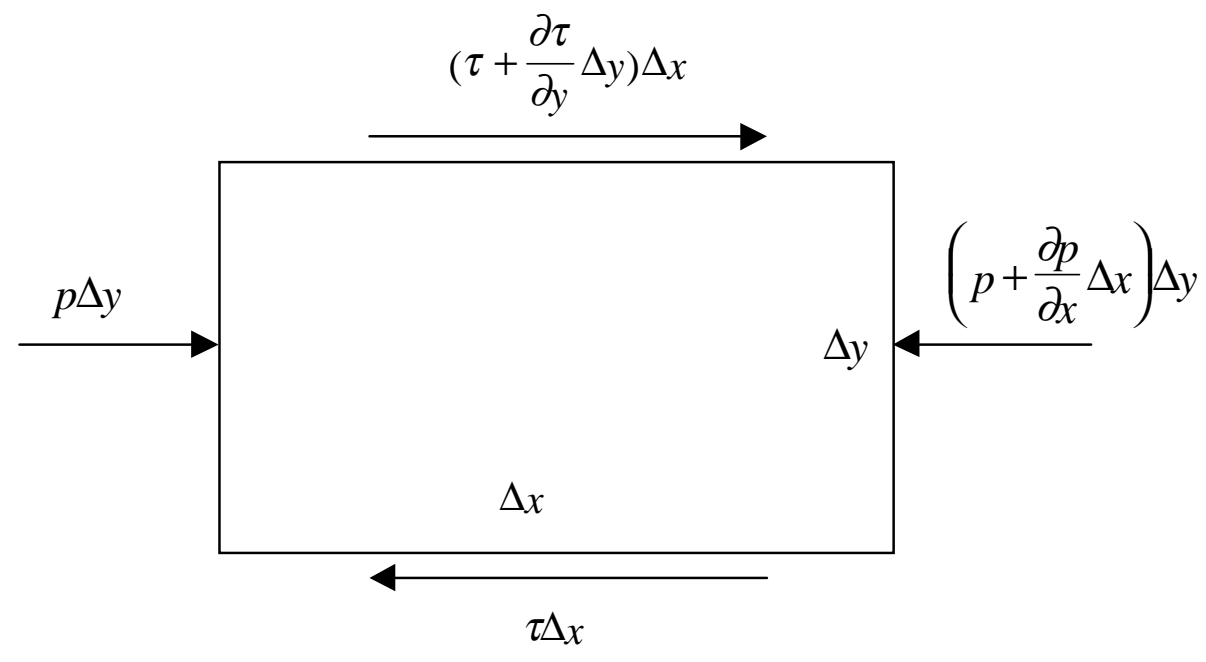

Figure 24 -Forces Acting on a Two-Dimensional Fluid Element

The letters $p$ and $\tau$ denote pressure and shear stress, respectively. By adding the terms in Figure 24, the force can be determined, as

$$
f=\left(-\frac{\partial p}{\partial x}+\frac{\partial \tau}{\partial y}\right) \Delta x \Delta y
$$

Since the force is acting in only one direction, the vector notation of bold lettering is dropped. Combining Equations 9 and 10, substituting into Equation 8 for a twodimensional fluid element, and dividing by the element area $\Delta x \Delta y$, Equation 11 results,

$$
\rho\left(\frac{\partial u}{\partial t}+u \frac{\partial u}{\partial x}+v \frac{\partial u}{\partial y}\right)=\left(-\frac{\partial p}{\partial x}+\frac{\partial \tau}{\partial y}\right)
$$

The shear stress is defined as, $\tau=\mu \frac{\partial u}{\partial y}$, and substituting this would yield the boundary layer equation of motion. For this case the flow is considered fully-developed, where fully-developed assumes all mean velocity profiles along the channel are ide n- 
tical $\left(\frac{\partial u}{\partial x}=0\right)$, and velocity, $\mathrm{u}$, is not a function of the $\mathrm{x}$-direction. Since the pressure gradient is a constant resulting from the fully-developed flow, the partial derivative, $\frac{\partial p}{\partial x}$, is a total derivative, $\frac{d p}{d x}$. Now, Equation 11 appears as below in Equation 12,

$$
\frac{\partial \tau}{\partial y}=\frac{d p}{d x}
$$

Integrate $\tau$ with respect to $\mathrm{y}$, and apply the boundary conditions $\tau=\tau_{w}$ at $\mathrm{y}=-\mathrm{h}$, and $\tau=0$ at $\mathrm{y}=0$, where $\mathrm{h}$ is the height of the channel as measured from the centerline as shown in Figure 25 to yield,

$$
\tau_{w}=-\frac{d p}{d x} h
$$

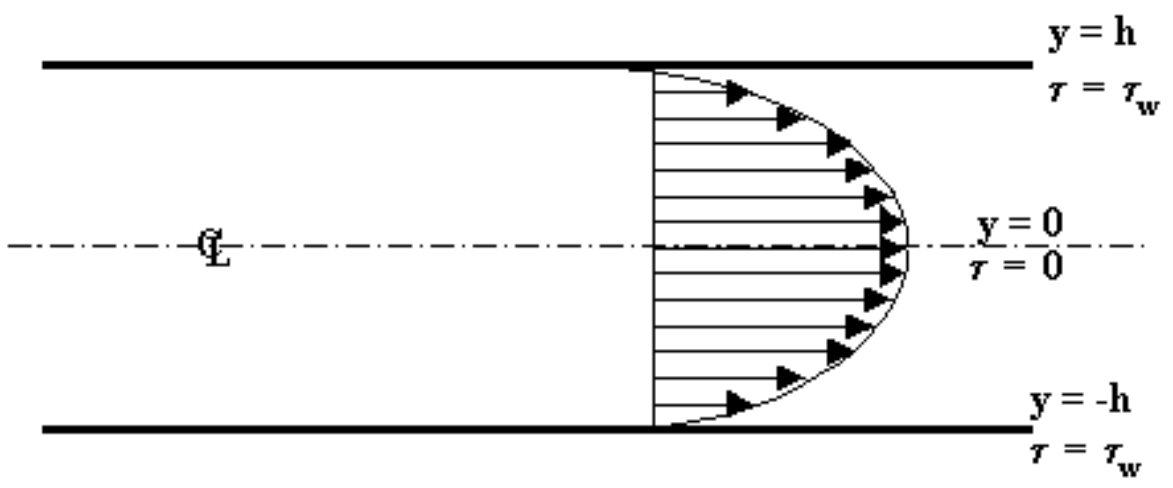

Figure 25-Fully Developed 2-D Channel Flow

\subsection{Achieving Fully Developed Flow}

The first step was to prove that the flow of glycerine in the channel was fully developed. Fully-developed flow is achieved at points far from the entrance of a channel flow, where, as stated previously the mean flow velocity profiles are identical (Kuethe and Chow, 1986). The original design consisted of a channel 16 inches long with a glycerine tank 3 feet, 7 inches tall and 9 inches in diameter at one end with a quarter inch opening slit at the other, see Figure 23 for a general schematic. The co 1lection tank keeps the glycerine from spilling, and the gage portals are the location $o$ 
the skin friction gages to be calibrated. The portals also have fitted plugs and adapter pieces for when the portals are not in use and for different size skin friction gages.

The Scanivalve system has 48 ports (not all were used) that rotate using onl one pressure transducer; therefore, a steady state has to be reached to make pressure measurements over a period of time. To reach a steady state, the level of the tank had to remain constant before the pressure gradient would be constant. A self-priming pump was purchased. It did pump the viscous glycerine, but not at a high enough flow rate. It was determined that the cost of a pump having a high enough flow rate would be too great. A large reservoir apparatus to supply the tank was then built. The reservoir apparatus consists of a 55 gallon drum mounted horizontally to a cinder-block wall approximately 3 feet above the tank. It is connected to the tank with $1.5 \mathrm{in}$. $\mathrm{d}$ iameter PCV pipe, and an atmospheric outlet of 1.5 in. diameter PCV pipe, see Figure 26. 


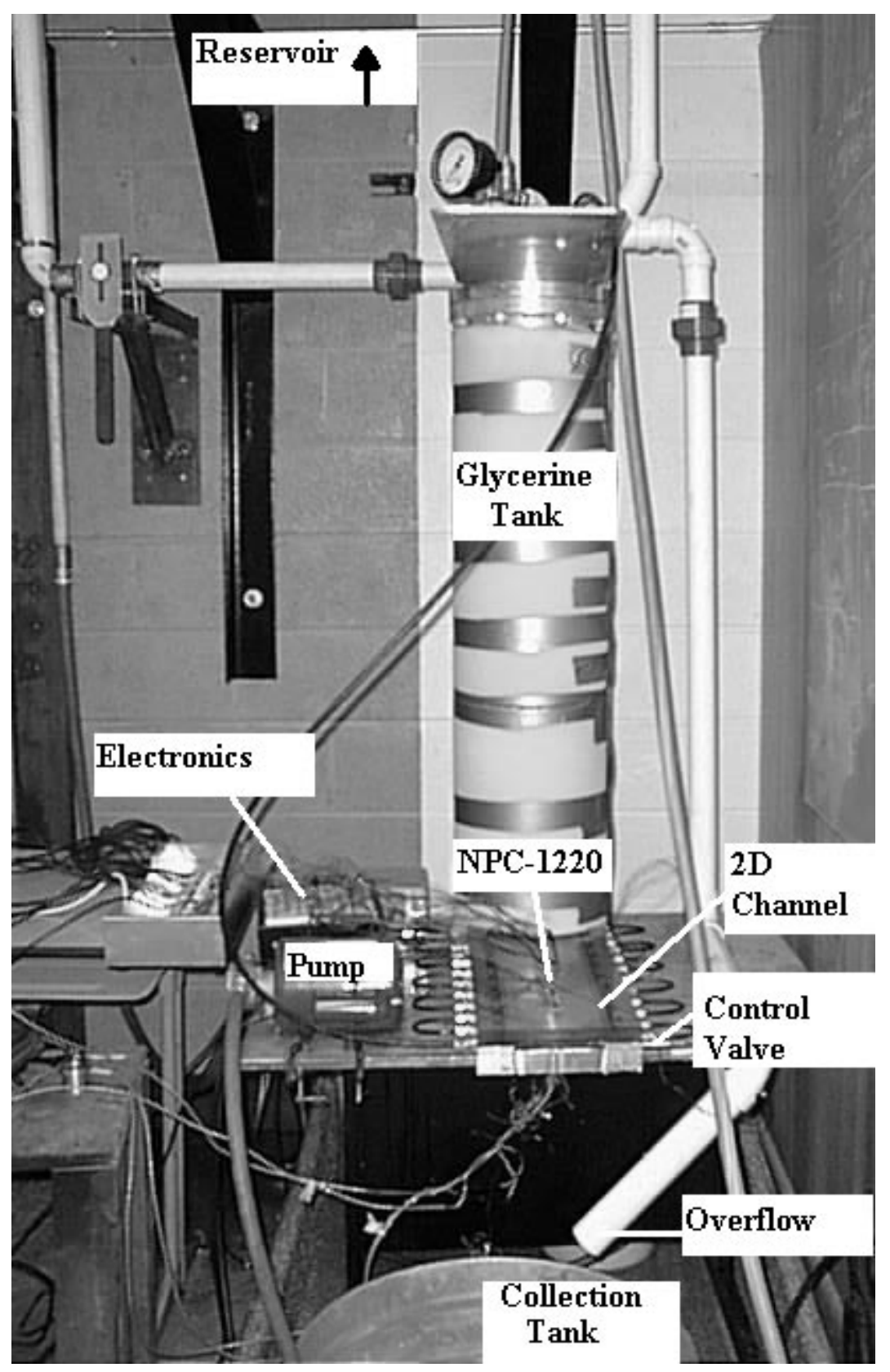

Figure 26-Calibration Rig Utilizing Glycerine

Theoretically, this configuration is correct, but measurements with the Scanivalve system were not successful. It was determined that the capillary forces in the 1/16 in. TYGON tubing connected to the Scanivalve were too great. This caused the reaction time of the glycerine to exceed the run time (a maximum runtime consisted of expelling 10 gallons of glycerine) and TYGON tubing of the proper diameter would be too large for the given system to handle. The frequency response to measure pressure needed to be increased dramatically. The NPC-1220 series pressure sensor from Lucas NovaSenor was determined to fit our needs. The NPC-1220 pressure se n- 
sor could be mounted nearly flush to the fluid flow itself, thus giving the highest $\mathrm{f}$ equency response possible. One was ordered, tested, and determined to be effective. Ten NPC-1220 series pressure sensors were ordered, but eventually only five sensors were determined to be operational.

The NPC-1220 series pressure sensor is based on Lucas NovaSenor 's SenStable piezoresistive sensing technology with design applications of air flow and liquid levels. The NPC-1220 offers the added advantage of high temperature performance over temperature compensated range of $0^{\circ} \mathrm{C}$ to $+60{ }^{\circ} \mathrm{C}$. The NPC-1220 series is available in pressure ranges from 0 to 5 through 0 to 100 psi. The gage pressure range of to 5 psi is suitable for these applications. Figure 27 shows the NPC-1220. This and more information on these sensors is located at http://www.novasensor.co. Note, leads were chosen downward for our application not upward as shown in Figure 27.

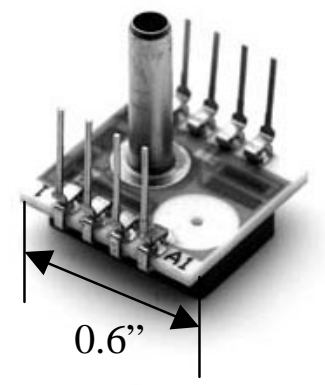

\section{Figure 27-NPC-1220 Pressure Senso}

The NPC-1220 sensor required the connection of three additional 741 op amps, two $100 \mathrm{~K}$ resistors, one $3.3 \mathrm{~K}$ resistor, and an input voltage of $1.235 \mathrm{~V}$ (this was supplied with a potentiometer) to complete the circuit. Figure 28 is a schematic of the circuit. 


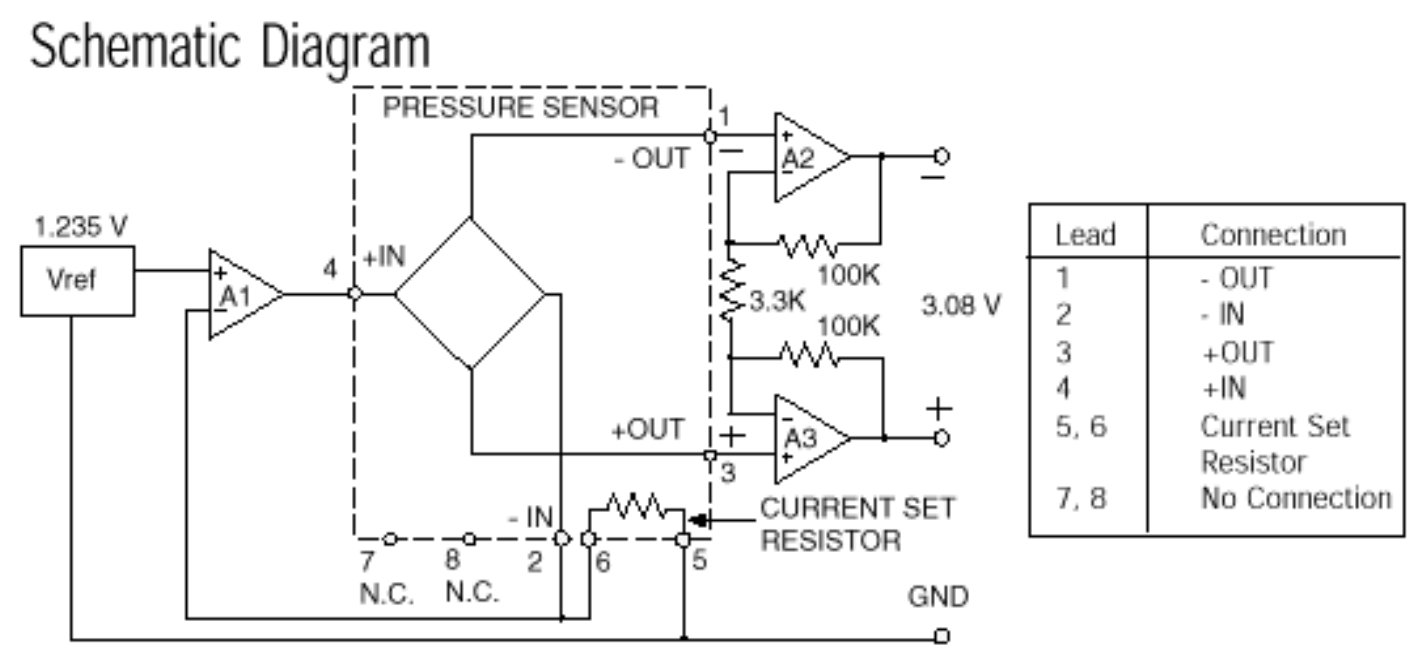

Figure 28-Schematic for NPC-1220 Pressure Sensor Circuit

The output voltages fluctuated, when several sensors were run off one power supply; therefore, five ELPAC power supplies were purchased. The power supplies had five prongs for $\pm 12 \mathrm{~V}$ for the op-amps, $\pm 5 \mathrm{~V}$ for the potentiometer, and ground. This worked well for repeated runs.

Each pressure sensor had to be calibrated. The Mansfield and Green deadweight tester consists of a spherical piston/ ball located within a vertical cylinder, and air is introduced through a supply valve from a compressed air tank, see Figure 29. 


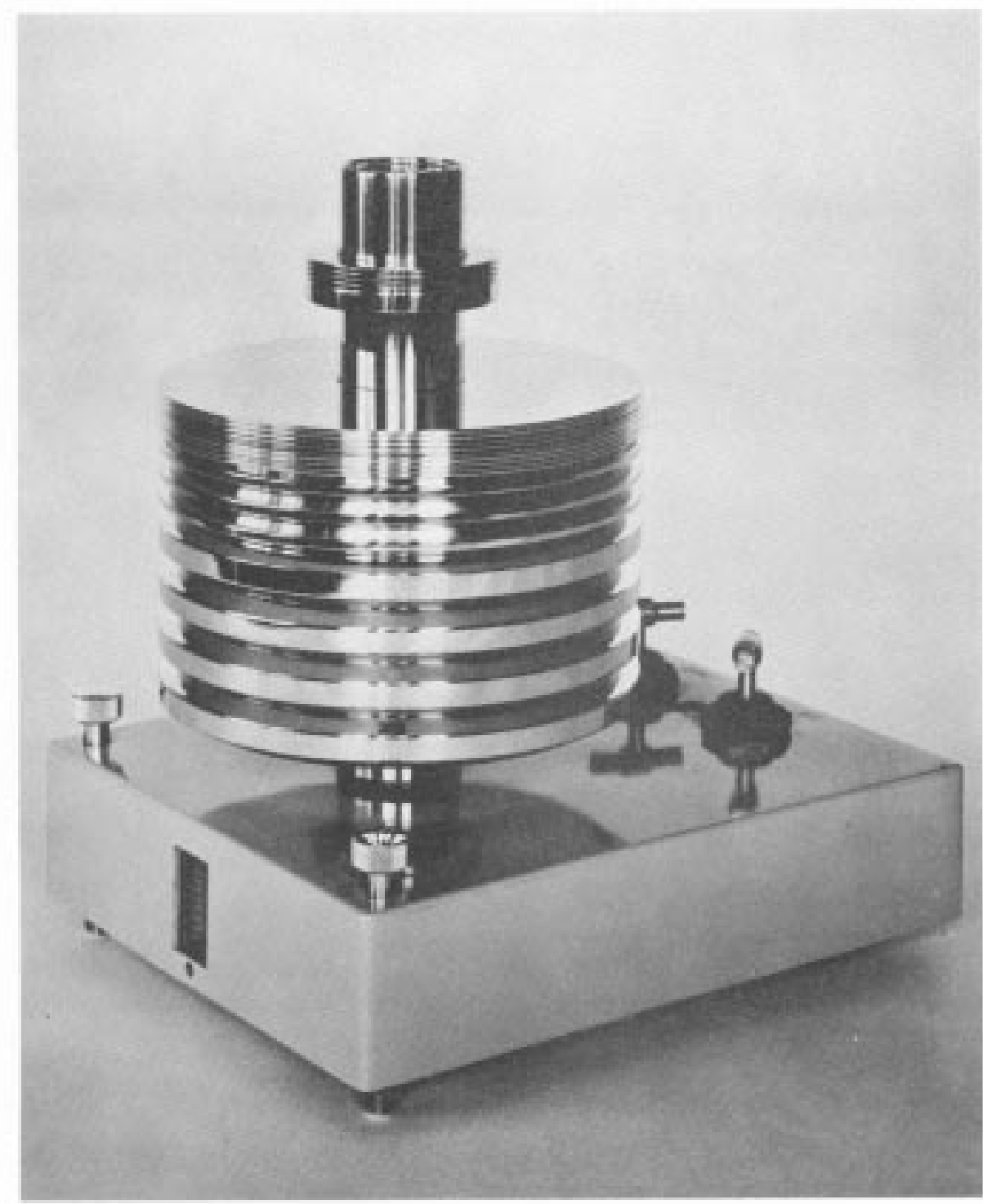

TYPE K MEODEL $750-A$

BELF-HECULATENG PRECISION PNEUMATIC TESTEI

Figure 29-Air Dead-Weight Tester (Mansfield \& Green Manual)

The air pressure causes the ball to rise, and as it reaches the opening of the vertical cylinder air escapes. The escaping air is equal to that of the flow regulator, and equilibrium is achieved. The static pressure supporting the ball is equal to the output pressure supporting the weight. Adding a t-connection to the pressure sensor, sends the same static pressure to the pressure sensor, thus allowing the corresponding voltage output from the strain gages to be recorded (Mansfield and Green Manual). Several weights would be used to produce a sufficient linear calibration curve. The 
calibration constants were similar for all transducers, approximately $1.6 \mathrm{psi} / \mathrm{V}$.

Now, it was possible to measure the pressure gradient in the calibration cha nnel to ensure fully-developed flow. For fully-developed flow the pressure gradient should be linear. A Microsoft Excel chart is shown below, proving the achievement o fully-developed flow with a linear curve. Figure 30 is the pressure distribution of an actual run in the Calibration Rig for a $h=0.125$ in..

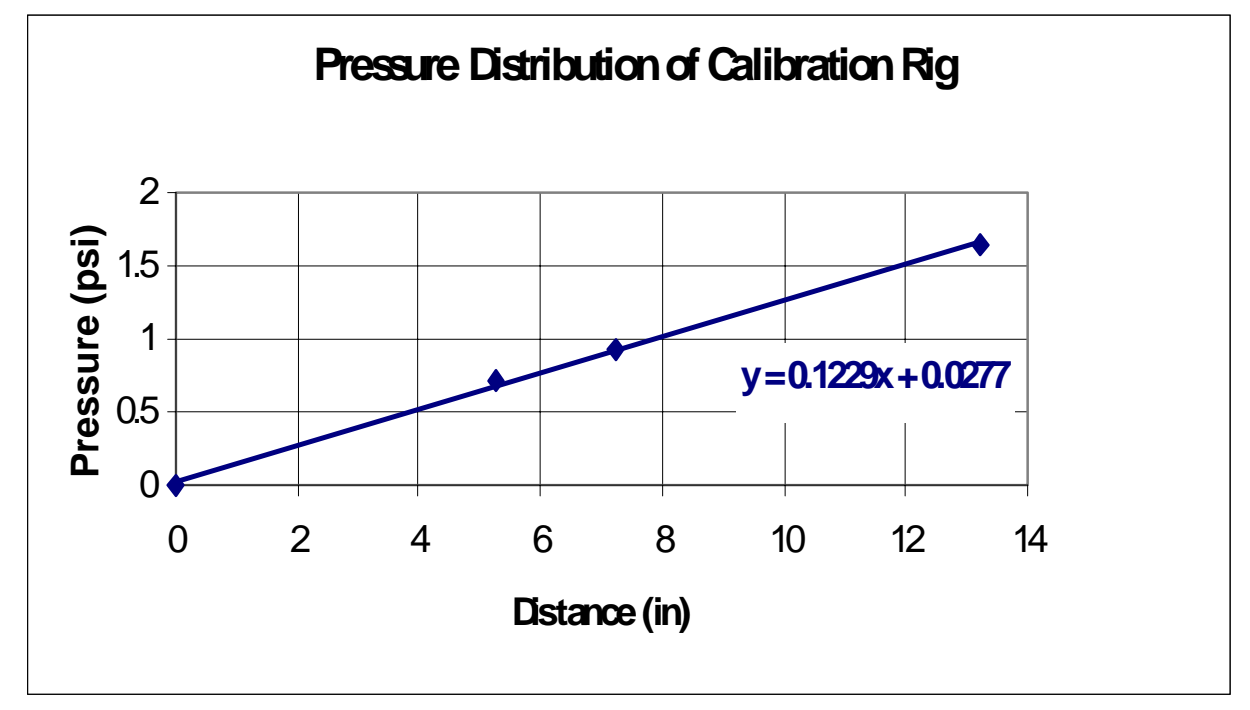

Figure 30-Pressure Distribution in Calibration Rig

Using Equation 7, this particular case, $\frac{d p}{d x}=0.1229 \mathrm{psi} / \mathrm{in}$, corresponds to a wall shear stress, $\tau_{\mathrm{w}}=106 \mathrm{~Pa}(0.0154 \mathrm{psi})$.

\subsection{Calibration Rig Computerization}

The Calibration Rig produced all the data in a short period of time, approx imately five seconds, and the data needed to be recorded accurately. For this task, a computerized data acquisition system was developed. A 486 IBM PC was fitted with Windows 95, LabVIEW 4.1, a National Instruments AT-MIO-16XE-50 NI DAQ card and BNC 2090 box. A LabVIEW 4.1 program was written that measured output voltage of the NPC-1220 sensors, converted it to a pressure in pounds per square inch, and graphed the pressure change over time for all sensors. The program could also read the strain gage output of the skin friction gage converting it to shear in Pascals or 
pounds per square inch or simply voltage. The output voltage of the NPC-1220 sensors is differential; therefore, the 16-channel DAQ card has 8 usable channels.

The devices implemented in this data acquisition system are defined in the subsections to follow.

\subsubsection{LabVIEW}

LabVIEW is a program development application, similar to the computer languages $\mathrm{C}$ or BASIC. The fundamental difference of LabVIEW is that, it is a graphical programming language not a text-based programming language. The graphical programming is more "user friendly" for the programmer and other users.

LabVIEW is a general-purpose programming system. It includes extensive libraries for data acquisition, analysis, presentation, storage, and so forth. LabVIEW utilizes modular programming. Modular programming divides a series of tasks into smaller less complicated tasks, and it can then divide those into even smaller less complicated tasks, until the series of tasks are considered simple. For instance, a LabVIEW program consists of an interactive user interface front panel, ablock di agram which is the graphical programming construction, and any subprograms. A total program as described is called a VI, virtual instrument, and any subprograms are called subVIs (LabVIEW User Manual, 1996).

\subsubsection{AT-MIO-16XE-50 NI DAQ board}

A data acquisition (DAQ) board is the interface between the analog signal o the device to be measured and the digital output of a computer . The DAQ board can take a digital signal from the computer and convert it to an analog signal for the device, i.e. a voltage signal is sent from the computer to run the device. It can also take the analog output of the device and convert it to a digital signal to the computer for further analysis. The AT E series board is a multifunction analog, digital, and timing input/output (I/O) board for compatible computers (MIO: multifunction I/O), and it is 
unique in that it allows one to easily change the board configuration without having to remove the board from the computer. This is made possible with National Instruments DAQ-PnP bus interface chip. This particular board is a 16-bit digital-to-analog and analog-to-digital converter (AT E Series User Manual, 1997).

\subsubsection{BNC-2090}

The BNC-2090 is an accessory which simplifies the connection of analog and digital signals to the DAQ board located in the computer. The BNC-2090 has signallabeled BNC connectors, spring terminal blocks, and analog signal conditioning areas.

The BNC-2090 can be configured to use eight differential signals or 16 single-ended analog input channels (BNC-2090 user Manual,1996).

$\mathrm{BNC}$ is an acronym for British Naval Connector (most common), Bayonet $\mathrm{Nu}$ Connector, or Bayonet Neill Concelman. It is a type of connector used with coaxial cables. The basic BNC connector is a male type mounted at each end of a cable. This connector has a center pin connected to the center cable conductor and a metal tube connected to the outer cable shield. A rotating ring outside the tube locks the cable to any female connector.

\subsection{Uncertainty Analysis on the Calibration Rig}

\subsubsection{Hardware Uncertainty}

The hardware uncertainty is the uncertainty of the instruments employed for the task. The manufacturer of the instrument has a specification for the uncertainty and these specifications are normally provided to the consumer.

An uncertainty analysis was performed on the hardware of the Calibration Rig. The instruments with manufacturer specifications for the uncertainty are listed in $\mathrm{T}$ able 4. The geometry effects are due to construction, and an analysis on burrs, depth, 
and diameter of a drilled hole for a pressure port was obtained from in Chue (1975). The total uncertainty is the square root of the sum of the squares of each component, also known as root mean square method (rms).

Table 4-Hardware Uncertainty Analysis on Calibration Rig

\begin{tabular}{|c|c|c|}
\hline & Hardwar & Uncertainty \% \\
\hline$\overline{1 . O u t p u t}$ & $\begin{array}{l}\text { NPC } 1220 \text { pressure sensor } \\
\text { (Manufacturer Specifications) } \\
\text { Power Supply/Amplifiers/POT } \\
\text { (Monitored output for +/-5\% variation in power supply, FSO) } \\
\text { A/D card (AT-MIO-16XE-50) } \\
\text { (Manufacturer Specifications) } \\
\text { Zero Drift } \\
\text { (Monitored static output for } 1.5 \text { hours, FSO) }\end{array}$ & $\begin{array}{l}+/-0.01 \% \\
+/-0.05 \% \\
+/-0.024 \% \max \\
+/-0.5 \%\end{array}$ \\
\hline$\overline{\text { 2.Calibration }}$ & $\begin{array}{l}\text { Mansfield \& Green, dead-weight tester } \\
\text { (Manufacturer Specifications) } \\
\text { A/D card (AT-MIO-16XE-50) } \\
\text { (Manufacturer Specifications) }\end{array}$ & $\begin{array}{l}+/-0.025 \% \\
+/-0.024 \% \max \end{array}$ \\
\hline 3. Geometry effects & $\begin{array}{l}\text { Pressure Port Construction } \\
\text { Geometry-hole diameter to hole depth ratio(Chue, 1975) } \\
\text { Manufacturing skill-drill burrs(Chue, 1975) } \\
\text { No burrs } \\
\text { Medium burr } \mathrm{h}=0.01 \mathrm{~mm} \text { (assumed here) } \\
\text { Large burr } \mathrm{h}=0.05 \\
\text { Spacing of Pressure Ports } \\
\text { (Monitored output with } \mathrm{dx}+/-0.001 \text { ") } \\
\text { Adapter/Gage misalignment with channel } \\
\text { (Monitored output with variation in adapter/gage alignment } \\
\text { with channel floor) }\end{array}$ & $\begin{array}{l}+/-0.4 \% \\
+/-0.0 \% \\
+/-0.4 \% \\
+/-2.8 \% \\
+/-0.1 \% \\
+/-0.5 \%\end{array}$ \\
\hline
\end{tabular}

overall rms

uncertainty $\quad+/-0.913 \%$ 


\subsubsection{Measured Variable Uncertainty Analysis}

The data reduction of the Calibration Rig utilizes a simple formula shown here.

$$
\tau_{w}=\frac{V C g}{A_{H E A D}}
$$

where $\mathrm{V}$ is the voltage output, $\mathrm{C}$ is the calibration constant of the skin friction gage, $\mathrm{g}$ is gravity, and HEAD is the surface area of the floating head. C, g, and HEAD are known, and $\mathrm{V}$ is determined, all to calculate $\tau_{w}$.

For calculation,

$\mathrm{C}=1.5385 \mathrm{~g} / \mathrm{mV}=1.5385 \mathrm{~kg} / \mathrm{V}$ (calibration constant for gage 40, Figure 7),

$\mathrm{g}=9.81 \mathrm{~m} / \mathrm{s}^{2}$,

and

$$
A_{H E A D}=\frac{\pi(0.5 \mathrm{in})^{2}}{4}=0.19625 \mathrm{in}^{2}=1.266613 \times 10^{-4} \mathrm{~m}^{2} .
$$

The uncertainties are dependent on the accuracy of the measuring device, such as, calipers, multimeters etc. and repeatability of measurement, i.e. the calibration co nstant, C, varies in repeatability by the thousandths. The determined uncertainties are listed below:

$\Delta \mathrm{V}= \pm 0.001 \mathrm{mV}$,

$\Delta \mathrm{g}= \pm 0.001 \mathrm{~m} / \mathrm{s}^{2}$,

$\Delta \mathrm{C}= \pm 0.005 \mathrm{~g} / \mathrm{mV}$,

and

$\Delta \mathrm{d}: \pm 0.001$ in. (diameter of floating head).

The absolute error, which is the worst case scenario, is given by Equation 15,

$$
E_{a}=\left|\Delta V \frac{\partial \tau_{w}}{\partial V}\right|+\left|\Delta g \frac{\partial \tau_{w}}{\partial g}\right|+\left|\Delta C \frac{\partial \tau_{w}}{\partial C}\right|+\left|\Delta A_{H E A D} \frac{\partial \tau_{w}}{\partial A_{H E A D}}\right| .
$$

The overall error represents a \pm 3 s limit on V, g, C, and HEAD (Doebelin, 1990) 


$$
E_{\text {arss }}=\left(\left|\Delta V \frac{\partial \tau_{w}}{\partial V}\right|^{2}+\left|\Delta g \frac{\partial \tau_{w}}{\partial g}\right|^{2}+\left|\Delta C \frac{\partial \tau_{w}}{\partial C}\right|^{2}+\left|\Delta A_{H E A D} \frac{\partial \tau_{w}}{\partial A_{H E A D}}\right|^{2}\right)^{\frac{1}{2}} .
$$

The partial derivatives from Equation 14 are as follows:

$$
\begin{aligned}
& \frac{\partial \tau_{w}}{\partial V}=\frac{C g}{A_{H E A D}}, \\
& \frac{\partial \tau_{w}}{\partial g}=\frac{V C}{A_{H E A D}}, \\
& \frac{\partial \tau_{w}}{\partial C}=\frac{V g}{A_{H E A D}}, \\
& \text { and } \\
& \frac{\partial \tau_{w}}{\partial A_{H E A D}}=-\frac{V C g}{A_{H E A D}^{2}} .
\end{aligned}
$$

Using a $\mathrm{V}=0.001 \mathrm{~V}$, which is optimal for the device with shear stress of $119 \mathrm{~Pa}$, the absolute error is $\mathbf{0 . 8 3 5 \%}$ and the overall error is $\mathbf{0 . 5 2 5 \%}$. All calculations are in A ppendix C. 


\section{DESIGN OF RUBBER SHEET SKIN FRICTION GAGE}

During this research, a new concept for a skin friction gage emerged. The original goals of this skin friction gage were still to eliminate oil leakage, dampen vibrations, and calibrate easily, but instead of filling the entire gap with silicone rubber, just cover it with a thin silicone rubber sheet and fill the gap with the usual silicone oil. The idea sounds promising, but several questions had to be answered before the design could be built. First, it is possible to fabricate a thin silicone rubber sheet? Second, how thin is thin enough for the silicone rubber sheet? And third, how wide is the necessary gap

\subsection{Fabrication of a Thin Silicone Rubber Sheet}

The silicone rubber in supply was the RTV-615 used by Novean (1996A). The fabrication of the rubber sheet also included the adhering of the rubber to the plastic, PES, used for construction of the skin friction gage. The rubber not only needs to "stick" to the plastic, but also be able to contain silicone oil. The steps to produce a silicone rubber sheet of thickness approximately 0.001 to 0.015 inches are as follows:

1. Clean flat, smooth surface (aluminum plate). Clean with acetone, even fine sandpaper maybe necessary to remove old rubber.

2. a. Wear gloves to mix parts A \& B at a 1:10 ratio (as instructed on bottles). Mix thoroughly with a toothpick. To achieve the 1:10 ratio you can use graduated cylinders, but the liquid is thick and messy, making it hard to pour out and use cylinders repeatedly accurately. Utilize a simple count method for the pour or "e eball" the quantities.

b. For thinning, add about a 5\% acetone. Be careful, because too much will cause the mixture not to cure.

3. a. Pour onto a metal sheet for thinnest and smoothest results, let room cure for approximately 72 hours, but usually $24-36$ hours is enough.

b. Let the mixture sit for approximately 1 hour or until all bubbles have disappeared, then place plate in pre-heated $150 \mathrm{~F}$ oven for 5-10 min. (use oven mits) 
c. $\quad$ Plate must cool completely before any attempt is made to $\mathrm{r}$ emove sheet, or it will tear and/or not separate easily from aluminum plate.

4. For results in adhering rubber sheet to plastic gage, use silicone caulk, DAP. Make a thin, even application, let sit for 24 hours upside down (so to apply some pressure). Use Exacto-knife to remove extra rubber, and one can apply thin caulk around edges to ensure adhesion

The $5 \%$ thinner, acetone or xylene, ratio was recommended by the manufacturer. Several adhesives were tested, such as, epoxy, rubber cement, and aerosol sprays like 3M's Super 77. After a discussion with Dr. Dillard of the Center of Adhesive and Sealant Science here at Virginia Polytechnic Institute and State University, the su ggestion of employing a silicone based adhesive for a silicone based rubber was $\mathrm{i}$ mplemented. The silicone sealant DAP by Dow Corning was determined to be ad equate. It adhered and sealed, but the silicone rubber sheet could be removed withou damage to the skin friction gage. The first question has been answered with an affirmative. Later the silicone rubber sheet layup was mod ified.

\subsection{Preliminary Design of the Silicone Rubber Sheet Skin Friction Gage}

Before the last two questions could be answered, a preliminary design of the skin friction gage had to be created. The design emerged from a previous design for a $1500 \mathrm{~Pa}$ shear level skin friction gage. The previous design and the new design were to have the same semi-conductor strain gages attached by a company that specializes in this, Micron Instruments. The two skin friction gages were to have the same m oment on the beam. This constraint would guarantee the proper semi-conductor strain gage had been chosen.

The moment $(M 1=\tau 1 \cdot A 1 \cdot L 1)$ of the previous skin friction gage (gage 1$)$ had to be equal to the moment $(M 2=\tau 2 \cdot A 2 \cdot L 2)$ of the skin friction gage (gage 2) to be designed. The known values are $\tau 1=1500 P a, \tau 2=100 P a, \mathrm{~A} 1$, and L1. A1 and L1 are the area of the floating head and the length of the cantilever beam of the skin friction gage previously designed, respectively. A2 and L2 are unknown and represent the area of the floating head and the length of the cantilever beam to be designed, respec- 
tively. Equation 17 was implemented in a Microsoft Excel spreadsheet to optimize the values $\mathrm{A} 2$ and L2,

$$
15=\left(\frac{A 2}{A 1}\right) \cdot\left(1+\frac{L 2}{L 1}\right)
$$

Arbitrary ratios of A2/A1 equal to 1 through 9.5 in increments of 0.5 were chosen to begin the optimization. The ratio $\mathrm{A} 2 / \mathrm{A} 1=7$ met numerical and manufacturing sta $\mathrm{n}$ dards, see Table 5.

Table 5 -Optimization of Floating Head Diameter and Length of Cantilever Beam

Equation: $15=(\mathrm{A} 2 / \mathrm{A} 1)^{*}(1+(\mathrm{L} 2 / \mathrm{L} 1))$

\begin{tabular}{|r|r|r|r|r|r|r|r|r|}
\hline A2/A1 & L2 (in) & d2 (in) & L1 (in) & A1 (in^2 & A2 (in^2 & d1 (in) & Total Length & \\
\hline 1 & 3.7212 & 0.187452 & 0.2658 & 0.027598 & 0.027598 & 0.1875 & 3.987 & \\
\hline 1.5 & 2.3922 & 0.229581 & 0.2658 & 0.027598 & 0.041396 & 0.1875 & 2.658 & \\
\hline 2 & 1.7277 & 0.265098 & 0.2658 & 0.027598 & 0.055195 & 0.1875 & 1.9935 & \\
\hline 2.5 & 1.329 & 0.296388 & 0.2658 & 0.027598 & 0.068994 & 0.1875 & 1.5948 & \\
\hline 3 & 1.0632 & 0.324677 & 0.2658 & 0.027598 & 0.082793 & 0.1875 & 1.329 & \\
\hline 3.5 & 0.873343 & 0.350691 & 0.2658 & 0.027598 & 0.096592 & 0.1875 & 1.139142857 & \\
\hline 4 & 0.73095 & 0.374904 & 0.2658 & 0.027598 & 0.110391 & 0.1875 & 0.99675 & \\
\hline 4.5 & 0.6202 & 0.397646 & 0.2658 & 0.027598 & 0.124189 & 0.1875 & 0.886 & \\
\hline 5 & 0.5316 & 0.419156 & 0.2658 & 0.027598 & 0.137988 & 0.1875 & 0.7974 & \\
\hline 5.5 & 0.459109 & 0.439614 & 0.2658 & 0.027598 & 0.151787 & 0.1875 & 0.724909091 & \\
\hline 6 & 0.3987 & 0.459162 & 0.2658 & 0.027598 & 0.165586 & 0.1875 & 0.6645 & \\
\hline 6.5 & 0.347585 & 0.477911 & 0.2658 & 0.027598 & 0.179385 & 0.1875 & 0.613384615 & \\
\hline 7 & 0.303771 & 0.495952 & 0.2658 & 0.027598 & 0.193184 & 0.1875 & 0.569571429 & $*$ ***** \\
\hline 7.5 & 0.2658 & 0.513359 & 0.2658 & 0.027598 & 0.206982 & 0.1875 & 0.5316 & \\
\hline 8 & 0.232575 & 0.530195 & 0.2658 & 0.027598 & 0.220781 & 0.1875 & 0.498375 & \\
\hline 8.5 & 0.203259 & 0.546513 & 0.2658 & 0.027598 & 0.23458 & 0.1875 & 0.469058824 & \\
\hline 9 & 0.1772 & 0.562357 & 0.2658 & 0.027598 & 0.248379 & 0.1875 & 0.443 & \\
\hline 9.5 & 0.153884 & 0.577767 & 0.2658 & 0.027598 & 0.262178 & 0.1875 & 0.419684211 & \\
\hline
\end{tabular}

note:

$\mathrm{A} 1, \mathrm{~L} 1$, and $\mathrm{d} 1$ refer to original size

$A 2$, L2, and d2 refer to new size

These parameters were implemented into a computer-aided design (CAD) program called AutoCAD, to yield a center piece for the skin friction gage being designed, seen in Figure 31. The parameters for the housing of the gage will be determined in the next section with the optimization of the rubber thi kness and gap size. 


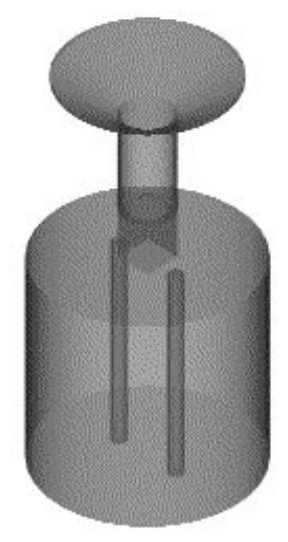

(a)

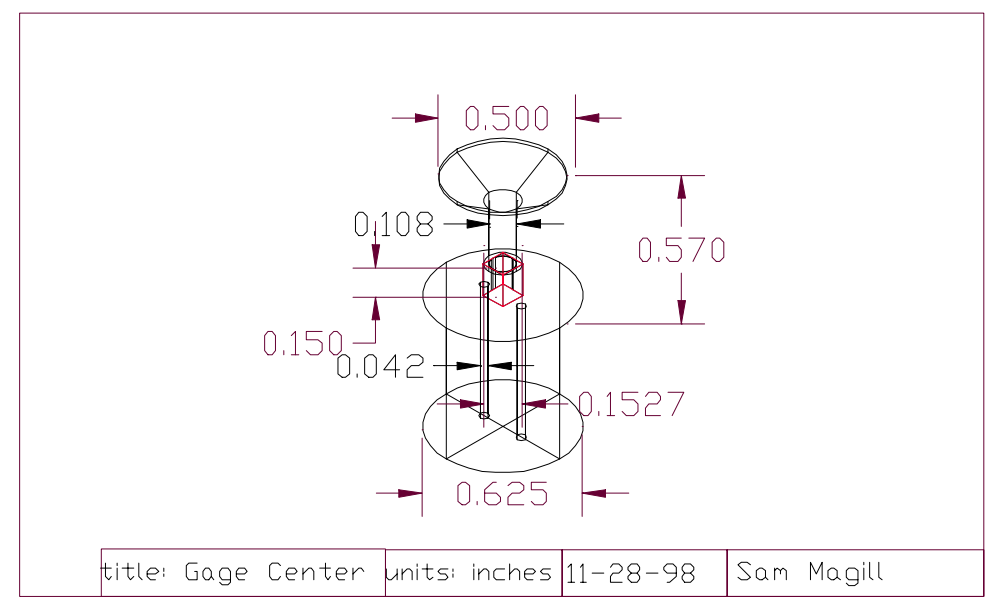

(b)

Figure 31-Center Piece Design for the Silicone Rubber Sheet Skin Friction Gage:

(a) Rendered Picture and (b) Dimensional Schematic

\subsection{Optimization of Silicone Rubber Sheet Thickness and Gap Size of the Skin Friction Gage}

To optimize the silicone rubber sheet thickness and the gap size of the skin friction gage, the previous FEM model built in ABAQUS was modified. The goal in this step was to determine the sheet thickness and gap size that would not seriousl affect the movement of the cantilever beam. This means that the strain, E33, output by ABAQUS should be the approximately the same with and without the silicone rubber sheet. 
Two educated assumptions were made to simplify the problem. First the oi could not be and was not modeled in ABAQUS. Since the intent of the oil is to dampen vibrations and not to interfere with the overall deflection of the beam, a ssumption one was reasonable. Second, the four flats at the base of the beam, as seen in Figure 31, were not modeled, (the four flats make the attachment of the strain gages easier). Assumption two is reasonable, because the cantilever beam is not in torsion; therefore, the square cross-section acts similarly to a circular cross-section.

The first run was with an empty gap, yielding a strain in the beam of $21.6 \mu \varepsilon$. The next runs had various gap sizes with a fixed thickness for the rubber sheet. Figure 32 plots the variation of strain versus gap size for a 0.007 in. thick silicone rubber sheet. The strain does not change dramatically with increasing gap size. The rubber sheet thickness of 0.007 in. was chosen, because it was originally believed that the sheet could be manufactured to that thickness. Also, from the data presented any rubber sheet thickness could be fitted to any gap size. The important part was that the gap size be reasonable to construct and adjoin to the rubber sheet. From this data, a gap size of 0.0625 in. was considered optimal for construction. Figure 33 is a strain contour plot for the gap size of 0.0625 inches. Notice the strain in the rubber sheet acting in tension where the rubber sheet contacts the housing and in compression where the rubber sheet contacts the beam head. This phenomena was also shown in Figure 22.

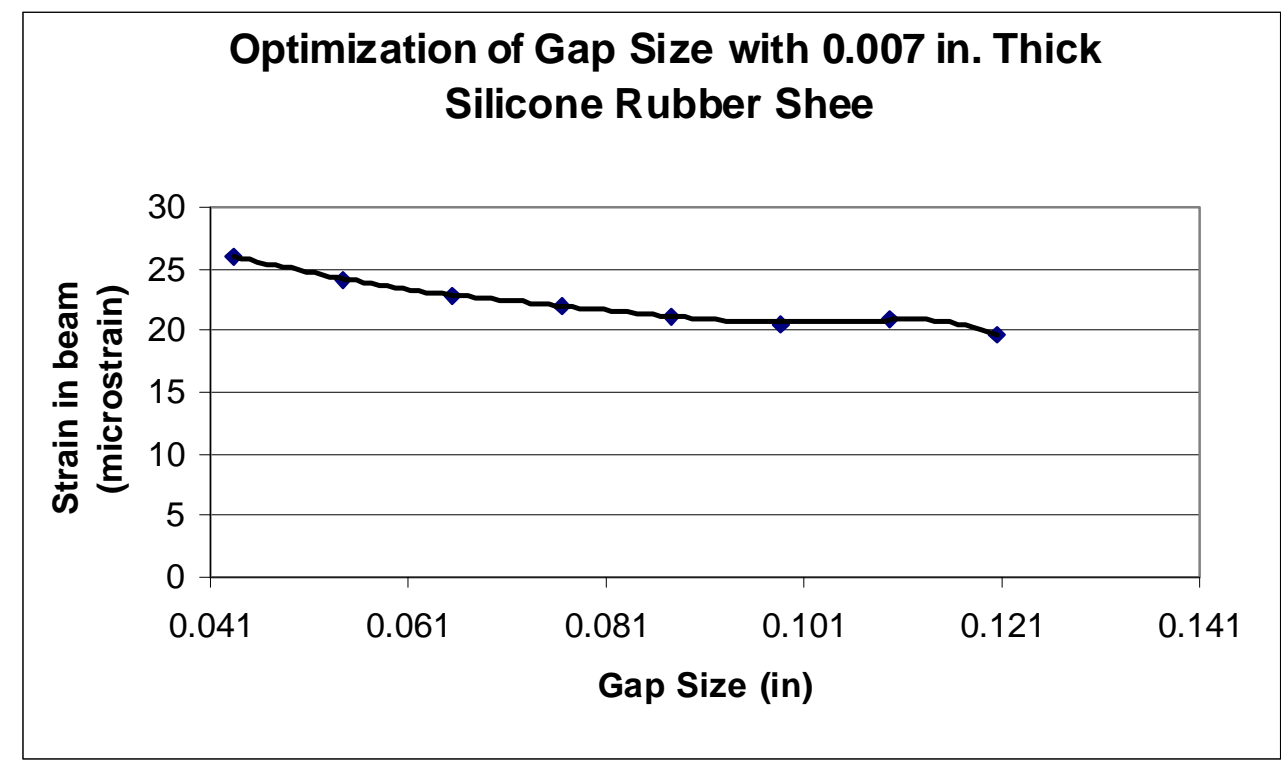

Figure 32-Optimization of Gap Size with a Silicone Rubber Sheet of 0.007 in. 


\section{ABAOUS}
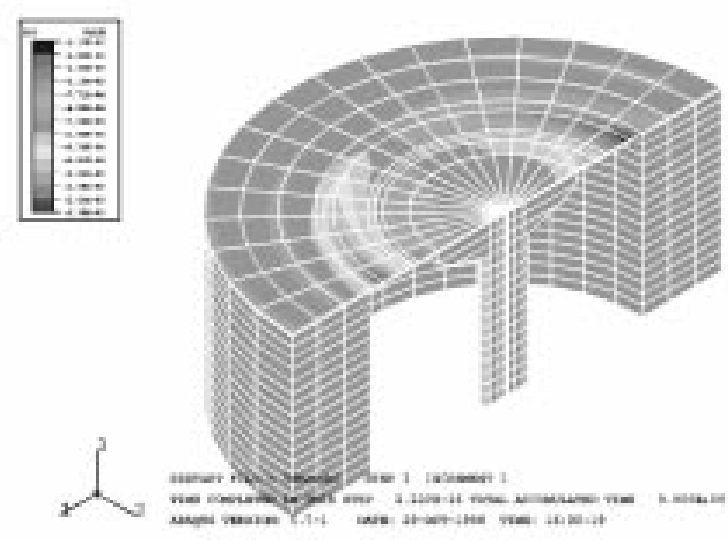

\section{Figure 33-Strain Contour Plot of Silicone Rubber Sheet Skin Friction Gage with a Gap Size of 0.0625 in.}

Several rubber thicknesses were chosen from 0.007 in. to 0.045 in., and these values were implemented in ABAQUS with a gap size of 0.0625 in.. Figure 34 shows the results, where the variation in beam strain is acceptable for a rubber sheet thickness 0 up to 0.015 in., which is the largest manufacturing thickness. The strain in the beam decreases more rapidly for an increase in the rubber sheet thickness, than for the ncrease in gap size, as in Figure 34. 


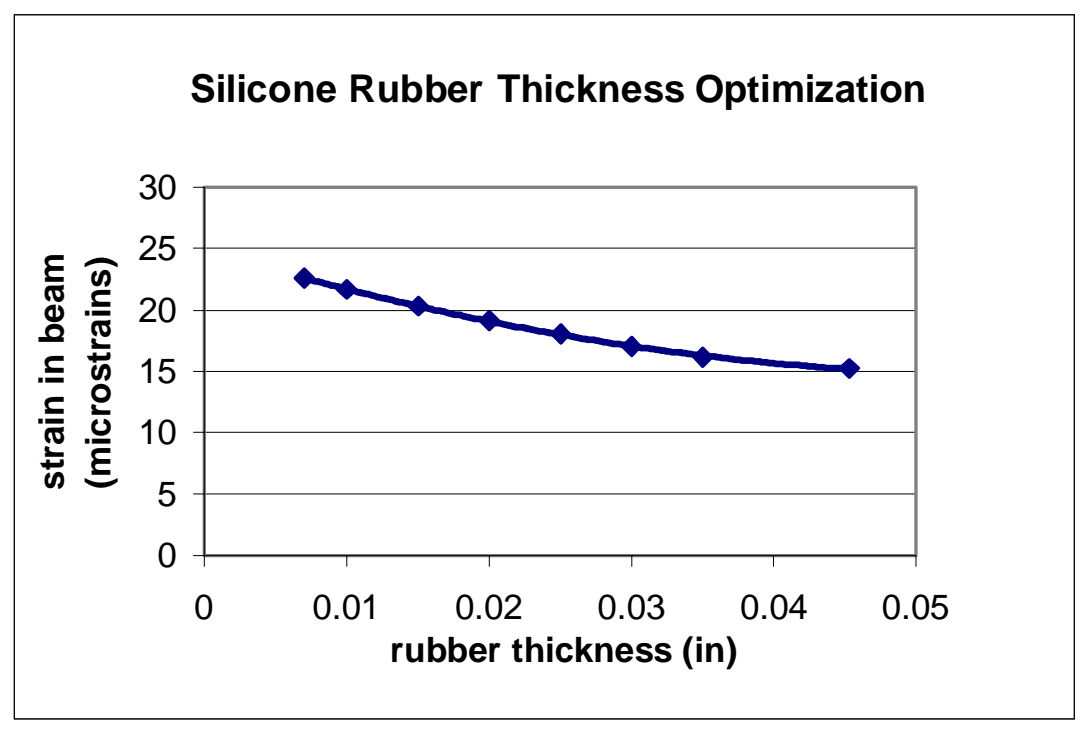

Figure 34-Optimization of Silicone Rubber Sheet Thickness

Note that, in the thickness and gap size optimization, the strain in the rubber sheet a symptotically went to infinity as the gap size and thickness went to zero. Figure 35 and Figure 36 are depictions of the asymptote for optimization of silicone rubber thickness and gap size, respectively. So, the rubber sheet should not be chosen too thin or the gap too small else the strain would be unreasonably large. The nominal values chose for use here were a gap of $0.625 \mathrm{in}$. and a rubber sheet of 0.007 in. thick.

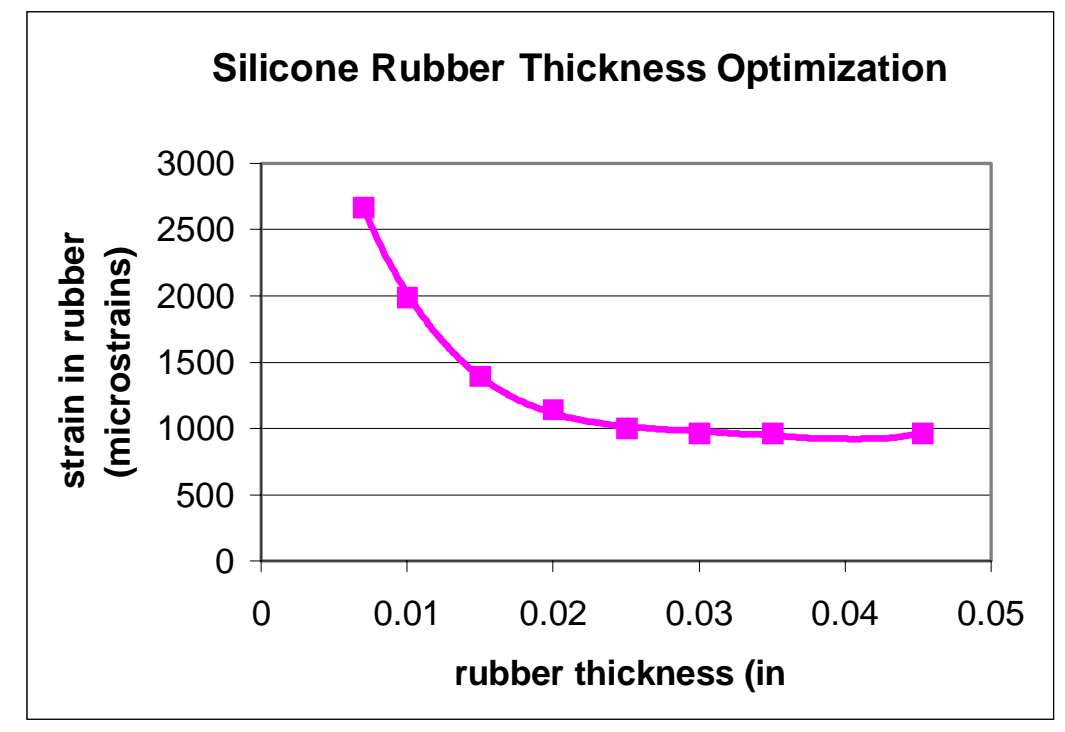

Figure 35-Strain in Silicone Rubber for Sheet Thickness Optimization 


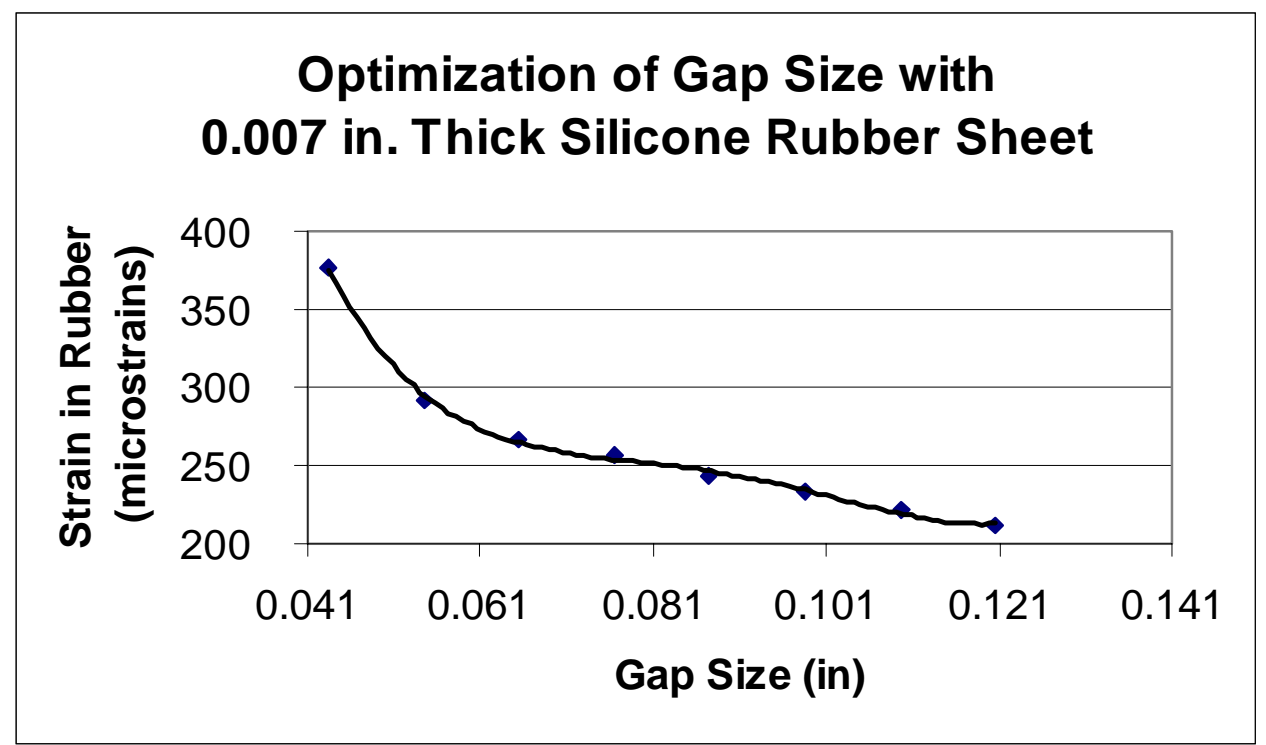

Figure 36-Strain in Silicone Rubber for Gap Size Optimization

The second and third questions of thickness and gap size posted at the beginning of this chapter have been answered. The parameters for the housing of this new gage were implemented into AutoCAD, Figure 37 is the result. 


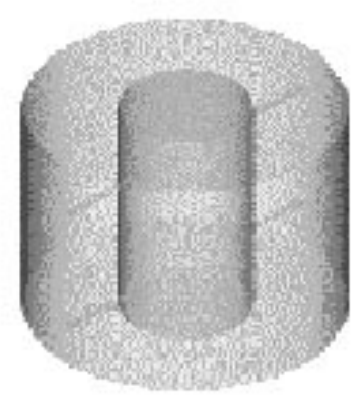

(a)

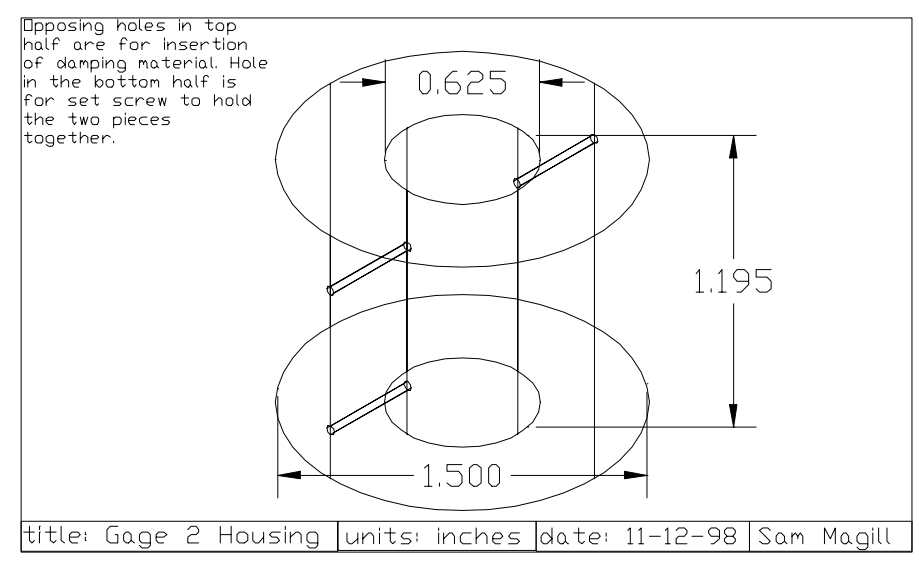

(b)

Figure 37-Housing for the Silicone Rubber Sheet Skin Friction Gage:

(a)Rendered View and (b)Dimensional Schematic

The pieces in Figure 31 and Figure 37 slide together and are locked in place with se screws. Figure 38 shows how the pieces fit together in two steps a and b. 


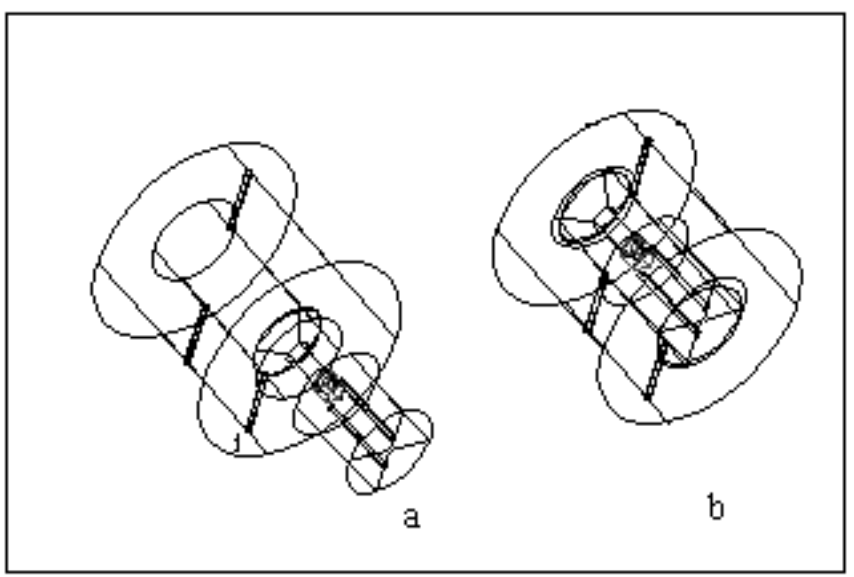

Figure 38-Schematic of Silicone Rubber Sheet Skin Friction Gage Assembly 


\section{VIBRATION TESTING OF SILICONE RUBBER SHEET SKIN FRICTION GAGE}

In testing and utilizing any skin friction gage, the vibrations of the testing facilities, and the erratic movement of constant use can cause damage to the skin fri ction gage; therefore, a type of damping must play an important role in the design. In the past, most skin friction gages have accomplished enough damping by the gap b eing filled with silicone oil. The skin friction gage designed by Novean (1996A) had the entire gap filled with silicone rubber, this obviously provided enough damping for any situation. The question arose, will the thin silicone rubber sheet without any sil icone oil produce enough damping?

The Modal Analysis Laboratory led by Dr. A. Wicks of the Mechanical Eng ineering Department here at Virginia Polytechnic Institute and State University has been used before for skin friction gage damping research. So, it was possible to make use of the facilities again.

\subsection{Vibration Test Method and Testing Facilities}

The method is simple, but the test components are complex. The calibration of the skin friction gage is a test of the static response of the semi-conductor strain gage output of the skin friction gage. To determine damping, a dynamic response test is necessary. A g-force is applied to the skin friction gage, preferably at the center of mass, for a specified frequency. For example, 1-g is applied every tenth of a second. The output of the semi-conductor strain gages can yield the natural frequency of the skin friction gage, and, when plots are compared, the output can yield damping inf rmation. A test that does not measure the output of the strain gage, but of the force transducer can also yield the natural frequency. This response is termed a frequency response.

The dynamic response analysis uses a complex array of hardware. The typica components and the actual devices used are listed below: 
1. Exciter-75 lb Electromagnetic Shaker

2. Transducer-Impedance Head

3. Signal Conditioning Amplifier-Signal Conditioning Amplifier

4. Analysis System-Hewlett Packard 35665A Dynamic Signal Analyzer A schematic of a typical setup for a dynamic response test is in Figure 39.

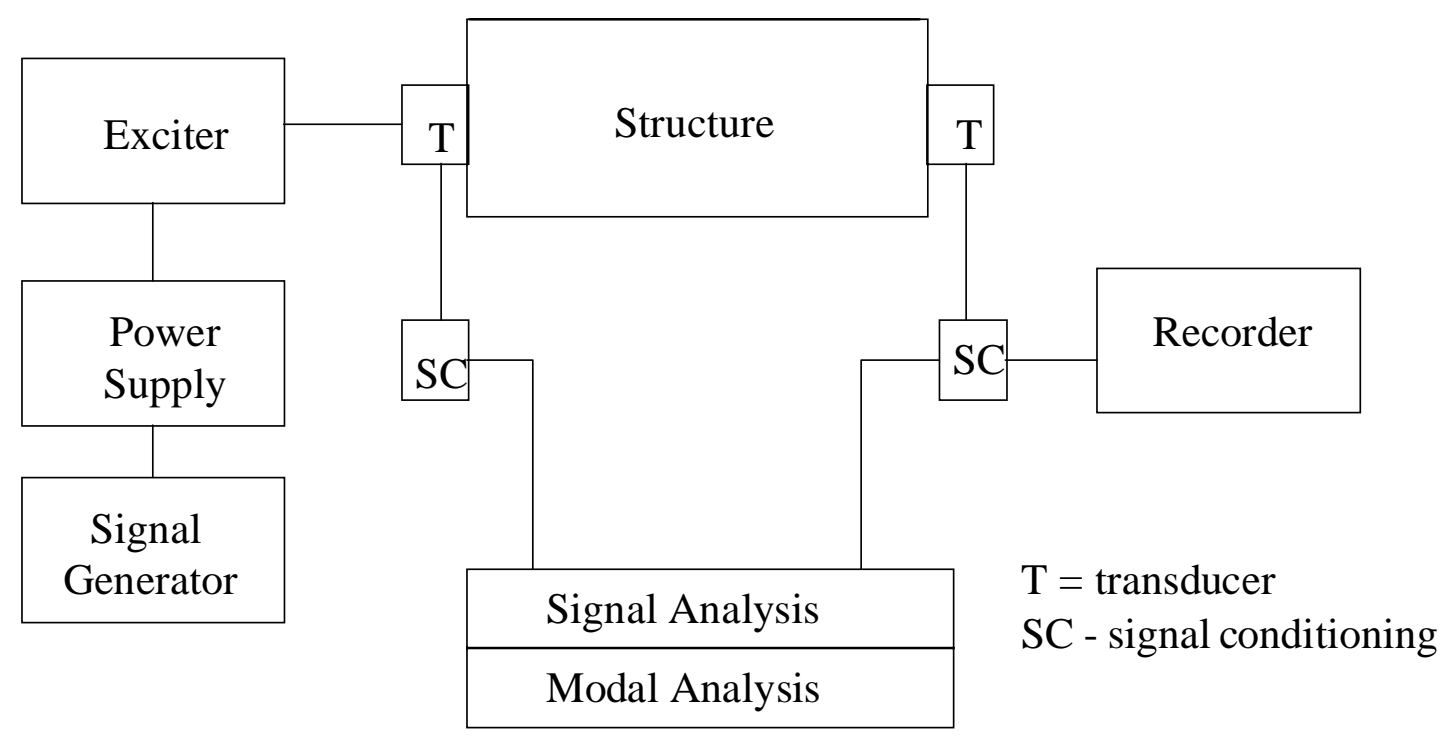

\section{Schematic of hardware used in performing a vibration test}

\section{Figure 39-Vibration Testing Setup (Inman, 1996)}

The skin friction gage is connected to the exciter/shaker by mounting a \#10-32 hex nut to the gage and screwing into shaker with a threaded rod. The data reducti is mostly controlled by the signal analyzer. The signal sampling rate is dependent the frequency range to be tested; the smaller the frequency range the smaller the sampling interval. A common "rule of thumb" states that the sampling rate must be at least twice the highest frequency in the signal. Aliasing is another problem to consider when choosing a sampling rate. It is caused by improper sampling time, and it can be corrected with an antialiasing filter, a low-pass filter, that cuts off frequencies higher than a half of the maximum frequency to be tested, also known as the Nyquist fr equency (Inman, 1996). With modern technology, the signal analyzer assesses and co rrects for any abnormalities. For this work, a frequency range of $0-3.2 \mathrm{kHz}$ was chosen, because that range corresponds with testing facilities. 
The impedance head is calibrated by the manufacturer, but a very simple method can test the calibration. The process takes a coin, in this case a dime, and varies the input voltage until the coin is being "bounced" on the head. This indicates that a 1-g vibration has been reached. This particular impedance head had a $10 \mathrm{mV} t$ $1-\mathrm{g}$ calibration.

\subsection{Theoretical Calculations for Natural Frequency}

The beam of the skin friction gage was modeled as a cantilever beam with a mass attached at the end, see Figure 40.

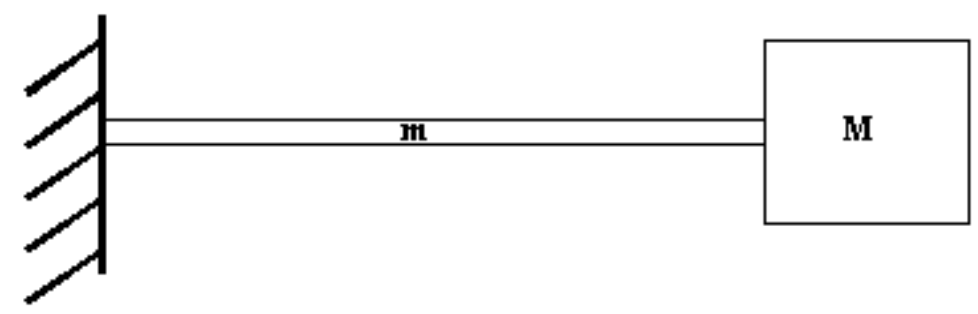

\section{Figure 40-Theoretical Model of Silicone Rubber Sheet Skin Friction Gage}

Equation 18 is the equation for natural frequency,

$$
\omega_{n}=2 \pi \sqrt{\frac{k}{M_{T}}},
$$

where $\omega_{n}$ is the natural frequency, $\mathrm{k}$ is the stiffness, and $\mathrm{M}_{\mathrm{T}}$ is the total mass of the beam. First k was calculated for this particular case using Equation 19,

$$
k=\frac{3 E I}{L^{3}},
$$

where E is Young's Modulus of Elasticity for the PES plastic, I is the moment of inertia, and $\mathrm{L}$ is the length of the cantilever beam. The moment of inertia for a circular cross-section is the same on the $\mathrm{x}$ and $\mathrm{y}$-axis and is given in Equation 20,

$$
I=\frac{\pi d^{4}}{64},
$$

where $\mathrm{d}$ is the diameter of the circular cross-section. The diameter is 0.1527 inches. Young's Modulus, E, is a parameter specified by the manufacturer for the PES plastic. 
The values for the variables in Equation 19 are listed below:

$\mathrm{E}=2.66 \mathrm{GPa}(385,800.4 \mathrm{psi})$,

$\mathrm{L}=0.5$ to 0.57 in.,

and

$\mathrm{I}=2.6675 \times 10^{-5} \mathrm{in}^{4}$.

The length of the cantilever beam is difficult to accurately determine. The necessity of this type of calculation was not foreseen, so the angle that the floating head meets the cantilever beam (Figure 31) was arbitrary in manufacturing. At the time of this calculation, the skin friction gage was assembled, and measurements of that parameter would mean disassembly. So, using the values above, Equation 19 yields a stiffness, $\mathrm{k}_{\mathrm{L}=0.5}=247 \mathrm{lb} /$ in and $\mathrm{k}_{\mathrm{L}=0.57}=167 \mathrm{lb} / \mathrm{in}$.

The total mass for this case is determined with Equation 21,

$$
M_{T}=M+0.23 m \text {, }
$$

where $\mathrm{M}$ and $\mathrm{m}$ are defined in Figure 40. Equations 22 and 23 define the mass of the floating head and the cantilever beam, respectively.

$$
M=\frac{\rho_{P E S} V_{M}}{g},
$$

and

$$
m=\frac{\rho_{P E S} V_{m}}{g},
$$

where $\rho_{P E S}$ is the density of the PES plastic, $\mathrm{V}_{\mathrm{M}}$ and $\mathrm{V}_{\mathrm{m}}$ are the volumes of the floating head and the cantilever beam, respectively, and $g$ is the local gravity. These values are listed below:

$\rho_{\text {PES }}=0.05 \mathrm{lb} / \mathrm{in}^{3}$,

$\mathrm{V}_{\mathrm{M}}=0.019625 \mathrm{in}^{3}$,

$\mathrm{V}_{\mathrm{m}}=0.009152 \mathrm{in}^{3}$,

and

$\mathrm{g}=9.81 \mathrm{~m} / \mathrm{s}^{2}\left(386.4 \mathrm{in} / \mathrm{s}^{2}\right)$.

Equations 22 and 23 now yield:

$\mathrm{M}=2.54 \times 10^{-6} \mathrm{lbf} / \mathrm{in} / \mathrm{s}^{2}$,

and

$\mathrm{m}=1.184 \times 10^{-6} \mathrm{lbf} / \mathrm{in} / \mathrm{s}^{2}$. 
So, total mass from Equation 20 is $\mathrm{M}_{\mathrm{T}}=2.812 \times 10^{-6} \mathrm{lbf} / \mathrm{in} / \mathrm{s}^{2}$. Finally, Equation 18 yields a natural frequency,

$\omega_{\mathrm{n}}=1.5 \mathrm{kHz}$ for $\mathrm{L}=0.5 \mathrm{in}$.

and

$\omega_{\mathrm{n}}=1.23 \mathrm{kHz}$ for $\mathrm{L}=0.57 \mathrm{in}$.

A calculation of this sort is considered an estimate due to the assumptions in geo etry. This calculation is adequate, because the only purpose is to be able to verify tha the experimental results are reasonable.

\subsection{Vibration Testing Results}

All vibration tests were done at 1-g and 2-g's. The tests were done with two identical skin friction gages. Gage 43 was used as a control and the gap remained empty. Gage 40 was tested with an empty gap, then the thin silicone rubber sheet was affixed across the top, and finally the gap was also filled with silicone oil. The nu mber notation of the skin friction gages correspond the serial number of the semiconductor strain gages attached by Micron Instruments.

Figure 41 displays the frequency response of the skin friction gage.

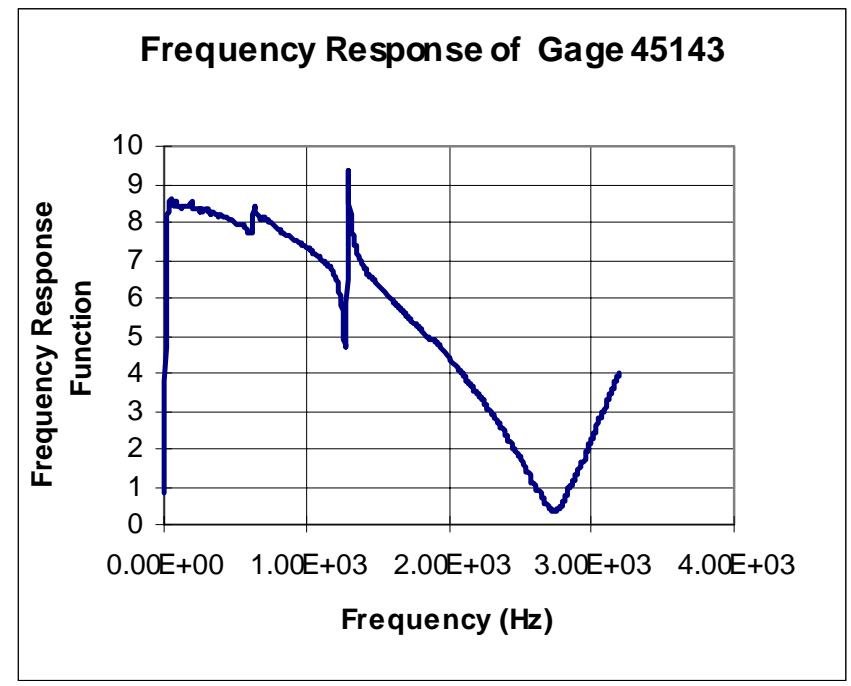

Figure 41-Frequency Response Plot

The frequency response of Gages 43 and 40 should be the same, because the geom etry is the same. The natural frequency occurs at an infinite slope, $\omega_{\mathrm{n}} \approx 1.3 \mathrm{kHz}$, 
which is in good agreement with the simple analytical estimate.

Figure 42 and Figure 43 show the vibration response the results of Gages 40 and 43 without any gap filler or rubber sheet, and as should be expected the output of the strain gages on the abscissa is virtually identical. Note, the output voltage of the strain gages on the abscissa is plotting logarithmically. To show symmetry of the skin friction gage an "Off” axis vibrational test was performed at 2-g's. As should be expected, the na ural frequency peak was no longer present, as seen in Figure 44.

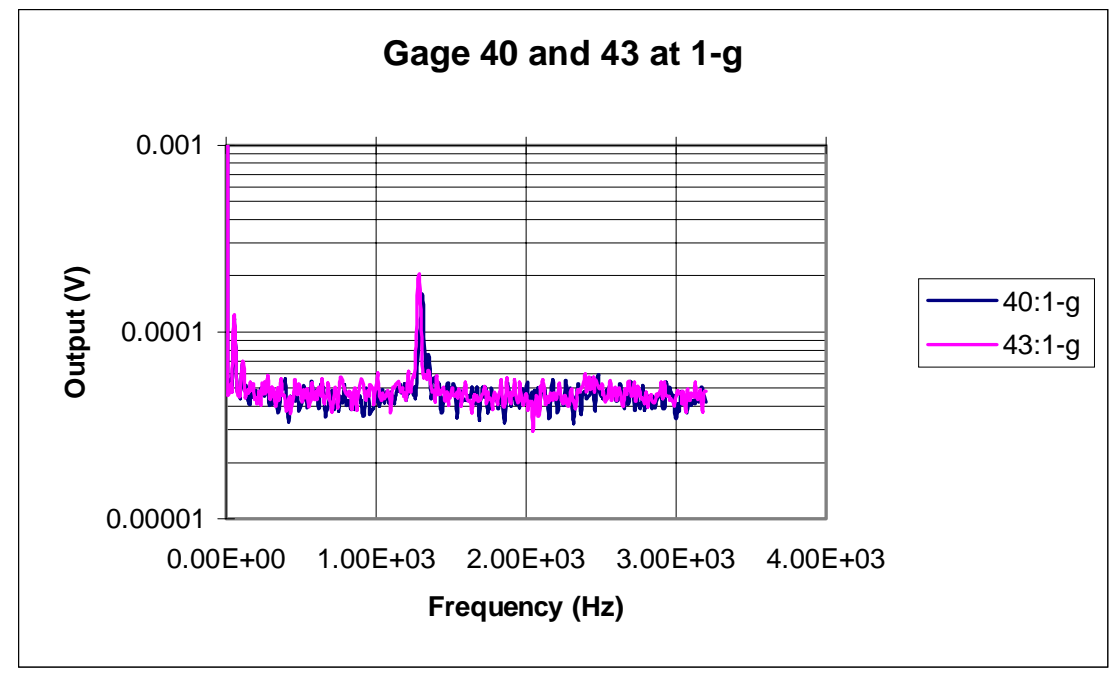

Figure 42-Vibration Results without a Gap Filler at 1-g

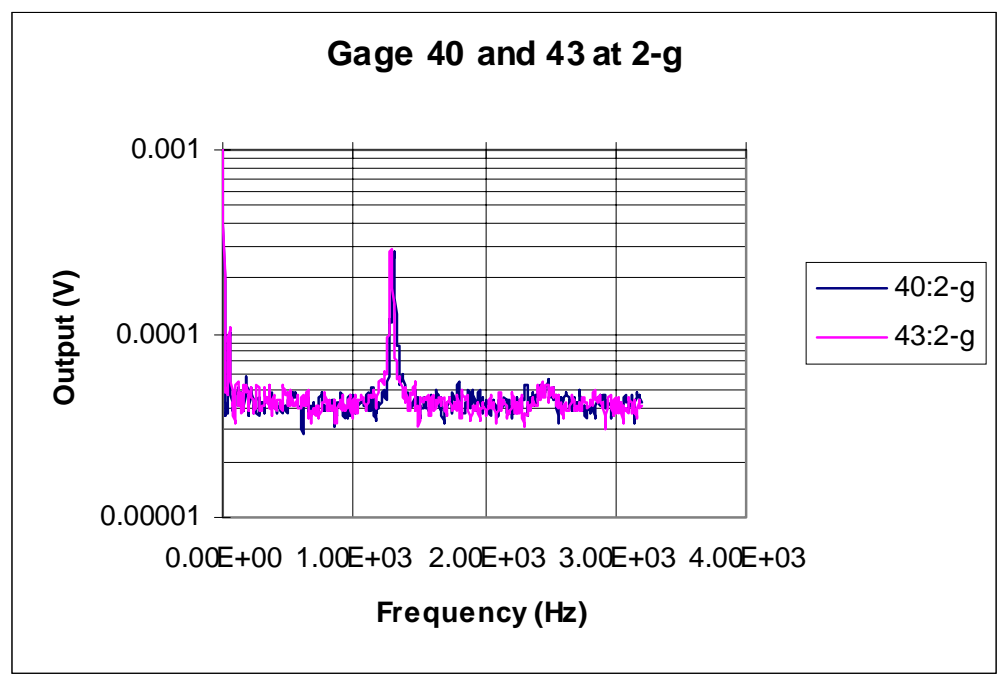

Figure 43-Vibration Results without a Gap Filler at 2-g's 


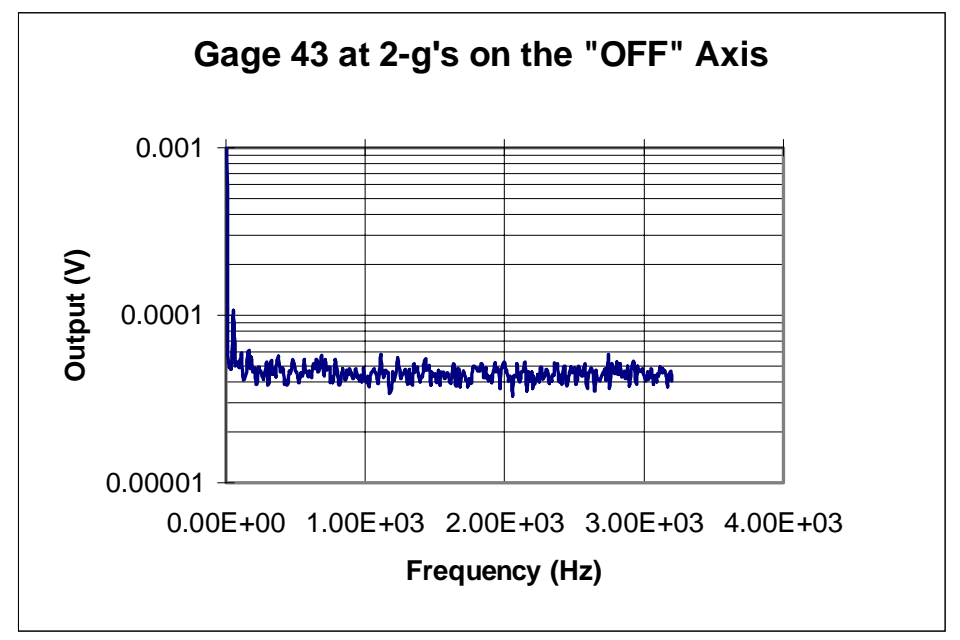

Figure 44-Vibrational Results of the "Off" Axis for Gage 43

The thin silicone rubber sheet was applied to skin friction Gage 40, now designated 40R. Figure 45 and Figure 46 show the large amount of damping obtained comparing Gages 40 and 40R at 1-g and 2-g's.

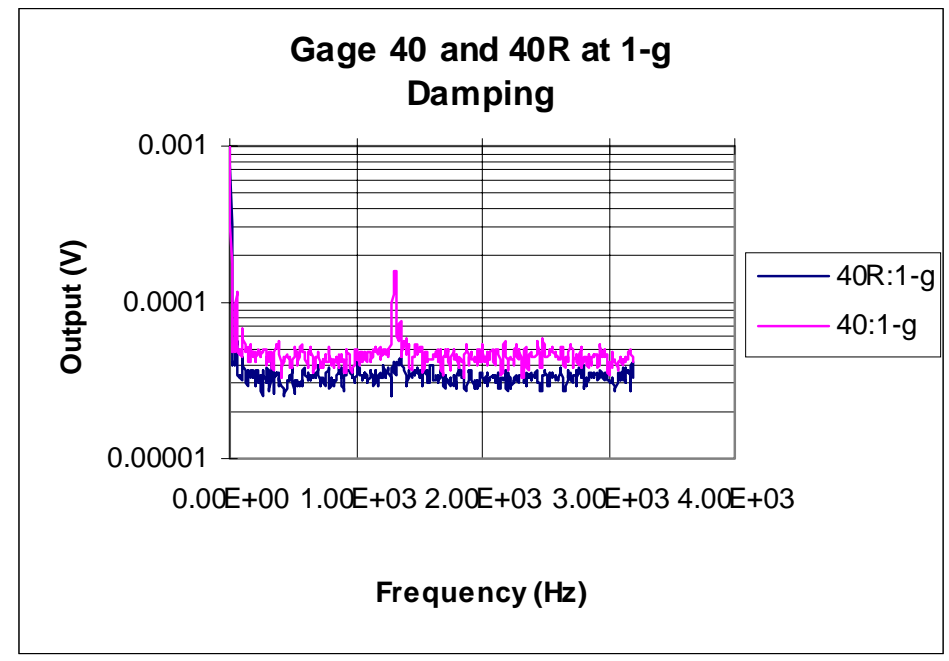

Figure 45-Damping Results for Gages 40 and 40R at 1-g 


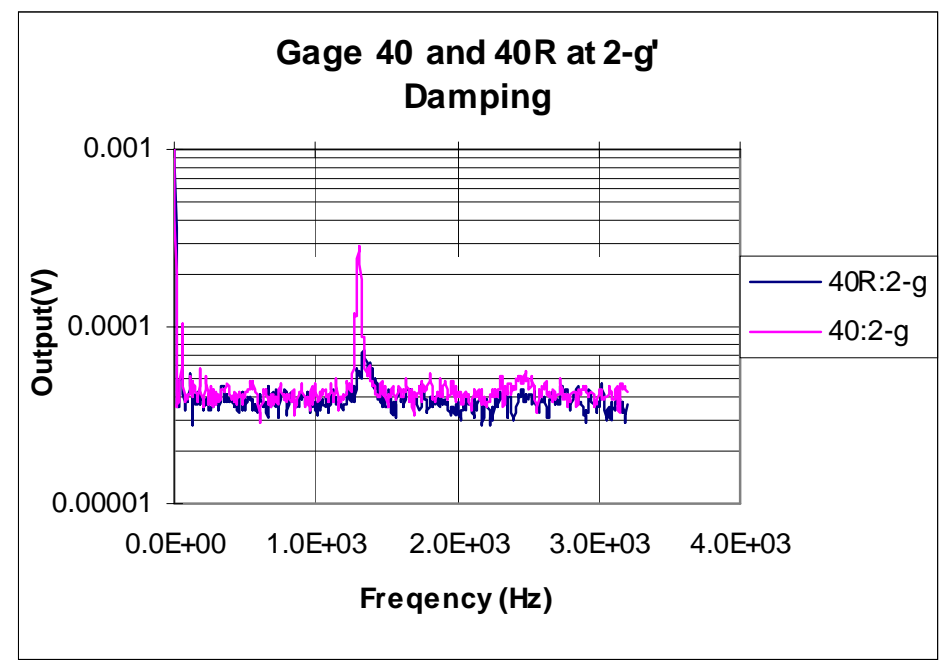

Figure 46-Damping Results for Gages 40 and 40R at 2-g's

The dynamic tests for Gage 40R produced excellent results. The peak was greatly damped, while the natural frequency shifted to the right slightly, which is to be e $\mathrm{x}$ pected, at $\omega_{\mathrm{n}}=1.344 \mathrm{kHz}$.

The next step was to fill the gap in Gage 40R with silicone oil, creating gage 40RO. The skin friction gage was shaken at 1-g and 2-g's, and the results are Figure 47 and Figure 48. The silicone oil appeared to provided little additional damping.

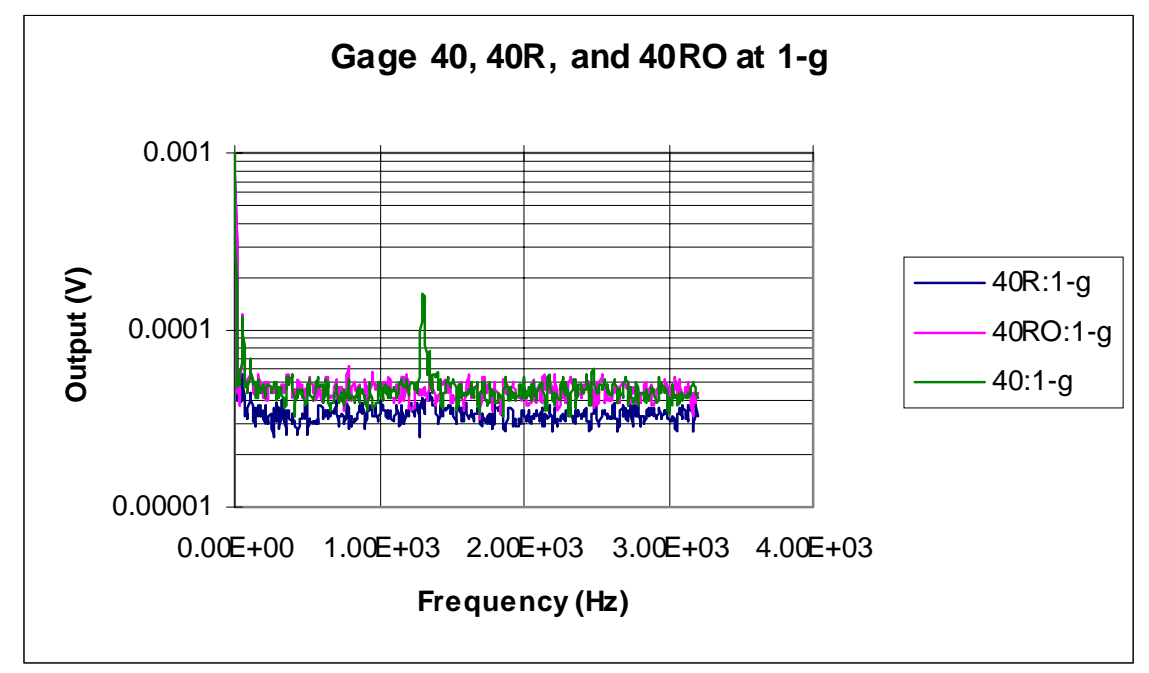

Figure 47-Damping Results of Gage 40RO at 1-g 


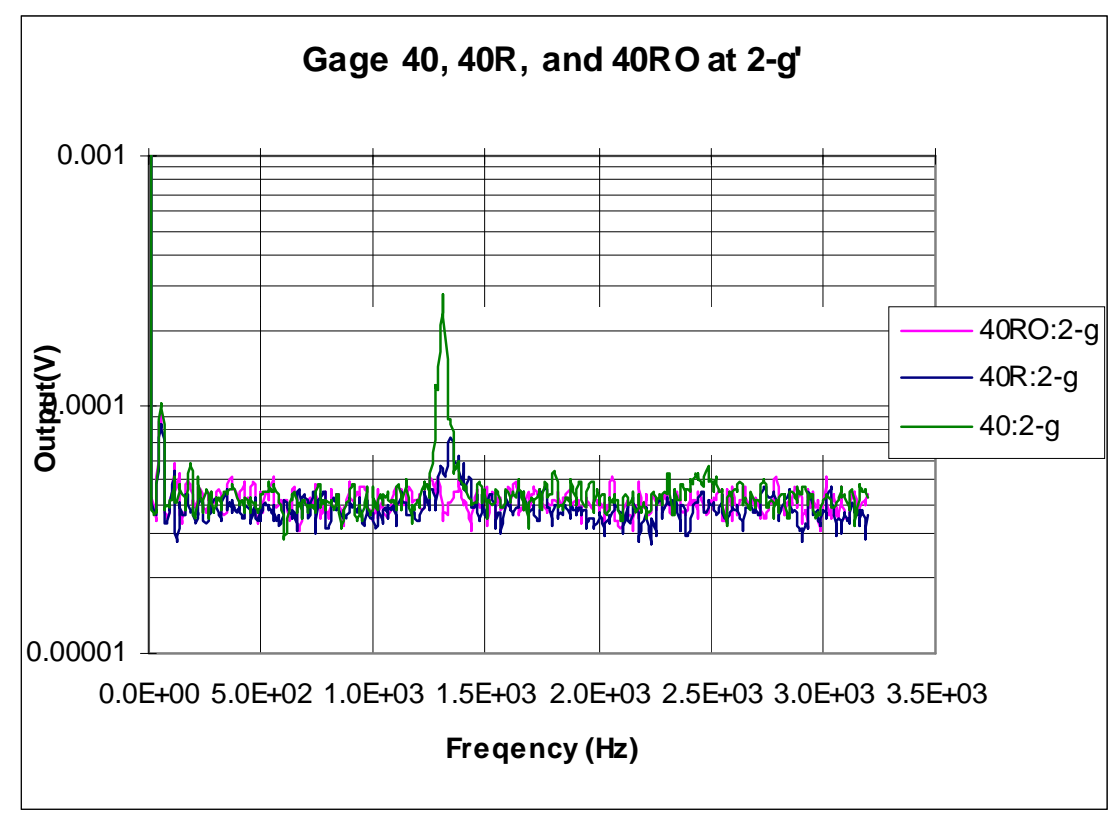

\section{Figure 48-Damping Results for Gage 40RO at 2-g's}

Questions arose about the smaller peak on the plots at $560 \mathrm{~Hz}$. This peak is best seen in Figure 41 of the frequency response plot. The theoretical calculations did not pr oduce any natural frequency at or near $560 \mathrm{~Hz}$, so it was concluded that the peak at 560 $\mathrm{Hz}$ might be a torsional effect due to the mounting of the gage on the shaker. If the gage is not mounted at the center of mass, the skin friction gage would shake nonrigidly. A calculation of the center of mass and re-testing is necessary to verify tha the peak at $560 \mathrm{~Hz}$ is erroneous. The center of mass tests were done on Gage 43.

\subsubsection{Center of Mass Calculations}

The skin friction gage is axisymmetric, so the centroid is the center o mass. Equations 24 and 25 are the $\mathrm{x}$ and y location of the centroid,

$$
\bar{X}=\frac{\sum_{i} A_{i} \bar{x}_{i}}{\sum_{i} A_{i}},
$$

and 


$$
\bar{Y}=\frac{\sum_{i} A_{i} \bar{y}_{i}}{\sum_{i} A_{i}} .
$$

The skin friction gage was divided into nine simple geometric shapes and the su bscript $i=1,2,3, \ldots$ represents each section. A in Equations 24 and 25 is the area, and the $\bar{x}$ and $\bar{y}$ are the centroid location for each section (Beer and Johnston, 1979). Figure 49 describes how the skin friction gage was broken up.

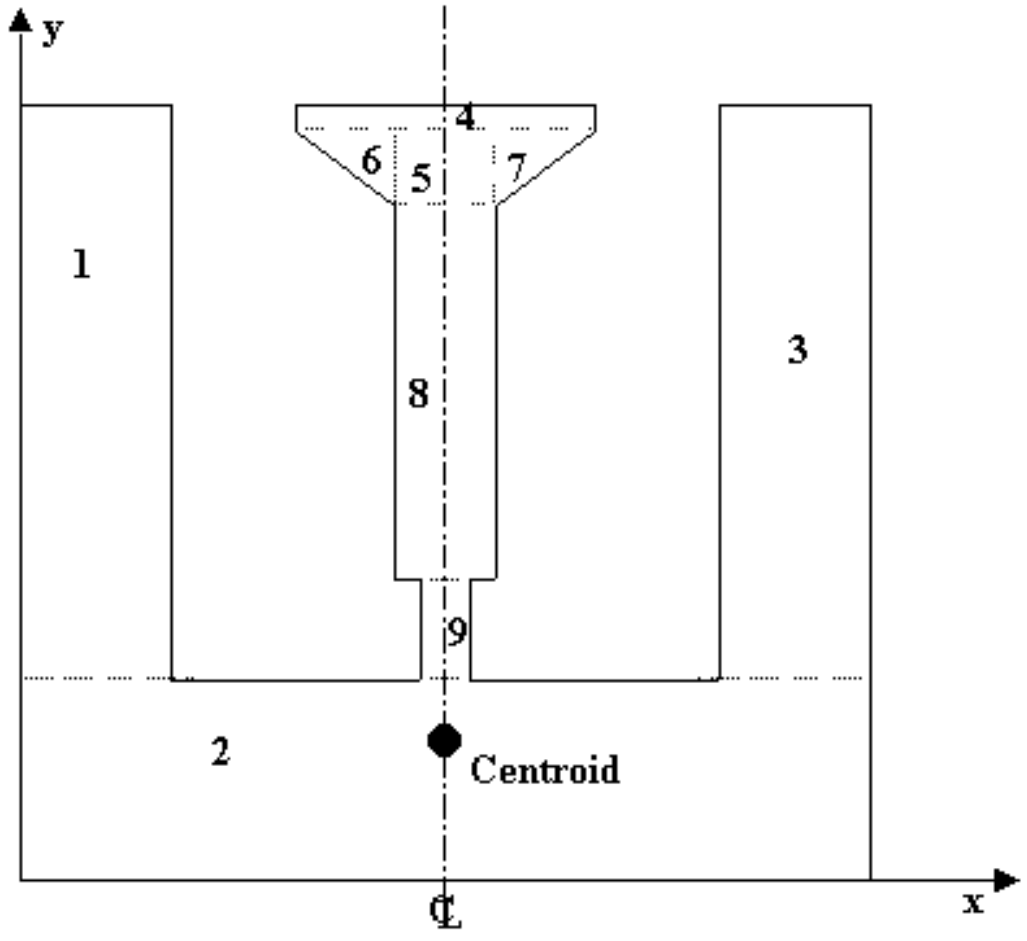

Figure 49-Center of Mass Geometric Sections

The calculations were organized and performed in Microsoft Excel, shown in Table 6.

Table 6 -Center of Mass Calculations for Gage 43

\begin{tabular}{|c|c|c|c|c|c|c|c|}
\hline Section & $\mathbf{A i}$ & xbari & ybari & $A i^{\star} x b a r i$ & $A i^{*}$ ybari & Xbar & Ybar \\
\hline 1 & 0.17385 & 0.1525 & 0.91 & 0.026512 & 0.158204 & & \\
\hline 2 & 0.9375 & 0.75 & 0.3125 & 0.703125 & 0.292969 & & \\
\hline 3 & 0.17385 & 1.3475 & 0.91 & 0.234263 & 0.158204 & & \\
\hline 4 & 0.0075 & 0.75 & 1.1875 & 0.005625 & 0.008906 & & \\
\hline 5 & 0.012369 & 0.75 & 1.1395 & 0.009277 & 0.014094 & & \\
\hline 6 & 0.007033 & 0.61577 & 1.126 & 0.004331 & 0.007919 & & \\
\hline 7 & 0.007033 & 0.86577 & 1.126 & 0.006089 & 0.007919 & & \\
\hline 8 & 0.049475 & 0.75 & 0.937 & 0.037106 & 0.046358 & & \\
\hline 9 & 0.0162 & 0.75 & 0.7 & 0.01215 & 0.01134 & & \\
\hline & 1.38481 & & & 1.038477 & 0.705913 & 0.749906 & 0.509754 \\
\hline
\end{tabular}

all units in inches 
The skin friction Gage 43 was reattached and tested at the center of mass. Figure 50 yields favorable results, showing the $560 \mathrm{~Hz}$ peak was reduced considerably.

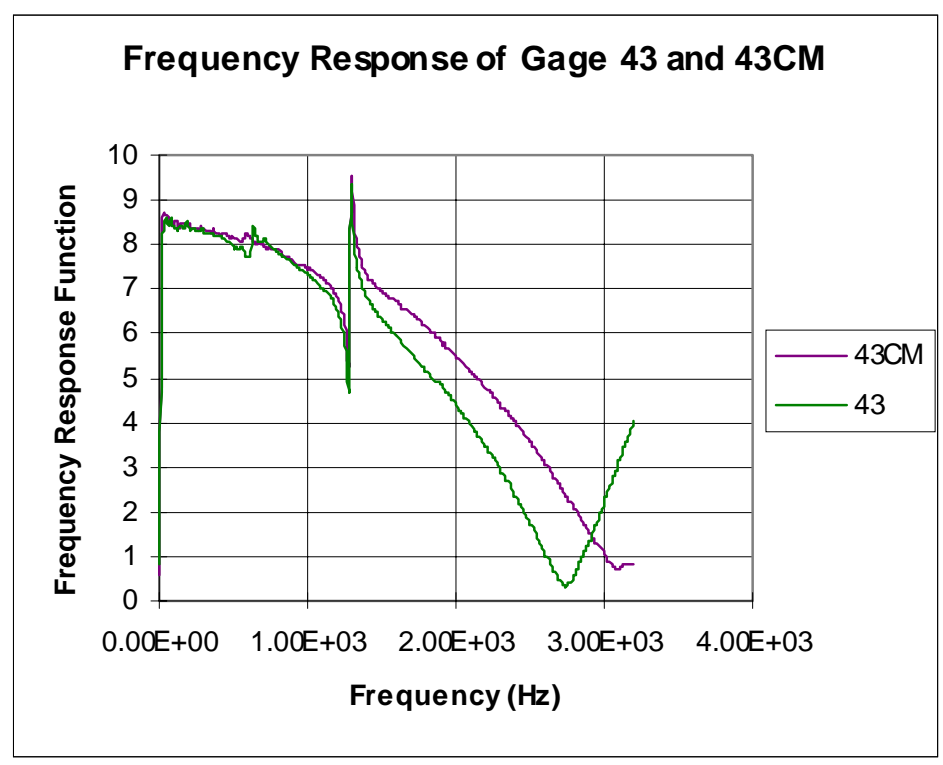

Figure 50-Center of Mass Frequency Response Comparison

\subsection{RTV-566 Silicone Rubber Layup}

Further research was done here on improving the thin silicone rubber sheet for ease of production and more durability. A toxic adhesive produced by General Ele ctric is considered best for affixing silicone rubber and plastic, called SS4004 primer. Most of this research was performed with the help of Dan Lofstrom.

1. Clean a flat, smooth surface (aluminum plate) with acetone as to ensure that no old rubber remains. Cover the aluminum plate with a smooth layer of plastic wrap and tape down. The goal is to create a surface that is as smooth as possible, so a mirror or sheet of glass may be used in place o the aluminum plate.

2. Take the gage that the rubber sheet is to be applied to and spread a thin layer of SS4004 primer to its surface. Note that this substance should not be inhaled, so it is recommended that a mask be worn at all times. pplying is best done with a Q-tip. Dip the Q-tip into the SS4004 primer and evenly spread across the gage. Blow on the thin layer of film as it is being applied. You will notice that it is dry by the color changing from orange to pink and the viscosity of the fluid becoming greater. Before the layer is completely dry (about 30 seconds) add another layer of SS4004 on top. 
Continue this procedure for 8 to 10 layers.

Allow the SS4004 to dry at least 30 minutes before applying RTV-566.

3.

a. Wear gloves and pour RTV 566 A compound uniformly across the plate. This spreads easily, so only about 5 large drops should be used (about $3 \mathrm{~mL}$ ).

b. Add acetone to thin. The RTV 566 compound cures rather quickly, and the amount of acetone added does not affect the curing time. good amount to produce a thin layer of RTV 566 is about $25 \%$ acetone to $75 \%$ RTV 566 A by volume (about $1 \mathrm{~mL}$ acetone to 5 drops of RTV $566 \mathrm{~A})$.

c. Add a very small amount of RTV 566 B into the acetone and RTV 566 A mixture. It is best to dip the end of a nail into the RTV $566 \mathrm{~B}$ so ution and then mix it into the RTV 566 A solution.

d. Mix the solution with the nail and spread across the top part of the plate. This must be done fairly quickly, because once the RTV $566 \mathrm{~B}$ agent is added there is only about a 90 second working time.

e. Use a metal dowel to spread the mixture across the plate. This is bes done in a rolling motion that drags the fluid down the aluminum plate. Set the aluminum plate down flat and start at the top of the solution. Slowly drag the dowel down the plate evenly spreading the silicone rubber across the plate.

f. Place the gage with dried SS4004 face down on the rubber sheet before it cures. Do this slowly to ensure that no air is trapped between the gage and the RTV 566 rubber sheet.

g. Allow at least 2 hours to cure at room temperature. This time is less than recommended in the manufacturer's instructions, but those curing times are for thicker sections. Heating the solution for about 15 minutes at $200^{\circ} \mathrm{C}$ can decrease the curing time. Curing for the full 24 hours does, however, produce the best results.

4. To ensure adhesion, apply Dap silicone caulk around the edges of the gage with a Q-tip.

5. Allow the silicone caulk to dry for at least 2 hours and cut away excess rubber around the edges of the gage with an exacto knife. Apply one layer of SS4004 around the edges of the gage once more to ensure adhesion. Allow 24 hours to dry before testing.

Figure 51, Figure 52, and Figure 53 were developed in AutoCAD and visually depict how the silicone rubber sheet is applied to the skin friction gage. Note, RTV-615 $\mathrm{i}$ clear or transparent and RTV-566 is a red or burnt sienna 


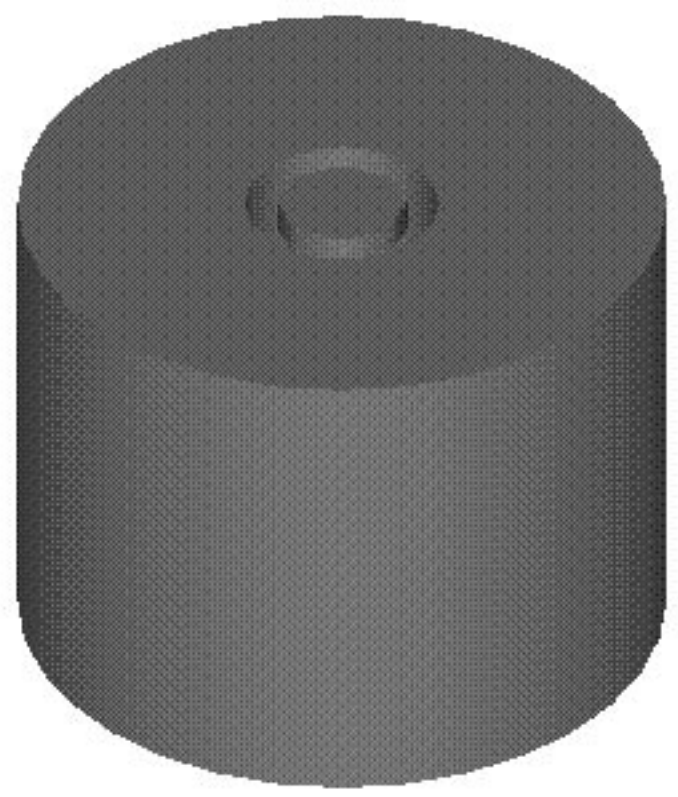

Figure 51-Skin Friction Gage

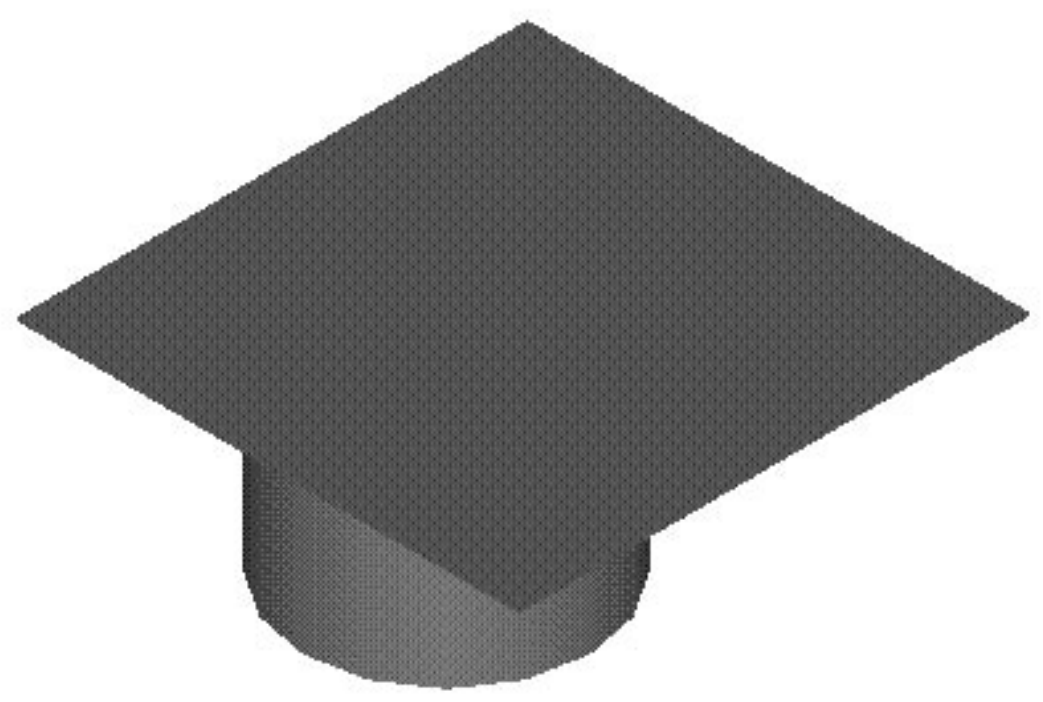

Figure 52-Skin Friction Gage with Unshaped Silicone Rubber Sheet 


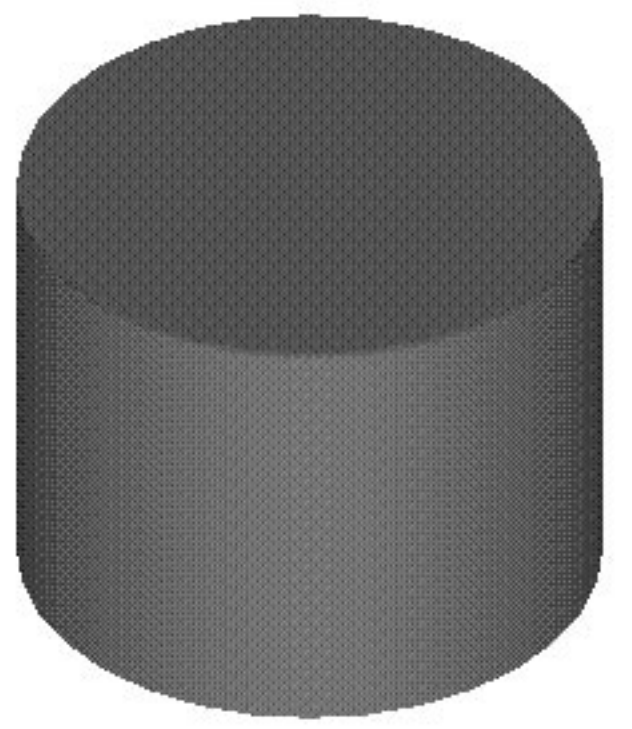

Figure 53-Skin Friction Gage with Silicone Rubber, RTV-566, Sheet Affixed to Top Surface 


\section{CALIBRATION RIG RESULTS}

The Calibration Rig was utilized to yield a calibration ratio. The calibration rati was necessary, because of the estimated $12-15 \%$ decrease in static sensitivity between the calibration of the silicone rubber sheet skin friction gage, 40R, and the calibration of Gage 40 without the rubber sheet. The calibration curves of these two skin friction gages are in Figure 8 and Figure 7. The calibration ratio is the ratio of the true ca ibration constant of the skin friction gage with a rubber sheet to the calibration constant of skin friction gage without any gap filler. Novean (1996B) calculated a ratio of 3.17 , which was very close to the geometric ratio of 3.22 , for a gage completely filled with silicone rubber. The geometric ratio is the ratio of the area of the exposed silicone rubber plus the floating head to the area of the floating head alone.

\subsection{Calibration Ratio Theory}

The skin friction gage designated 43 was calibrated without any rubber sheet for damping by the method described in Chapter 2. The results are in Table 7.

The RTV-566 thin rubber sheet was affixed to the skin friction Gage 43 (yielding Gage 43Red), and it was placed in the portal B shown in Figure 23. Five runs were performed for repeatability. The shear stress in the Calibration Rig is known from Equation 7. By knowing the true shear stress and the output from the semi-conductor strain gages, an effective area can be deduced. Equation 26 is similar to Equation 3,

$$
\tau_{w}=\frac{V C g}{A_{e f f}},
$$

where $A_{\text {eff }}$ is the effective area, and $C$ is the calibration constant from Figure 7 for gage 43 . The ratio of the effective area to the true area of the floating head, $(0.000127$ $\mathrm{m}^{2}$ ) is the same as the true calibration constant to the calibration constant in Figure 7 for Gage 43. This can be seen by setting Equations 26 equal to Equation 27,

$$
\tau_{w}=\frac{V C_{\text {true }} g}{A_{\text {Head }}},
$$


where $C_{\text {true }}$ is the actual calibration constant of the skin friction gage 43Red, and $\mathrm{A}_{\mathrm{HEAD}}$ is the area of the floating head.

\subsection{Calibration Rig Runs}

Five runs were performed, and an average of the runs yielded a calibration ratio. Table 7 is a summary of the output

Table 7 -Calibration Rig Results

\begin{tabular}{|c|c|c|c|c|c|c|c|}
\hline Run & $d p / d x(p s i / i n)$ & Gage (mV) & Shear (psi) & Shear (Pa) & Aeff $\left(m^{\wedge} 2\right)$ & Ahead (m^2) & Aeff/Ahead \\
\hline & & & & & & & \\
\hline 1 & $1.30 \mathrm{E}-01$ & 1.5 & $1.62 \mathrm{E}-02$ & 111.78 & $1.88 \mathrm{E}-04$ & $1.27 \mathrm{E}-04$ & 1.48 \\
\hline 2 & $1.26 \mathrm{E}-01$ & 13 & $158 \mathrm{~F}-02$ & 108.68 & $1.68 \mathrm{E}-04$ & $127 F-04$ & 132 \\
\hline & & & & & & & \\
\hline 3 & $1.23 \mathrm{E}-01$ & 1.24 & $1.54 \mathrm{E}-02$ & 105.92 & $1.64 \mathrm{E}-04$ & $1.27 \mathrm{E}-04$ & 1.29 \\
\hline & & & & & & & \\
\hline 4 & $1.23 \mathrm{E}-01$ & 1.38 & $1.54 \mathrm{E}-02$ & 105.92 & $1.83 \mathrm{E}-04$ & 1.27E-04 & 1.44 \\
\hline & 102501 & & & & 07501 & 27501 & \\
\hline 5 & $1.23 \mathrm{E}-01$ & 1.41 & $1.53 \mathrm{E}-02$ & 105.66 & 1.87E-04 & $1.27 \mathrm{E}-04$ & 1.47 \\
\hline average $A_{\text {eff }}$ & $A_{\text {HEAD: }}$ & & & & & & 1.40 \\
\hline & & & & & & & \\
\hline \multicolumn{2}{|c|}{ Ratio of $A_{\text {rubber }} / A_{\text {head }}$ : } & & & & & & 1.56 \\
\hline
\end{tabular}

Calculations in Table 7 yielded a calibration ratio of 1.4 ; the ratio of 1.4 can be compared to the geometric ratio of 1.56 for this gage. Also from Table 7 the average voltage output of the skin friction gage is $1.37 \mathrm{mV}$. Using this and Equation 4 (take $\mathrm{GF}=150$ ), a comparison between the results of the Calibration Rig and that $\mathrm{o}$ the strain from ABAQUS in Chapter 5 can be made. For the given geometry of the gage, ABAQUS predicts a strain between approximately 20 and 23 microstrains. This is estimated fro Figure 32 and Figure 34. Solving for strain in Equation 4 yields 18.2 microstrains. This result is extremely favorable in the use of FEM for designing present and future skin friction gages. Figure 54 is the pressure distribution of the five runs in the calibration rig. The slope of these lines are the pressure gradients $(\mathrm{dp} / \mathrm{dx})$ used to determine the shear stress in the Rig. 


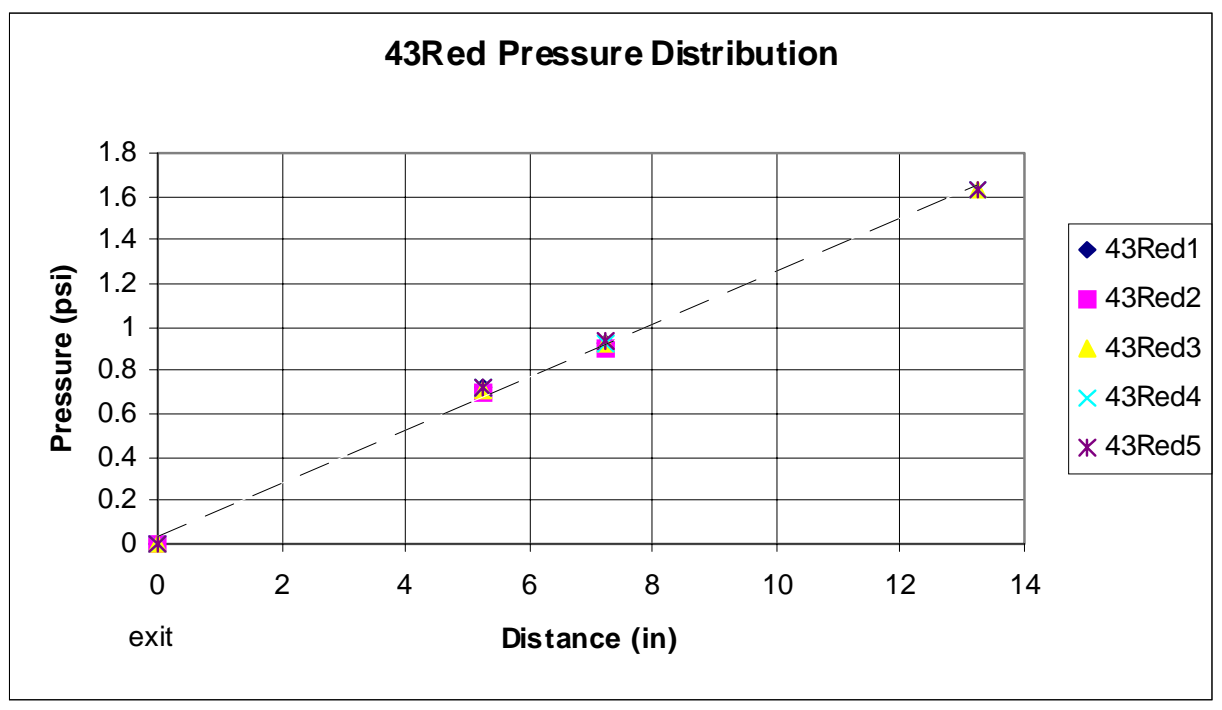

Figure 54 -Pressure Distribution in Calibration Rig for Gage 43Red 


\section{VIRGINIA TECH SUPERSONIC TUNNEL TESTING RESULTS}

The dynamic response test of the thin silicone rubber sheet skin fri ction gage were excellent, so the next logical step was to test the skin friction gage in the supe rsonic tunnel of Virginia Polytechnic Institute and State University. The estimated shear for the Mach 2.4 nozzle with a total pressure of $55.0 \mathrm{psi}$ is $150 \mathrm{~Pa}$. This value was workable for the rubber sheet skin friction gage, which was designed for a nominal shear of $100 \mathrm{~Pa}$.

\subsection{Virginia Polytechnic Institute and State University Supersonic Wind Tu n- nel}

The Virginia Tech $23 \times 23 \mathrm{~cm}$ supersonic wind tunnel was originally designed and constructed at the NASA Langley Research Center. In 1958, the tunnel was pu r-

chased by Virginia Polytechnic Institute and State University and put into operation in 1963. In recent years, several modifications were introduced for longevity and higher capability into the air pumping, tunnel control, and instrumentation equipment. The tunnel is equipped with three complete nozzle chambers which presently are fitted with the nozzles for the Mach numbers 2.4, 3.0, and 4.0. These experiments use the Mach 2.4 nozzle. Figure 55 is a schematic of the supersonic tunnel. This schematic and more information is located at http://www.aoe.vt.edu/aoe/physical/superson.html . 


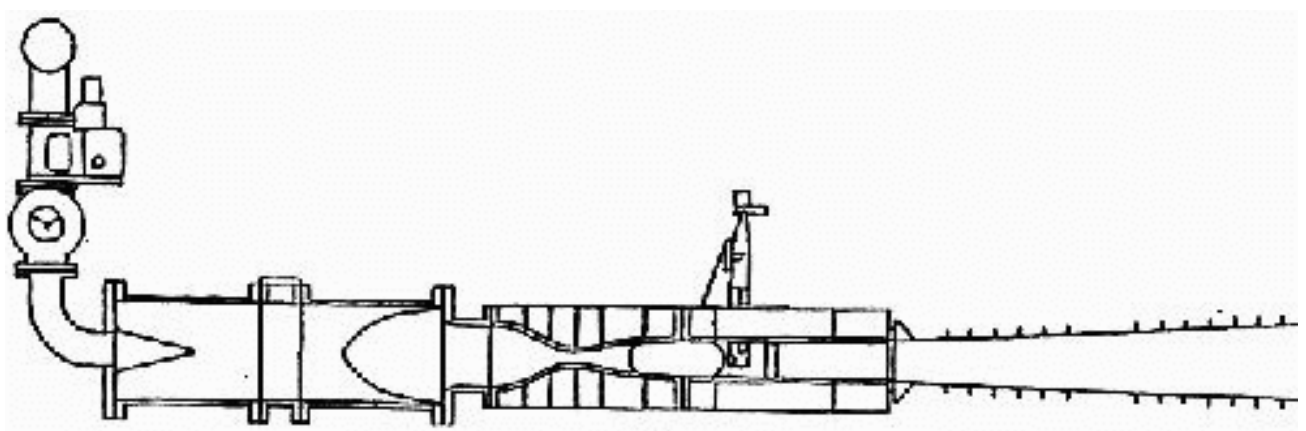

a)

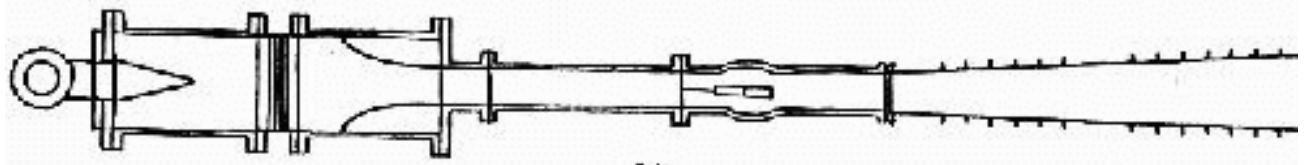

b)

Figure 55-Schematic of Virginia tech Supersonic Wind Tunnel, a) side view, b) top view

\subsection{Supersonic Tunnel Runs}

The rubber sheet was torn off or destroyed for each run. From the results the skin friction gage with the thin silicone rubber sheet is not robust enough for the forces exhibited by violent startup of the supersonic tunnel. The startup loads are a ssumed to be the problem, because the shear stresses during steady operation of the supersonic tunnel are known to be approximately $150 \mathrm{~Pa}$. The skin friction gage was designed well within that shear range. It was evident by the end of the testing, that the semi-conductor strain gage had been damaged and/or the beam was permanently d eformed. The shear stresses indicated by the semi-conductor strain gages are unre asonably large, anywhere from 3,000 to 50,000 Pa. An example is shown in Figure 56, purely for the sake of illustration, because there is no reliable information in it 


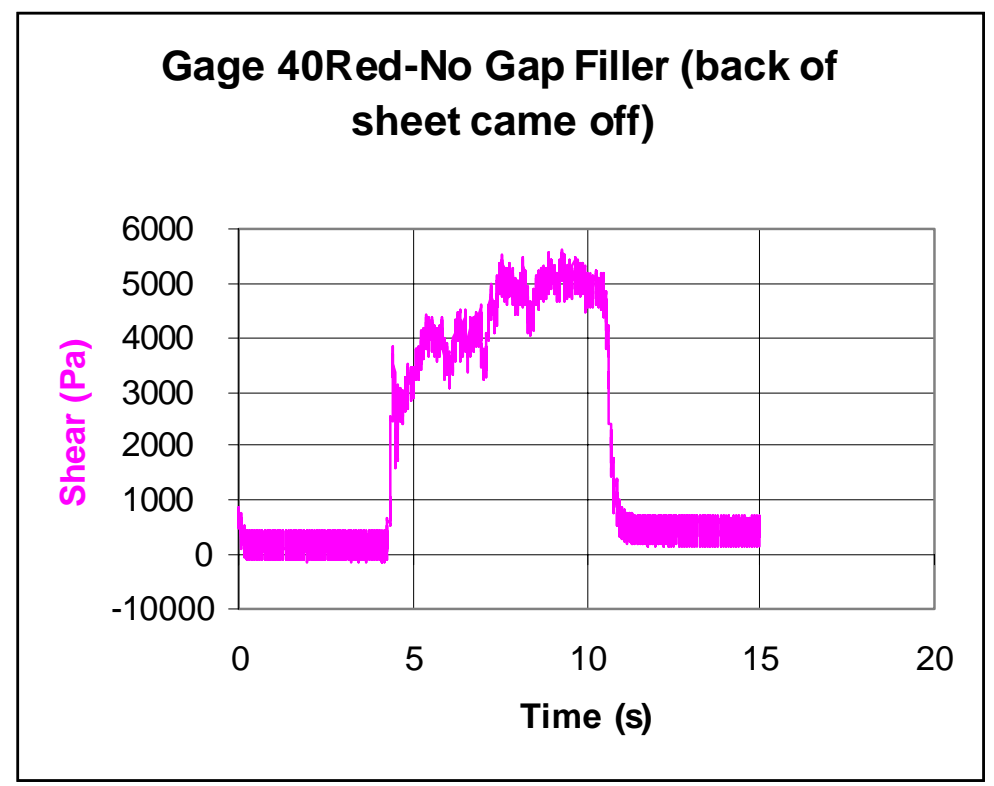

Figure 56-Example of Supersonic Tunnel Run

Two methods were implemented in attempt to equalize the pressure in the gage gap with that in the tunnel test section as the starting shock passed over the gage. In method one, the gap was filled with glycerine. Glycerine was used instead of silicone oil, because the oil corroded the silicone rubber sheet and the strain gage adh esive. This method was difficult to employ, because the high viscosity of glycerine hindered the filling of the gap, and the fill holes, seen in Figure 37 were too small for this application. The second method tried was to add a t-connection to the static pressure port in the tunnel test section, allowing the test section and the gap to be linked, equalizing the pressure. More of these efforts were successful. The skin friction gage employed was 40Red, a "G" indicates if filled with glycerine. Described in Table 8 is the manner in which the rubber sheet failed and which method of pressure equalization was employed. 
Table 8 -Supersonic Tunnel Runs

\begin{tabular}{|c|c|c|c|c|}
\hline Run & Gap Filler & Adhesive & Rubber & Rubber Sheet Failure \\
\hline & 1 glycerine & DAP & RTV-566 & $\begin{array}{l}\text { First try sheet stays on, } \\
\text { but glyercine splatters out back }\end{array}$ \\
\hline & 2 glycerine & DAP & RTV-566 & $\begin{array}{l}\text { Sheet is not completely adhered } \\
\text { from Run } 1 \text {, but testing for durability. } \\
\text { Sheet is completely torn off }\end{array}$ \\
\hline & 3 glycerine & DAP & RTV-566 & $\begin{array}{l}\text { Hole popped in gap at the back } \\
\text { and glycerine poured out. }\end{array}$ \\
\hline & 4 none & DAP & RTV-566 & $\begin{array}{l}\text { Rubber sheet ripped off at back, } \\
\text { but not at gap. }\end{array}$ \\
\hline & 5 none & DAP & RTV-566 & $\begin{array}{l}\text { Rubber Sheet has piece missing } \\
\text { from back from Run } 4 \text {, this run } \\
\text { sheet completely ripped off. }\end{array}$ \\
\hline & 6 none & SS4004 & RTV-566 & Rubber sheet completely ripped off. \\
\hline
\end{tabular}




\section{CONCLUSIONS AND RECOMMENDATIONS}

In this study, several analyses were performed on a skin friction gage utilizing rubber compounds for damping including: finite element modeling, advancement in calibration techniques and/or devices, vibrational testing, and supersonic wind tunne testing. This involved theoretical and experimental scenarios, and in conclusion, the results are generally favorable, but the results also indicate a need for more study.

The numerical FEM study of the skin friction gage was suc cessful in such a way that future skin friction gage designs could apply the same techniques. The proper element types, and necessary grid arrangement were set here, and it was proven that a FEM program could accurately simulate shear loading on a skin friction gage.

A recommendation is made to upgrade the Calibration Rig enabling it to be used daily. The advantages of accurate calibrations far outweighs the cumbersomeness of the rig. For completion of the rig, one of the three mentioned methods in Chapter 4 for changing the shear stress needs to be implemented.

From the excellent results of the vibration testing, the implications of a thin rubber sheet could solve the problem of oil leakage and provide adequate damping. Many types of rubber exist that could be used in many types of environments and maintain the material properties. Presently, a great demand for the rubber sheet in conjunction with the skin friction gage exists to alleviate the high maintenance pro blems of the oil-filled gages. But to continue a patient and deliberate study of a method for supersonic wind tunnel tests should commence. The determination of the point at which the silicone rubber sheet fails is necessary. Is that point really in the starting and the unstarting of the tunnel? If so, would the skin friction gage designed operate successfully for flight tests? And, a fool-proof method of adhering the silicone rubber sheet to the skin friction gage needs to be set. A new concept is currently in the process of being implemented. A motorized removable cover would fit snuggly over the skin friction gage to be tested. After the initial shock wave of the tunnel starting passed, the cover would be lifted vertically or rotated horizontally by a motor, and then replaced before the tunnel stopped. So, the skin friction gage would not be subjected to the harsh effects of the tunnel starting and unstarting. 


\section{REFERENCES}

Allen, J.M., "Improved Sensing Element for Skin-Friction Balance Measurements," AIAA Journal, Vol. 18, pp. 1342-1345, Nov. 1980.

Anderson, John D. Modern Compressible Flow with Historical Perspective. McGrawHill, Inc. New York, NY, pp.s 27, 1990

Beer, F.P. and Johnston, E. R. Mechanics of Materials. McGraw-Hill, Inc. New York, NY, Appendix A, pp. 690-699, 1979.

Blumer, Charles B. The Direct Measurement of Skin Friction on a Cone at Supersonic Speed. Thesis in Partial Fulfillment for the Degree of Master of Sc ience in Aeronautical Engineering, University of Minnesota, November, 1954.

Cessna Pilot Center, Manual of Flight. Jeppesen \& Co. Vol.1, pp. 1-15, 1993.

Chadwick, K.M., An Actively Cooled Floating Element Skin Friction Balance for D $i$ rect Measurement in High Enthalpy Supersonic Flows. Dissertation in Partial Fulfillment for the Degree of Doctor of Philosophy, Virginia Polytechnic Institute and State University, Blacksburg, VA, December, 1992.

Chapman, D.R. and Kester, R.H. "Measurements of Turbulent Skin Friction on Cylinders in Axial Flow and Subsonic and Supersonic Velocities." Journal of the Aeronautical Sciences, Vol. 20, No. 7, pp.441-448, July, 1953.

Chue, S.H., "Pressure Probes for Fluid Measurement," Progress in Aerospace Sci ences, Vol. 16, No. 2, pp. 147-223, 1975. 
Coles, D., Measurements in the Boundary Layer on a Smooth Flat Plate in Supersonic Flow, Dissertation in Partial Fulfillment for the Degree of Doctor of Philosophy, California Institute of Technology, Pasadena, CA, June, 1953.

DeTurris, D.J., A Technique for Direct Measurement of Skin Friction in Supersonic Combustion Flo , Dissertation in Partial Fulfillment for the Degree of Doctor of Philosophy, Virginia Polytechnic Institute and State University, Blacksburg, VA, November, 1992.

Dhawan, S., "Direct Measurement of Skin Friction," NACA Report 1121, 1953

Doebelin, E.O., Measurement Systems Application and Design Fourth Edition . McGraw-Hill, Inc., New York, NY, Chapter 10, pp. 826-828, 1990.

Dow Chemical Company, "Synthetic Glycerine Products Properties."

Eimer, M., Direct Measurement of Laminar Skin Friction at Hypersonic Speeds, Dis sertation in Partial Fulfillment for the Degree of Doctor of Philosophy, California Institute of Technology, Pasadena, CA, 1953.

Everett, H.U., Calibration of Skin Friction Balance Discs for Pressure Gradient, Dis sertation in Partial Fulfillment for the Degree of Master of Science in Aeronautical Engineering, University of Texas, Austin, TX, August 1958.

"GE Silicones, RTV615 Specifications Sheet."

"GE Silicones, RTV566 Specifications Sheet."

Hakkinen, R. J. “ Measurements of Turbulent Skin Friction on a Flat Plate at Tran sonic Speeds.” NACA 3486, 1955. 
Hibbitt, Karlsson \& Sorensen, Inc. ABAQU ${ }^{\circledR} /$ Standard User's Manual. Vol. II, Ver sion 5.8, 1998.

Hibbitt, Karlsson \& Sorensen, Inc. ABAQU ${ }^{\circledR} /$ Standard Getting Started With. Version $5.8,1998$.

Inman, D.J., Engineering Vibration. Prentice-Hall, Inc., Englewood Cliffs, NJ,Chapter 7, pp. 365-380, 1996.

Karamchti K., Principles of Ideal-Fluid Aerodynamics. Kreiger Publishing Company, Malabar, FL, Chapter 5, pp. 175-178, original edition, 1966, reprint edition, 1980.

Kuethe, A.M., and Chow, C., Foundations of Aerodynamics: Bases of Aerodynamic Design Fourth Edition. John Wiley \& Sons, Inc., New York, NY, Chapter 14 \& 18, pp. 314-315, 399, 1996.

Mansfield \& Green, a Division of Ametek ${ }^{\circledR}$, Inc., Air Dead-Weight Tester Manual, Solon, $\mathrm{OH}$.

Massachusetts Institute of Technolgy's Hypermedia Teaching Facility, Thermal F u ids Engineering Class (2006) Page. MIT. July 8, 1999 <http://curricula.mit.edu/ 2006/Textbook/Nodes/chap06/node23.html >

NASA's Glenn Research Center "Beginner's Guide to Aeronautics" Page. NASA. July, 8, 1999 $\langle$ http://www.grc.nasa.gov/WWW/IFMD/airplane/forces.htm 〉.

National Instrument ${ }^{\circledR}, A T$ E Series User Manual. October, 1997.

National Instrument ${ }^{\circledR}$, BNC-2090 User Manual. March, 1996. 
National Instrument ${ }^{\circledR}$, LabVIEW $^{\circledR}$ User Manual. January, 1996.

Novean, M., Direct Measurement of Skin Friction in Complex Supersonic Flows.

Dissertation in Partial Fulfillment for the Degree of Doctor of Philos ophy, Virginia Polytechnic and State University, Blacksburg, VA, March, 1996A.

Novean, M., "Summary of Rubber-Filled $\mathrm{C}_{\mathrm{f}}$ Gage Calculations with a ThreeDimensional FEM Model," Report AOE-236, Virginia Polytechnic Institute and State University, Blacksburg, VA, August, 1996B.

Paik, S. and Schetz, J.A.” Simultaneous Direct Measurements of Skin Friction and Heat Transfer in Supersonic Flow." Proc Sixth Asian Congress Fluid Mechanics, YT Chew and CP Tso (eds) Nanyang Tech. Univ, Singapore, 1995.

Remington, A., A Study of Non-Fluid Damped Skin Friction Measurements for Transonic Flight. Dissertation in Partial Fulfillment for the Degree o Master of Science in Aerospace Engineering, Virginia Polytechnic and State University, Blacksburg, VA, July, 1999.

Schoenherr, K.E., Resistance of Flat Surfaces Through a Fluid, Soc. Nav. Arch. And Marine Engrs. (SNAME)Trans., Vol. 40, 1932.

Webster's Dictionary. Drag. Riverside Publishing Company, 1991.

Wolff, J.M., Lieutenant USN. An Evaluation of Equipment to Measure Directly the Skin Friction Forces on a Flat Plate. Thesis in Partial Fulfillment for the Degree of Master of Science in Aeronautical Engineering, University of Minnesota, May, 1956. 
Winter, K.G., "An Outline of the Techniques Available for the Measurement of Skin Friction in Turbulent Boundary Layers," Progress in Aerospace Sciences, Vol. 18, pp. 1-57, 1977.

Wooden, P.A. and Hull, G.H. "Correlation of Measured and Theorectical Heat Trans fer and Skin Friction at Hypersonic Speeds Including Reynolds Analogy,” AIAA Paper No. 90-5244, October, 1990. 


\section{APPENDIX A}

Specifications for Materials Used 
RTV-615, GE Silicones

Table A. 1 -UNCURED PROPERTIES

\begin{tabular}{|l|c|c|}
\hline & RTV615A & RTV615B \\
\hline Color & Clear & Clear \\
& Colorless & Colorless \\
Consistency & Easily Pourable & Easily Pourable \\
Viscosity, cps & 4300 & - \\
Specific Gravity & 1.02 & - \\
\hline
\end{tabular}

Table A. 2-UNCURED PROPERTIES WITH CURING AGENT ADDED

\begin{tabular}{|l|c|}
\hline & 10 RTV615 \\
\hline Color & Clear, Colorless \\
Consistency & Easily Pourable \\
Viscosity, cps & 4000 \\
Work Time @ $25^{\circ} \mathrm{C}\left(77^{\circ} \mathrm{F}\right), \mathrm{hrs}$ & 4 \\
\hline
\end{tabular}




\section{RTV615, GE Silicones cont'd}

Table A. 3-CURED PROPERTIES (CURED 1 HR. @ 100C/212F)

\begin{tabular}{|l|c|}
\hline & RTV615 \\
\hline Mechanical & 44 \\
Hardness & $65(920)$ \\
Tensile Strength, kg/cm ${ }^{2}$ (psi) & 120 \\
Elongation, \% & 0.2 \\
Shrinkage, \% & 1.406 \\
Refractive Index & \\
\hline Electrical & $19.7(500)$ \\
Dielectric Strength, kv/mm & 2.7 \\
(v/mil) $(1.9 m m$ thick) & 0.0006 \\
Dielectric Constant @ 1000 Hz & $1.8 \times 10^{15}$ \\
Dissipation Factor @ 1000 Hz & \\
Volume Resistivity, ohm-cm & -60 to 204 \\
\hline Thermal & $(-75$ to 400$)$ \\
Useful Temperature Range, & \\
${ }^{\circ} \mathrm{C}\left({ }^{\circ} \mathrm{F}\right)$ & 0.00045 \\
Thermal Conductivity, & $(0.11)$ \\
Gm-cal/sec,c ${ }^{2},{ }^{\circ} \mathrm{C} / \mathrm{cm}$ & $27 \times 10^{-5}$ \\
(Btu/hr, $\left.{ }^{2},{ }^{\circ} \mathrm{F} / \mathrm{ft}\right)$ & $\left(15.3 \times 10^{-5}\right)$ \\
$\mathrm{Coefficient}^{-5}$ of expansion, & 0.3 \\
$\mathrm{Cm} / \mathrm{cm}{ }^{\circ} \mathrm{C}$ & $(0.3)$ \\
(in/in, $\left.{ }^{\circ} \mathrm{F}\right)$ & \\
Specific Heat, & \\
Cal/gm ${ }^{\circ} \mathrm{C}$ (Btu/lb, $\left.{ }^{\circ} \mathrm{F}\right)$ & \\
\hline
\end{tabular}

Table A. 4-CURING TIME

\begin{tabular}{|c|c|}
\hline Temperature, ${ }^{\mathbf{0}} \mathbf{C}\left({ }^{\mathbf{0}} \mathbf{F}\right)$ & Cure Time $^{*}$ \\
\hline $25(77)$ & $6-7$ days \\
$65(149)$ & $4 \mathrm{hrs}$. \\
$100(212)$ & $1 \mathrm{hr}$. \\
$125(257)$ & $45 \mathrm{~min}$. \\
$150(302)$ & $15 \mathrm{~min}$. \\
\hline
\end{tabular}

*Cure times are only approximate. The actual time is affected by the mass of the unit and the time required to reach the desired temperature

(GE Silicones Specifications for RTV615) 
RTV-566, GE Silicones

Table A. 5-TYPICAL UNCURED PROPERTIES

\begin{tabular}{|lcc|}
\hline & RTV566A & RTV566B \\
\hline Color & Red & Yellow Brown \\
Viscosity, cps & 42,700 & 11 N/A \\
Specific Gravity & 1.49 & 1.15 \\
\hline
\end{tabular}

Table A. 6-TYPICAL CATALYZED PROPERTIES(Mixture by weight of a 100 parts RTV566A and 0.1 part RTV566B)

\begin{tabular}{|lc|}
\hline & RTV566 \\
\hline Application Rate, gm/min & 180 \\
(45 minutes after mixing) & \\
(0.125 in. orfice @ 90 psi) & \\
Work Life, Hrs. & 1.5 \\
Tack Free Time, Hrs. & 2.2 \\
\hline
\end{tabular}

Table A. 7-TYPICAL CURED PROPERTIES (Cured 7 days @ 25C (77F), and 50\% R.H.)

\begin{tabular}{|c|c|}
\hline & RTV566 \\
\hline Hardness Shore A Durometer & 61 \\
\hline Tensile Strength, $\mathrm{kg} / \mathrm{cm}^{2}$ (psi) & $56(80)$ \\
\hline Elongation, \% & 120 \\
\hline $\begin{array}{l}\text { Lap Shear Strength, } \mathrm{kg} / \mathrm{c}^{2} \text { (psi) } \\
\text { (on primed Al) }\end{array}$ & $33(465)$ \\
\hline Volatile Condensible Material, $\%{ }^{*}$ & 0.02 \\
\hline Total Weight Loss, \%* & 0.14 \\
\hline *After 24 hrs. @ 25C (275F) and $1 \times 10^{-4}$ Torr & \\
\hline
\end{tabular}

(GE Silicones Specifications for RTV566) 


\section{Glycerine, USP 99.7\%}

Table A. 8-Physical Properties(1) of OPTIM Glycerine 99.7\% USP

\begin{tabular}{|c|c|}
\hline Property & $\begin{array}{l}\text { OPTIM Glycerine } \\
\text { 99.7\% USP }\end{array}$ \\
\hline Appearance & Colorless, viscous liquid \\
\hline Boiling point $(760 \mathrm{~mm})$ & $290^{\circ} \mathrm{C}\left(554^{\circ} \mathrm{F}\right)$ \\
\hline Chemical name & Glycerol or 1,2,3- Propanetroil \\
\hline Common name & Glycerine \\
\hline \multicolumn{2}{|l|}{ Density } \\
\hline $\mathrm{gm} / \mathrm{cc}, 25^{\circ} \mathrm{C}$ & 1.25802 \\
\hline $\mathrm{lb} / \mathrm{gal}, 25^{\circ} \mathrm{C}$ & 10.50 \\
\hline Dielectric constant, $20^{\circ} \mathrm{C}$ & 41.14 at $2 \times 10^{6} \mathrm{~Hz}$ \\
\hline Empirical formula & $\mathrm{C}_{3} \mathrm{H}_{8} \mathrm{O}_{3}$ \\
\hline \multicolumn{2}{|l|}{ Flash point, $\mathrm{PMCC}$} \\
\hline (Pensky Matens Closed Cup) & $195.5^{\circ} \mathrm{C}\left(384^{\circ} \mathrm{F}\right)$ \\
\hline Freezing poin & $17^{\circ} \mathrm{C}\left(62.5^{\circ} \mathrm{F}\right)$ \\
\hline Heat capacity, $25^{\circ} \mathrm{C}, \mathrm{cal} / \mathrm{gm}, 25^{\circ} \mathrm{C}$ & 0.62 \\
\hline Heat of formation, $\mathrm{kcal} / \mathrm{mol}, 25^{\circ} \mathrm{C}$ & 159.8 \\
\hline Heat of fusion, cal $/ \mathrm{g}$ & 47.5 \\
\hline Heat of vaporization, $\mathrm{cal} / \mathrm{mol}, 55^{\circ} \mathrm{C}$ & 21,060 \\
\hline Molecular weight & $92.09 \mathrm{gm} / \mathrm{mol}$ \\
\hline Odor & Oderless \\
\hline Refractive index, $20^{\circ} \mathrm{C}$ & 1.47399 \\
\hline \multicolumn{2}{|l|}{ Solubility, $25^{\circ} \mathrm{C}$} \\
\hline Benzene & Immiscible \\
\hline Chlorofor & Immiscible \\
\hline Ethyl alcohol & Miscible \\
\hline Ethyl ether & Immiscible \\
\hline n-Heptane & Immiscible \\
\hline Isopropanol & Miscible \\
\hline Water & Miscible \\
\hline Specific gravity, $25 / 25^{\circ} \mathrm{C}$ & 1.26201 \\
\hline Surface tension, Dynes $/ \mathrm{cm}, 20^{\circ} \mathrm{C}$ & 63.0 \\
\hline Taste & Swee \\
\hline \multicolumn{2}{|l|}{ Vapor pressure, $\mathrm{mm} \mathrm{Hg}$} \\
\hline $50^{\circ} \mathrm{C}$ & 0.0025 \\
\hline $100^{\circ} \mathrm{C}$ & 0.195 \\
\hline Viscosity, cp, $20^{\circ} \mathrm{C}$ & 1410 \\
\hline
\end{tabular}




\section{Glycerine Specifications cont'd}

Table A. 9-Viscosity of 100 Percent Glycerine at High Temeratures

\begin{tabular}{|l|l|l|l|l|l|l|l|}
\hline${ }^{\mathbf{O}} \mathbf{C}$ & $\mathbf{8 0}$ & $\mathbf{9 0}$ & $\mathbf{1 0 0}$ & $\mathbf{1 1 0}$ & $\mathbf{1 2 0}$ & $\mathbf{1 3 0}$ & $\mathbf{1 4 0}$ \\
\hline Centiposes & 32.18 & 21.2 & 14.6 & 10.48 & 7.797 & 5.986 & 4.726 \\
\hline${ }^{\mathbf{0}} \mathbf{C}$ & $\mathbf{1 5 0}$ & $\mathbf{1 5 8}$ & $\mathbf{1 6 7}$ & & & & \\
\hline Centiposes & 3.823 & 3.282 & 2.806 & & & & \\
\hline
\end{tabular}

(Dow Chemical Company Synthetic Glycerine Specifications) 


\section{APPENDIX B}

Specifications for Semi-Conductor Strain Gages 


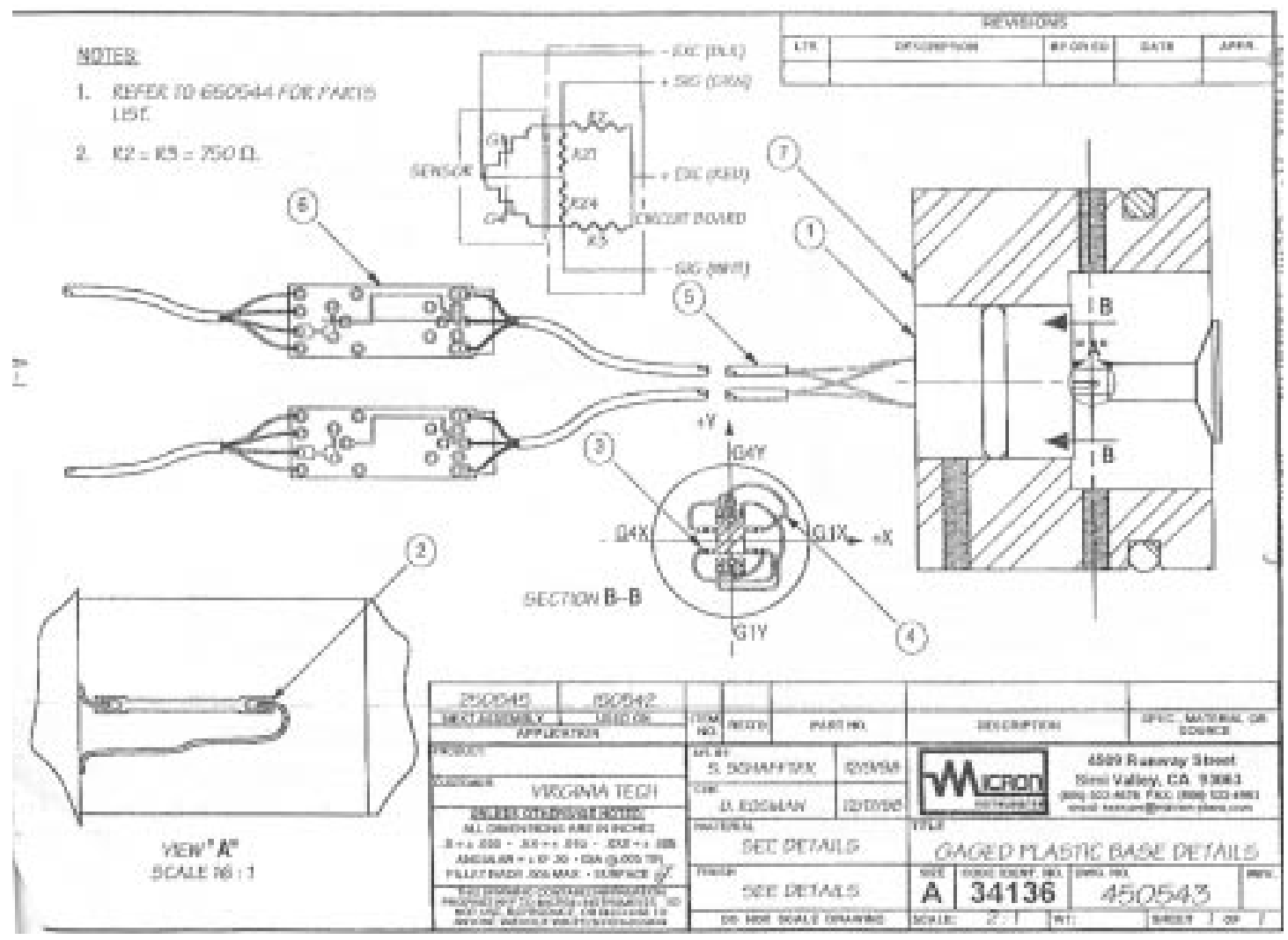

Figure B. 1- Semi-conductor strain gage Schematic 


\section{APPENDIX C}

Calculations for Measured Variable Uncertainty Analysis 
Calculations for Uncertainty Analysis

$$
\tau_{w}=\frac{V C g}{A_{H E A D}}
$$

for calculations: $\quad \mathrm{V}=0.001 \mathrm{~V} \Rightarrow \tau_{w}=119.2033 \frac{\mathrm{kg}}{\mathrm{m} \cdot \mathrm{s}^{2}}(\mathrm{~Pa})$

$$
\begin{aligned}
& \frac{\partial \tau_{w}}{\partial V}=\frac{C g}{A_{H E A D}}=\frac{\left(1.5385 \frac{\mathrm{kg}}{\mathrm{V}}\right)\left(9.81 \frac{\mathrm{m}}{\mathrm{s}^{2}}\right)}{\left(1.26613 \times 10^{-4} \mathrm{~m}^{2}\right)}=119203.28 \frac{\mathrm{kg}}{\mathrm{V} \cdot \mathrm{m} \cdot \mathrm{s}^{2}} \\
& \frac{\partial \tau_{w}}{\partial g}=\frac{V C}{A_{H E A D}}=\frac{(0.001 \mathrm{~V})\left(1.5385 \frac{\mathrm{kg}}{\mathrm{V}}\right)}{\left(1.26613 \times 10^{-4} \mathrm{~m}^{2}\right)}=12.1512 \frac{\mathrm{kg}}{\mathrm{m}^{2}} \\
& \frac{\partial \tau_{w}}{\partial C}=\frac{V g}{A_{H E A D}}=\frac{(0.001 \mathrm{~V})\left(9.81 \frac{\mathrm{m}}{\mathrm{s}^{2}}\right)}{\left(1.26613 \times 10^{-4} \mathrm{~m}^{2}\right)}=77.4802 \frac{\mathrm{V}}{\mathrm{m} \cdot \mathrm{s}^{2}} \\
& \frac{\partial \tau_{w}}{\partial A_{H E A D}}=\frac{-V C g}{A_{H E A D}^{2}}=\frac{-(0.001 \mathrm{~V})\left(1.5385 \frac{\mathrm{kg}}{\mathrm{V}}\right)\left(9.81 \frac{\mathrm{m}}{\mathrm{s}^{2}}\right)}{\left(1.26613 \times 10^{-4} \mathrm{~m}^{2}\right)^{2}}=941477.422 \frac{\mathrm{kg}}{\mathrm{m}^{3} \cdot \mathrm{s}^{2}}
\end{aligned}
$$

Absolute Error, $\mathrm{E}_{\mathrm{a}}$

$$
\begin{aligned}
& E_{a}=\left|\Delta V \frac{\partial \tau_{w}}{\partial V}\right|+\left|\Delta g \frac{\partial \tau_{w}}{\partial g}\right|+\left|\Delta C \frac{\partial \tau_{w}}{\partial C}\right|+\left|\Delta A_{H E A D} \frac{\partial \tau_{w}}{\partial A_{H E A D}}\right|= \\
& \left|1 \times 10^{-6} \mathrm{~V} \cdot 119203.28 \frac{\mathrm{kg}}{\mathrm{V} \cdot \mathrm{m} \cdot \mathrm{s}^{2}}\right|+\left|0.001 \frac{\mathrm{m}}{\mathrm{s}^{2}} \cdot 12.1512 \frac{\mathrm{kg}}{\mathrm{m}^{2}}\right|+\mid 0.005 \frac{\mathrm{kg}}{\mathrm{V}} \cdot 77.4802 \frac{\mathrm{V}}{\mathrm{m} \cdot \mathrm{s}^{2}}(\mathrm{C} .6) \\
& +\left|5.0594 \times 10^{-7} \mathrm{~m}^{2} \cdot 941477.422 \frac{\mathrm{kg}}{\mathrm{m}^{3} \cdot \mathrm{s}^{2}}\right|= \pm 0.9951 \frac{\mathrm{kg}}{\mathrm{m} \cdot \mathrm{s}^{2}} \Rightarrow \pm 0.8348 \%
\end{aligned}
$$

The diameter of the floating head is $\mathrm{d}$

$$
\Delta d= \pm 0.001 \mathrm{in}( \pm 0.0000254 \mathrm{~m}) \Rightarrow \Delta A_{H E A D}= \pm 0.000784215 \mathrm{in}^{2}\left( \pm 5.0594 \times 10^{-7} \mathrm{~m}^{2}\right)
$$

Overall Error, $\mathrm{E}_{\text {arss }}$ 


$$
\begin{aligned}
& E_{\text {arss }}=\left(\left|\Delta V \frac{\partial \tau_{w}}{\partial V}\right|^{2}+\left|\Delta g \frac{\partial \tau_{w}}{\partial g}\right|^{2}+\left|\Delta C \frac{\partial \tau_{w}}{\partial C}\right|^{2}+\left|\Delta A_{H E A D} \frac{\partial \tau_{w}}{\partial A_{H E A D}}\right|^{2}\right)^{\frac{1}{2}}= \\
& {\left[\left(0.1192033 \frac{\mathrm{kg}}{\mathrm{m} \cdot \mathrm{s}^{2}}\right)^{2}+\left(0.0121512 \frac{\mathrm{kg}}{\mathrm{m} \cdot \mathrm{s}^{2}}\right)^{2}+\left(0.387401 \frac{\mathrm{kg}}{\mathrm{m} \cdot \mathrm{s}^{2}}\right)^{2}+\left(0.47633 \frac{\mathrm{kg}}{\mathrm{m} \cdot \mathrm{s}^{2}}\right)^{2}\right]^{\frac{1}{2}}=(\mathrm{C} .7)} \\
& \pm 0.62556 \frac{\mathrm{kg}}{\mathrm{m} \cdot \mathrm{s}^{2}} \Rightarrow 0.5248 \%
\end{aligned}
$$


APPENDIX D

Facilities Employed 
1. F \& S, Inc.

PO Box 11704

Blacksburg, VA 24062-1704

Tele: 540-552-5128

www.f-s.co

2. Boedecker Plastics, Inc

Route 2 Box 5

904 West $6^{\text {th }}$ Stree

Shiner, TX 77984

Tele: 512-594-2941

Fax: 512-594-2349

3. Micron Instruments

4509 Runway Street

SimiValley, CA 93063

Tele: $805-522-4676$

Fax: 805-522-4982

http://www.micron-piezo.co

e-mail: sensors@micron-piezo.com

contact: Stephen Schafter

4. AOE Shop

15A Randolph Hall

Virginia Tech

Blacksburg, VA 24061

Tele:540-231-6752

Contact: Bruce Stranger
5. GE Silicones

260 Hudson River Road

Waterford, NY 12188

Tele: $800-255-8886$

6. Center for Adhesive and Sealant

Science

2 Davidson Hall (0201)

Virginia Tech

Blacksburg, VA 24061

Fax: 540-231-3971

e-mail: cass@vt.edu

Director: J.G. Dillard

Tele: 540-231-6929

7. Modal Analysis Lab

New Engineering Building

Virginia Tech

Blacksburg, VA 24061

Director: A. Wicks

8. National Instruments Corporation 1150 N. Morpac Expressway

Austin, TX 78759-3504

Tele: 512-794-0100

Fax: 512-683-8411

http://www.natinst.co 


\section{VITA}

The author, Samantha Magill, was born in Myrtle Beach, SC on May 29, 1975 to Marie and Arthur Magill. She graduated with honors from Myrtle Beach High School in June 1993. Following, she went to Auburn University in Auburn, AL and graduated Cum Laude with a Bachelor of Aerospace Engineering degree in June 1997. The next fall she entered Virginia Polytechnic Institute and State University in Blacksburg, VA to receive a Master in Science degree in Aerospace Engineering in July 1999. 